\title{
LIGIA SHIMABUKURO OKUDA
}

\section{Albumina modificada por glicação avançada}

sensibiliza macrófagos à inflamação

prejudicando o transporte reverso de colesterol e a atividade anti-inflamatória da HDL

Tese apresentada à Faculdade de Medicina da Universidade de São Paulo para obtenção do título de Doutor em Ciências

Programa de Endocrinologia

Orientadora: Profa. Dra. Marisa Passarelli

São Paulo

2012 
Dados Internacionais de Catalogação na Publicação (CIP)

Preparada pela Biblioteca da

Faculdade de Medicina da Universidade de São Paulo

\section{Creprodução autorizada pelo autor}

Okuda, Ligia Shimabukuro

Albumina modificada por glicação avançada sensibiliza macrófagos à inflamação prejudicando o transporte reverso de colesterol e a atividade antiinflamatória da HDL / Ligia Shimabukuro Okuda. -- São Paulo, 2012.

Tese(doutorado)--Faculdade de Medicina da Universidade de São Paulo. Programa de Endocrinologia.

Orientadora: Marisa Passarelli.

Descritores: 1.Aterosclerose 2.Diabetes mellitus 3.Colesterol 4.Produtos finais de glicação avançada 5.HDL 6.Transporte reverso de colesterol

USP/FM/DBD-161/12 
Este estudo foi realizado no Laboratório de Lípides (LIM 10) do Serviço de Endocrinologia e Metabologia do Hospital das Clínicas da Faculdade de Medicina da Universidade de São Paulo.

Este projeto foi desenvolvido com apoio da Fundação de Amparo à Pesquisa do Estado de São Paulo (FAPESP) - Bolsa de Doutorado Direto 2010/50147-0. 
Dedico esta tese aos meus pais, Setsuco e Massao, meus verdadeiros exemplos de vida, caráter, amor e determinação. Sem o carinho e apoio incondicional deles, nada disso seria possível. Dedico ao meu querido irmão Bruno, que sempre esteve presente na minha vida e quem eu admiro muito.

Dedico também ao meu melhor amigo, namorado e marido, Marcelo. Obrigada pelo carinho, apoio, paciência, amor, presença e constante incentivo. 


\section{AGRADECIMENTOS}

Essa é, definitivamente, a parte mais complicada na tese. Dificil expressar com palavras os sentimentos e as emoções que sinto ao pensar nesses 8 anos de convivio no laboratório. Foram muitos momentos bons, de alegria e realizações e também outros difíceis e estressantes, mas que contribuíram para o meu aprendizado, crescimento e fazem parte do que eu sou hoje. Quero agradecer do fundo do meu coração por todos os momentos, alegres e dificeis, e a todas as pessoas que contribuíram para que esse momento fosse possível.

Em especial, gostaria de agradecer:

À Dra. Marisa Passarelli que foi bem mais do que uma orientadora, mas uma grande amiga. A Má, além de excelente profissional, ética e inteligente, é uma mãe carinhosa e atenciosa e uma mulher alegre, determinada e forte mesmo nos momentos mais dificeis, e por todas essas razões a admiro muito. Obrigada por me ensinar o que é fazer pesquisa e por fazer parte da minha vida.

À Dra. Edna Regina Nakandakare, uma das pessoas mais tranquilas, centradas e generosas que conheço. Obrigada pelo apoio, carinho e por abrir as portas do laboratório para mim.

Ao Dr. Éder Quintão, pela inspiração e constante incentivo. A sua energia e imenso amor pela pesquisa e ciência de qualidade irradia e contagia todos que estão a sua volta.

Ao Dr. Sérgio Catanozi, pelos ensinamentos e amizade. Obrigada pelos momentos de descontração e brincadeiras que tornaram o dia a dia do laboratário mais leve e pelas longas conversas e desabafos, você se tornou um grande amigo.

À Dra. Ana Maria Pitta Lottenberg, obrigada por me inspirar sempre a querer ser uma profissional melhor, você é um exemplo de nutricionista.

À Dra. Mônica Neves, pelo apoio e discussões durante as reuniões científicas. Suas sugestões e observações foram sempre muito construtivas. 
À Gabriela Castilho. Ao longo desses anos de bancada a Gabi se tornou uma grande amiga, com ela pude dividir muitos momentos de alegria, dificuldades e estresse e aprendi muitas coisas também. A Gabi é uma pessoa muito especial, cheia de vida, inteligente, extremamente critica e com grande potencial para crescer cada vez mais, só precisa acreditar nisso e aprender a aproveitar as pequenas alegrias da vida. Fico muito feliz por ter dividido esses momentos com você.

À Dra. Adriana Machado Saldiba de Lima, obrigada por tudo: pelo apoio, amizade, conversas e incentivo. A Dri, apesar do tamanho, é a pessoa mais fofa, meiga e sensível do laboratório. Você é muito querida

À Dra. Débora Rocco, a melhor companheira de bancada. É simplesmente impossível ficar triste ou brava ao lado dessa pessoal tão especial, sua energia é contagiante. Usando as palavras da própria Dé: Você é vida!

Ao Dr. Raphael de Souza Pinto pela amizade e carinho. O Rapha é uma pessoa muito especial, sempre atencioso e carinhoso com todos. Te adoro.

Ao Dr. Rodrigo T lborra, apesar de banguceiro, ele está sempre pronto para ajudar a todos do laboratório e é, definitivamente o mais tranquilo entre os alunos da Marisa, acho que você, sim, é o verdadeiro "zen" do grupo! Obrigada pela amizade, conversas e apoio.

À Juliana Tironi, pela amizade e apoio. Muito legal ver o crescimento da Juju, desde a iniciação cientifica até agora. Você é muito especial Ju.

À Paula Ramos. Essa mocinha entrou no lab faz pouco tempo, mas já se tornou uma grande amiga! Admiro muito sua força e determinação. Continue sempre assim que você vai longe!

Ao Diego Gomes, que faz parte da nova geração do lab e que tem grande potencial para crescer muito, não desanine com as dificuldades, elas nos ajudam a crescer ainda mais. Continue sempre assim, alegre e descontraído. 
À Fabiana Dias Ferreira, pela amizade, carinho e conversas. A Fabi no início parecia ser super durona, mas quando a conheci melhor, percebi como é atenciosa, prestativa e amiga.

À Dra. Valéria Suti Nunes, pela paciencia, amizade e pelos batepapos. A Val está sempre de bom humor e disposta a ajudar todos que precisam, além de ser super dedicada ao trabalho.

À Dra. Patricia Cazita, pela ajuda com os animais CETP, pelas conversas descontraídas e carinho. Obrigada por tudo

À Jussara Rocha, quem me ajudou muito no meu início no laboratório e me ensinou muitas coisas. Obrigada por tudo Ju, você é muito especial para mim

À Tatiana Venancio, pelas conversas e apoio. Continue sempre assim, alegre, divertida e decidida.

À Renata Bombo, pelo carinho, apoio e conversas no lab. Conheço a Renata faz pouco tempo, mas ela me conquistou com sua simpatia e gentileza. Você é muito especial.

À Milessa Afonso. Tchura, você é uma comédia, é muito divertido dividir a bancada com você. Obrigada por tornar os dias no lab mais alegres!

À Paula Philipson, pela amizade e companhia na bancada. Entramos exatamente no mesmo dia no laboratório e aprendemos muitas coisas juntas. Fico muito feliz por ter dividido esses momentos com você

À Camila Canteiro, obrigada pela amizade e apoio. O que eu admiro na Camila é sua simplicidade e elegância.

À Rosibel pelas conversas, amizade e carinho. A função dela no lab é a mais trabalhosa e sem ela nada funcionaria no laboratório. Obrigada por tudo Rosi.

À Claudia Souza, pela amizade, carinho e apoio. A Claudia está sempre disposta a ajudar todos com as questões burocráticas e está sempre de bom humor, tenho muito que aprender com você como levar a vida de forma mais leve. 
À Senária Egutti, pela ajuda nas questões burocráticas, pela amizade e carinho. Admiro muito sua disposição e determinação.

Às nutricionistas Roberta Marcondes Machado, Maria Silvia Ferrarri, Angela Ilha, Klara Rahmann, Fabiana Goes e Patricia Rios pelo carinho, apoio e conversas descontraídas no lab.

Aos alunos Camila Holanda Sartori, Maria Olivia Carvalho, Mila Alvarenga, Joilsa Monteiro, Fernanda Fusco, Karina Oliveira, Alessandra Carreiro, Simone Batista e Karoline Santana pelas conversas, brincadeiras e carinho.

À Cida, pela paciência e ajuda em todos as questões burocráticas.

Aos meus queridos e amados pais, Setsuco e Massao, que me incentivaram desde o início e sempre estiveram perto me apoiando em cada decisão e em cada momento dificil. Amo vocês mais do que tudo e tenho muito orgulho de ser filha de vocês. Obrigada.

Ao meu irmão Bruno pelo constante incentivo e apoio. Não costumo dizer muito isso, mas te admiro muito, você é o melhor irmão mais velho que alguém pode ter.

Ao meu marido Marcelo, pelo apoio, paciência, amor e incentivo. Não existem palavras que possam expressar o quanto você é importante para mim e o quanto você me faz feliz e completa. Te amo.

À Fundação de Amparo à Pesquisa do Estado de São Paulo pela concessão da bolsa de doutorado direto e pelo apoio financeiro para a realização desta pesquisa. 
"Só existem dois dias no ano que nada pode ser feito. Um se chama ontem e o outro se chama amanhã, portanto hoje é o dia certo para amar, acreditar, fazer e principalmente viver." 


\section{SUMÁRIO}

LISTA DE ABREVIATURAS

RESUMO

SUMMARY

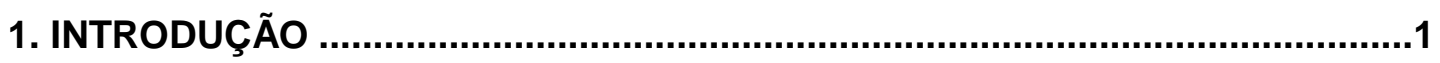

1.1. Transporte Reverso de Colesterol....................................................... 1

1.2. Inflamação, Transporte Reverso de Colesterol e Aterosclerose .....................6

1.3. Produtos de Glicação Avançada e Transporte Reverso de Colesterol .........11

1.4. Produtos de Glicação Avançada e Inflamação .........................................17

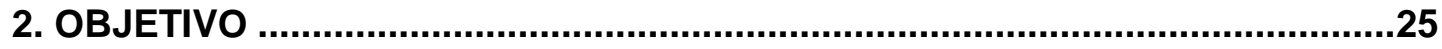

3. MÉTODOS ................................................................................................26

3.1. Preparo da albumina glicada in vitro ....................................................26

3.2. Dosagem de endotoxina das albuminas controle e glicada in vitro...............27

3.3. Obtenção de lipoproteínas ..............................................................27

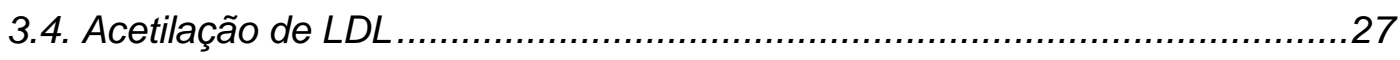

3.5. Obtenção e cultivo dos macrófagos de peritônio de camundongos..............28

3.6. Meio condicionado sem e com sobrecarga de colesterol ...........................29

3.7. Determinação do papel da HDL em modular a resposta inflamatória induzida por albumina-AGE, S100B e LPS .................................................... 31

3.8. Determinação do papel do inibidor de NF-kB em modular a resposta inflamatória induzida por albumina-AGE, S100B e LPS ..................................32

3.9. Quantificação de citocinas pró-inflamatórias (IL-1 $\beta$ e IL-6, TNF- $\alpha$ ), quimiocina MCP-1 e molécula de adesão VCAM-1 .................................................... 32

3.10. Efluxo de ${ }^{14} \mathrm{C}$-colesterol, mediado por $\mathrm{HDL}_{3}, H D L_{2}$ e apoA-I mediante incubação com meio condicionado, contendo citocinas ...................................33

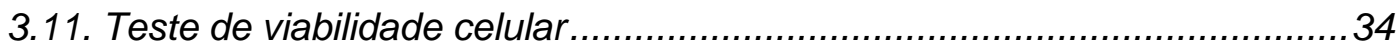

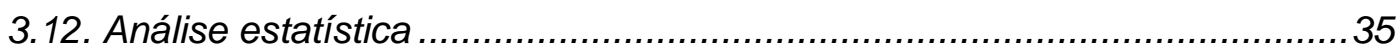

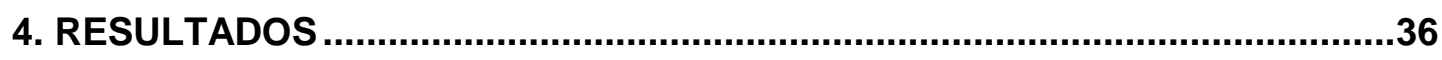

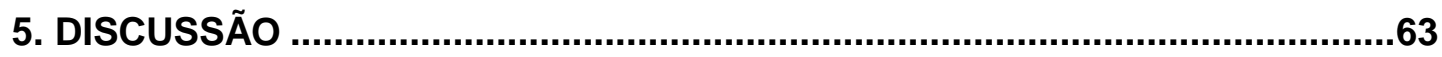

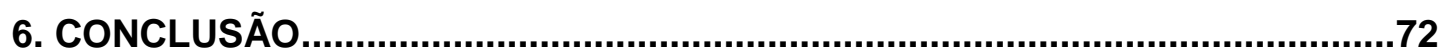

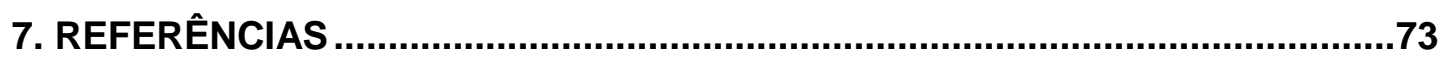




\section{LISTA DE ABREVIATURAS}

ABCA-1: ATP-binding cassette transporter, subfamily A, member 1 ABCG-1: ATP-binding cassette transporter, subfamily G, member 1 AGE: Produto de glicação avançada AGER1: Receptor 1 para AGE

AMPc: 8-Bromoadenosine 3', 5'- cyclic monophosphate apoA-I: Apolipoproteína A-I

CETP: Proteína de transferência de colesterol esterificado

FAFA: albumina isenta de ácidos graxos

GAPDH: Gliceraldeído fosfato desidrogenase

HDL: Lipoproteína de alta densidade

HMGB1: High Mobility Group Box 1

IFN-Y: Interferon gama

IL-10: Interleucina -10

IL-6: Interleucina -6

IL-Iß: Interleucina -1 beta

LCAT: Lecitina colesterol aciltransferase

LDL: Lipoproteína de baixa densidade

LPS: Lipopolissacarídeo

LXR: Receptor X hepático

MCP-1: Proteína 1 quimiotática de monócitos

NADPH oxidase: Nicotinamida adenina dinucleotídeo fosfato-oxidase NF-KB: Fator nuclear kappa B 
Qm: Quilomicron

RAGE: Receptor para produtos de glicação avançada

RXR: Receptor X retinóico

ROS: Espécies reativas de oxigênio

S100B: Calgranulina S100B

SRA: Receptor scavenger classe A

SR-BI: Receptor scavenger classe B, tipo 1

TGF- $\beta$ : Fator de crescimento transformador beta

TLR: Receptor símile aoToll

TNF- $\alpha$ : Fator de necrose tumoral

VCAM-1: Molécula de adesão celular vascular - 1

VLDL: Lipoproteína de muita baixa densidade 


\section{RESUMO}

Okuda LS. Albumina modificada por glicação avançada sensibiliza macrófagos à inflamação prejudicando o transporte reverso de colesterol e a atividade anti-inflamatória da HDL [tese]. São Paulo: Faculdade de Medicina, Universidade de São Paulo; 2012. 91p.

No diabete melito, produtos de glicação avançada (AGE) reduzem o efluxo de colesterol celular o que agrava o desenvolvimento da aterosclerose. Neste estudo, investigou-se o papel da albumina modificada por glicação avançada (albumina-AGE) sobre a sensibilização de macrófagos à resposta inflamatória e o impacto da secreção de citocinas, quimocinas e moléculas de adesão sobre o efluxo de colesterol mediado por apolipoproteína A-I e subfrações de HDL. Além disso, determinou-se a capacidade da HDL em modular a resposta inflamatória em macrófagos tratados com albuminaAGE. Macrófagos de peritônio de camundongo foram tratados com ou sem sobrecarga de colesterol, na presença de $2 \mathrm{mg} / \mathrm{mL}$ de albumina-controle (albumina-C) ou albumina-AGE, por $72 \mathrm{~h}$, seguindo-se de incubação, por 24 h, com calgranulina S100B $(20 \mu \mathrm{g} / \mathrm{mL}$ ) ou lipopolissacarídeo (LPS; $1 \mu \mathrm{g} / \mathrm{mL}$ ). Em comparação com albumina-C, a albumina-AGE, isenta em endotoxinas, isoladamente não alterou a secreção de citocinas em macrófagos. No entanto, a albumina-AGE sensibilizou macrófagos não enriquecidos em colesterol a uma maior secreção de interleucina 6 (IL-6), fator de necrose tumoral alfa (TNF- $\alpha$ ), proteína quimoatraente de monócitos 1 (MCP-1), interlucina 1 beta (IL-1 $\beta$ ) e molécula de adesão celular vascular 1 (VCAM-1) após estimulação com S100B ou LPS, o que foi potencializado pela sobrecarga de colesterol celular. Em macrófagos não estimulados, o meio condicionado, advindo das incubações de células com albumina-AGE e S100B (meio enriquecido em citocinas), reduziu o efluxo de ${ }^{14} \mathrm{C}$-colesterol mediado por apoA-I, $\mathrm{HDL}_{2}$ e $\mathrm{HDL}_{3}$ em, respectivamente, $23 \%, 43 \%$ e $20 \%$, em comparação com células incubadas com meio isolado do tratamento com albumina-C e S100B. De forma similar, o efluxo de ${ }^{14} \mathrm{C}$-colesterol mediado 
por apoA-I, $\mathrm{HDL}_{2}$ e $\mathrm{HDL}_{3}$ foi reduzido em macrófagos tratados com meio advindo de incubações com albumina-AGE e LPS, respectivamente, 37\%, $47 \%$ e $8,5 \%$ em comparação ao tratamento com albumina-C e LPS. Em macrófagos tratados com albumina-C e S100B, a incubação prévia com HDL reduziu a secreção de IL-6, TNF- $\alpha$, MCP-1 e VCAM-1 em, respectivamente, $72 \%, 57 \%, 50 \%$ e $41 \%$ quando comparada à incubação na ausência de HDL. Em incubações com albumina-C, a secreção de IL-6, TNF- $\alpha$, MCP-1, IL-1 $\beta$ e VCAM-1 induzida por LPS foi respectivamente, $58 \%, 54 \%, 42 \%$, $74 \%$ e $45 \%$ menor mediante incubação com HDL, em comparação a incubações similares, porém na ausência desta lipoproteína. Por outro lado, em macrófagos tratados com albumina-AGE e S100B, a HDL não foi capaz de reduzir a secreção de TNF- $\alpha$, IL-1 $\beta$ e VCAM-1 e aumentou a secreção de IL-6 (54\%) e MCP-1 (20\%). Nas células tratadas com albumina-AGE e LPS, a HDL também não reduziu a secreção de TNF- $\alpha$, MCP-1 e IL-1 $\beta$ e aumentou a secreção de IL-6 (16\%) e VCAM-1 (20\%). Redução na secreção de mediadores inflamatórios foi observada em macrófagos tratados com albumina-AGE apenas quando a HDL foi incubada juntamente com S100B ou LPS. Em conclusão, a albumina-AGE sensibiliza macrófagos à resposta inflamatória induzida por calgranulina S100B e LPS, prejudicando o transporte reverso de colesterol de macrófagos. Além disso, a albuminaAGE reduz as propriedades anti-inflamatórias da HDL, o que pode agravar a aterosclerose no diabete melito.

Descritores: 1.aterosclerose 2.diabetes mellitus 3.colesterol 4.produtos finais de glicação avançada 5.HDL 6.transporte reverso de colesterol. 


\section{SUMMARY}

Okuda LS. Advanced glycated albumin primes macrophages to an inflammatory response that reduces reverse cholesterol transport and impairs the HDL anti-inflammatory properties [thesis]. São Paulo: "Faculdade de Medicina, Universidade de São Paulo"; 2012. 91p.

In diabetes mellitus, advanced glycation end products (AGE) reduces the cholesterol efflux from cells, which aggravates the development of atherosclerosis. In this study, we investigated the role of advanced glycated albumin (AGE-albumin) on macrophage inflammatory response and the impact of cytokines, chemokines and adhesion molecules secretion on cholesterol efflux mediated by apolipoprotein A-I (apoA-I) and HDL subfractions. Furthermore, the HDL ability in modulating inflammatory response in macrophages treated with AGE-albumin was also determined. Mouse peritoneal macrophages previously enriched or not with cholesterol were treated in the presence of $2 \mathrm{mg} / \mathrm{mL}$ of control-albumin (C-albumin) or AGE-albumin, for $72 \mathrm{~h}$, followed by incubation, for $24 \mathrm{~h}$, with S100B calgranulin $(20 \mu \mathrm{g} / \mathrm{mL})$ or lipopolysaccharide (LPS; $1 \mu \mathrm{g} / \mathrm{mL})$. In comparison to free endotoxin-C-albumin, AGE-albumin, by itself did not alter cytokine secretion by macrophages. However, AGE-albumin primed non-cholesterol enriched macrophages to a higher secretion of interleukin -6 (IL-6), tumor necrosis factor alpha (TNF- $\alpha$ ), monocyte chemotactic protein 1 (MCP-1), interleukin 1 beta (IL-1 $\beta$ ) and vascular cell adhesion molecule 1 (VCAM-1) after stimulation with $\mathrm{S100B}$ or LPS, which was potentiated by cell cholesterol overload. In non-stimulated macrophages, conditioned medium, derived from incubation with $A G E-a l b u m i n$ and S100B (cytokine enrichedmedium), reduced the ${ }^{14} \mathrm{C}$-cholesterol efflux mediated by apoA-I, $\mathrm{HDL}_{2}$ and $\mathrm{HDL}_{3}$ in, respectively, $23 \%, 43 \%$ and $20 \%$, in comparison to cells incubated with conditioned medium isolated from treatment with C-albumin and S100B. Similarly, ${ }^{14} \mathrm{C}$-cholesterol efflux mediated by apoA-I, $\mathrm{HDL}_{2}$ and $\mathrm{HDL}_{3}$ was reduced in macrophages treated with medium derived from incubation with 
AGE-albumin and LPS, respectively, $37 \%, 47 \%$ and $8,5 \%$ in comparison to treatment with $\mathrm{C}$-albumin and LPS. In macrophages treated with C-albumin and $\mathrm{S} 100 \mathrm{~B}$, previous incubation with $\mathrm{HDL}$ reduced the secretion of IL-6, TNF- $\alpha$, MCP- 1 and VCAM-1 in, respectively $72 \%, 57 \%, 50 \%$ and $41 \%$ in comparison to incubation in the absence of HDL. In incubations with Calbumin, the secretion of IL- 6, TNF- $\alpha$, MCP-1, IL-1 $\beta$ and VCAM- 1 induced by LPS was respectively, $58 \%, 54 \%, 42 \%, 74 \%$ and $45 \%$ lower in cells treated with HDL in comparison to similar incubations in the absence of this lipoprotein. On the other hand, in macrophages treated with AGE-albumin and S100B, HDL was unable to reduce the TNF- $\alpha$, IL-1 $\beta$ and VCAM-1 secretion and increased the secretion of IL-6 (54\%) and MCP-1 (20\%). In cells treated with AGE-albumin and LPS, HDL was unable to reduce the secretion of TNF- $\alpha$, MCP-1 and IL-1 $\beta$ and increased IL- 6 (16\%) and VCAM-1 $(20 \%)$. Reduction in inflammatory mediators was observed in macrophages treated with AGE-albumin only when HDL was incubated simultaneously with S100B or LPS. In conclusion, AGE-albumin primes macrophages to an inflammatory response elicited by $\mathrm{S100B}$ calgranulin and LPS, impairing macrophage reverse cholesterol transport. Moreover, AGE-albumin impairs the HDL anti-inflammatory properties, which can aggravate the atherosclerosis in diabetes mellitus.

Descriptors: 1.atherosclerosis 2.diabetes mellitus 3.cholesterol 4.advanced glycation end products 5.HDL 6.reverse cholesterol transport 


\section{INTRODUÇÃO}

\subsection{Transporte Reverso de Colesterol}

O transporte reverso de colesterol é o sistema que promove o fluxo de colesterol dos tecidos periféricos para o fígado, protegendo contra o acúmulo de lípides em células da parede arterial (Rosenson et al., 2012).

Em macrófagos, a principal via de regulação do conteúdo de colesterol ocorre por meio do efluxo de colesterol e fosfolípides para diferentes subfrações de HDL e apolipoproteína A-I dissociada. Este processo é intermediado pelos receptores ABCA-1 (ATP binding cassette transporter AI) e ABCG-1 (ATP binding cassette transporter G-I) que, à custa da energia liberada pela hidrólise do ATP, transferem colesterol do folheto interno para o externo da membrana plasmática e, daí, para os aceptores extracelulares (Cavelier et al., 2006; Rosenson et al., 2012) (Figura 1). Em macrófagos sobrecarregados em lípides, a atividade do transportador ABCA-1 contribui de maneira mais significativa para a retirada de colesterol celular (Adorni et al., 2007) e o prejuízo neste sistema é, diretamente, implicado com o acúmulo de colesterol celular e aterosclerose, como nos casos de mutação deste receptor, observados na doença de Tangier e na deficiência familial de HDL (Soro-Paavonen et al., 2007 ).

A expressão de ABCA-1 e ABCG-1 é regulada pelo conteúdo de colesterol em macrófagos, mais especificamente, óxidos de colesterol, os quais são ligantes dos receptores nucleares LXR/RXR (receptor X hepático, 
receptor X retinóico) (Hozoji et al., 2008) (Figura 1). Agonistas sintéticos de LXR promovem aumento na transcrição gênica de ABCA-1 e ABCG-1 em macrófagos, levando ao aumento do efluxo de colesterol, mediado por apoAI e HDL maduras, respectivamente (Naik et al., 2006). Em macrófagos humanos, agonistas de LXR aumentam a exportação de colesterol para aceptores externos, o que não é influenciado pelo silenciamento do ABGG-1. Assim, de fato, o ABCA-1 parece ser o principal responsável pelo efluxo de colesterol em humanos (Larrede et al., 2009). Em hamsters dislipidêmicos, a injeção de agonista de LXR, embora não promova melhora no perfil lipídico, aumenta o transporte de colesterol dos macrófagos para as fezes, por meio do transporte reverso de colesterol (Briand et al., 2010).

O tratamento de alguns tipos celulares com AMP cíclico (8Bromoadenosine 3',5'-cyclic monophosphate) também aumenta a expressão de $A B C A-1$, embora os mecanismos relacionados com sua ação não estejam esclarecidos (Oram et al, 2000; Oram e Vaughan, 2006).

Diversas vias de transdução de sinal suscitadas pela interação de apo A-I e ABCA-1 têm sido descritas e envolvem, principalmente, a ativação de proteína cinase A, por intermédio de proteínas G e adenil ciclase, proteína cinase C por meio de fosfolipases de membrana e janus cinase 2 (JAK2)/STAT3 (Zhao et al., 2012). A atuação seletiva destas vias parece variar de acordo com o tipo celular, embora todas propiciem estabilização de ABCA-1 na superfície celular pela proteção contra a degradação mediada por calpaína (Yamauchi et al., 2003). A ativação da via JAK2/STAT3 promove, ainda, a repressão de genes inflamatórios o que estabelece um elo entre a 
exportação de colesterol de macrófagos e a redução da resposta inflamatória nestas células, ambas intermediadas pelo ABCA-1(Tang et al., 2009; Yin et al., 2011).

Além da via ativa, o colesterol pode, por difusão facilitada, ser transferido para as HDL, por intermédio do receptor SR-BI (receptor scavenger classe B tipo 1). Este processo depende, fundamentalmente, do gradiente de colesterol gerado entre a célula e as partículas aceptoras de colesterol no meio extracelular, bem como da composição das HDL em fosfolípides, o que garante sua interação com microdomínios da membrana plasmática, ricos em esfingolípides e colesterol (Zhang et al., 2005). Além disso, a subsequente esterificação do colesterol pela lecitina colesterol aciltransferase (LCAT), apensa à estrutura da HDL, previne a recaptação celular do colesterol livre e garante seu transporte, no núcleo das lipoproteínas, pelo compartimento plasmático (Aztalos et al., 2007) (Figura 1).

A atividade da LCAT promove o acondicionamento do colesterol esterificado no núcleo hidrofóbico da HDL, a qual passa de partícula discoide (pré- $\beta \mathrm{HDL}$ ) para esférica, denominada $\mathrm{HDL}_{3}$. A posterior ação da proteína de transferência de colesterol esterificado (CETP) garante o enriquecimento da $\mathrm{HDL}_{3}$ em triglicérides advindos das lipoproteínas que contêm apolipoproteína B (quilomícrons, QM; lipoproteínas de muito baixa densidade, VLDL e lipoproteínas de baixa densidade, LDL), o que aumenta seu tamanho e sua conversão à $\mathrm{HDL}_{2}$. Estas interagem com os receptores SR-BI, que no fígado e órgãos esteroidogênicos removem, seletivamente, o 
colesterol esterificado das HDL em detrimento dos demais componentes da lipoproteína. Paralelamente, a CETP transfere colesterol esterificado para QM, VLDL e LDL, os quais podem ser removidos pelos receptores hepáticos B-E (receptor de LDL), LRP (proteína relacionada ao receptor de LDL) e E. Na bile, o colesterol é eliminado na forma livre ou pela ação das enzimas 7 alfa hidroxilase e 27 alfa hidroxilase pode ser convertido, a ácidos biliares. Desta forma, o transporte reverso de colesterol garante o fluxo de colesterol dos tecidos periféricos para o fígado, protegendo contra a aterosclerose (Rader et al., 2009) (Figura 1).

Embora em diversos estudos o fluxo de colesterol ao longo do transporte reverso não se reflita na sua excreção biliar, deve-se levar em consideração a pequena massa de colesterol arterial, em comparação àquela presente na circulação sanguínea, linfática e no fígado. Neste sentido, o termo transporte reverso de colesterol de macrófagos parece aplicar-se mais intimamente ao evento que contribui para prevenção do acúmulo de lípides na parede arterial (Figura 1).

Além do transporte reverso, as HDL desempenham outras importantes ações antiaterogênicas, representadas por sua capacidade em minimizar a oxidação de LDL (Bandeali e Farmer, 2012; Lee et al., 2005), inibir a apoptose (Kontush et al., 2007), mediar vasodilatação (Nofer et al., 2004), favorecer o metabolismo glicídico (Drew et al. 2012; Drew et al., 2009) e inibir processos inflamatórios (Barter et al., 2004). Neste último aspecto, evidências recentes apontam para importante papel da infusão de HDL reconstituída ou miméticos de apo A-I na melhora da resposta vascular 
durante a síndrome coroanariana aguda humana, pela redução do insulto inflamatório e aceleração na remoção de lípides celulares (Di Bartolo et al., 2011a; Borthwick et al., 2012).

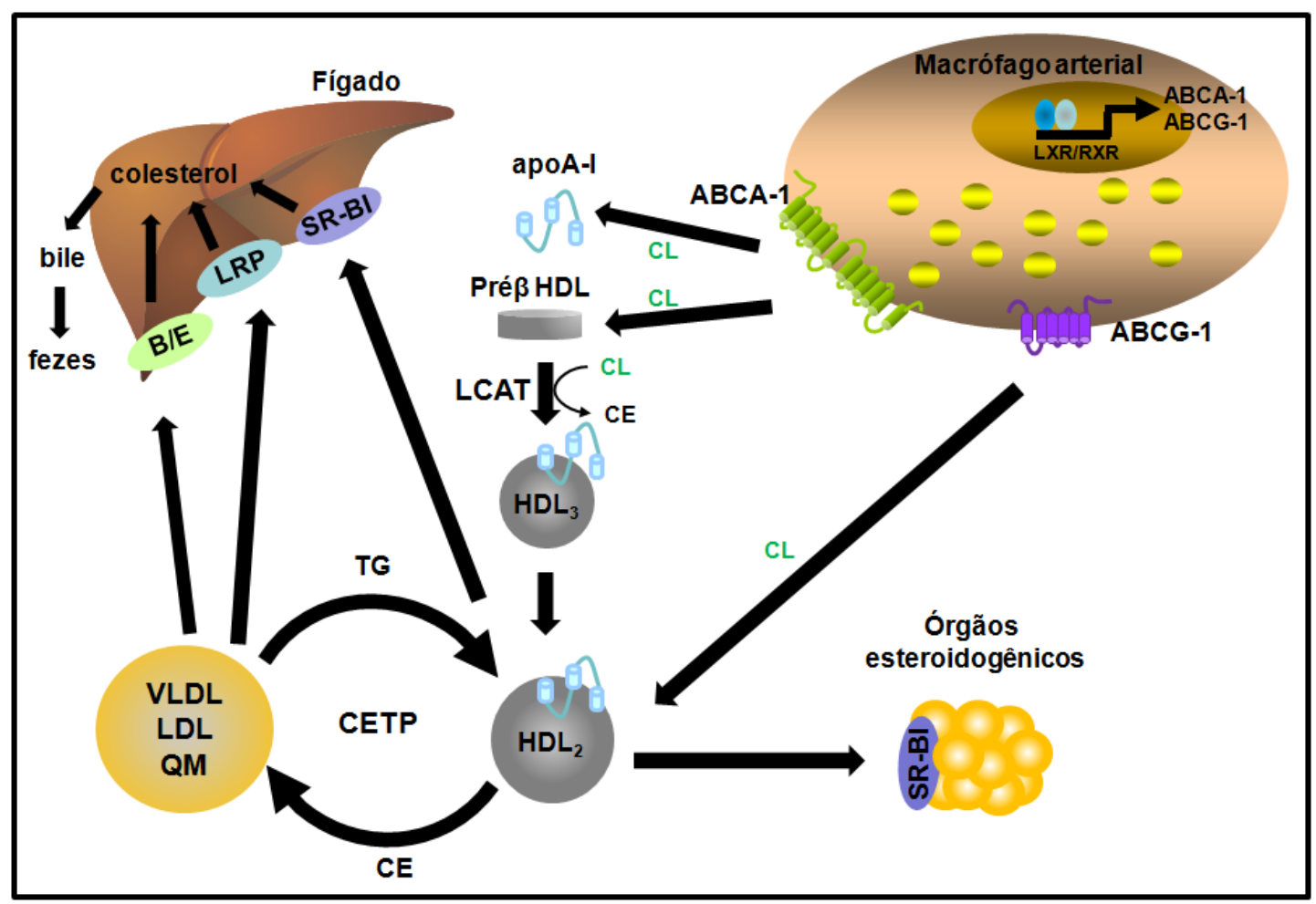

Figura 1. Transporte Reverso de Colesterol. Apolipoproteínas A-I e partículas nascentes de HDL (pré $\beta$ HDL) removem o excesso de colesterol de macrófagos por meio da interação com o receptor ABCA-1. Após esterificação do colesterol pela LCAT, formam-se, gradativamente, partículas maiores de HDL $\left(\mathrm{HDL}_{3}\right.$ e $\left.\mathrm{HDL}_{2}\right)$. As partículas de $\mathrm{HDL}$ maduras também são capazes de remover o excesso de colesterol celular via receptor ABCG-1. O colesterol esterificado (CE) pode ser diretamente removido das HDL pelo receptor SR-BI no fígado ou órgãos esteroidogênicos, podendo ser convertido em ácidos biliares ou hormônios esteroídicos. Por intermédio da CETP, o CE é transferido para os QM, VLDL e LDL, as quais podem ser removidas pelos receptores $B-E$ ou LRP no fígado. A expressão de ABCA-1 e ABCG-1 é positivamente modulada pelo receptor nuclear $L X R$, que se heterodimeriza com RXR. 


\subsection{Inflamação, Transporte Reverso de Colesterol e Aterosclerose}

Mediadores inflamatórios desempenham importante papel na gênese e progressão da doença macrovascular aterosclerótica. Nos estágios iniciais, células endoteliais passam a expressar na sua superficie moléculas de adesão que se ligam a diversas classes de leucócitos. Em particular a molécula de adesão celular vascular 1 (VCAM-1) parece ser capaz de se ligar aos tipos de leucócitos encontrados nos primeiros estágios da formação do ateroma, e a diminuição da expressão desta molécula de adesão reduz o desenvolvimento da lesão (Libby et al., 2002)

Uma vez aderida ao endotélio, os leucócitos penetram na íntima e esse processo de recrutamento é feito por meio da ação de moléculas quimioatraentes como, por exemplo, a proteína quimoatraente de monócitos (MCP-1), uma das quimiocinas responsáveis pela migração de monócitos para a íntima nas regiões de formação de lesão (Libby et al., 2002).

$\mathrm{Na}$ íntima, os monócitos diferenciam-se em macrófagos. Estes expressam receptores scavenger capazes de reconhecer lipoproteínas modificadas, permitindo o acúmulo de lipides intracelular e a formação de células espumosas. Dentro deste contexto, o macrófago enriquecido em lípides passa a secretar maiores quantidades de componentes inflamatórios, criando assim um ciclo vicioso (Libby et al., 2002).

Em estados inflamatórios crônicos, como no diabete melito, mediadores inflamatórios atuam concomitantemente com outros fatores de risco, entre eles, dislipidemia, hiperinsulinemia, hipertensão e distúrbios hemostáticos, 
concorrendo para a manifestação de complicações macrovasculares (Koh et al., 2005).

Diversos genes moduladores do metabolismo lipídico têm suas atividades transcricionais alteradas por citocinas e endotoxinas. Invariavelmente, tais modificações associam-se ao prejuízo no fluxo de lípides celulares (influxo e efluxo) e estabelecem um elo importante entre resposta inflamatória e acúmulo de lípides em células da parede arterial. Notadamente, em macrófagos, mediadores inflamatórios modulam o tráfego de lípides, por meio do controle da expressão de receptores celulares (Khovidhunkit W et al., 2004; Ruan et al., 2004). Em última instância, tais receptores determinam o conteúdo líquido de esteroides no meio intracelular por governarem a captação de lipoproteínas de baixa densidade (LDL) modificadas e a exportação de colesterol para as lipoproteínas de alta densidade (HDL).

Uma gama de receptores scavenger é descrita na literatura, sendo responsáveis pelo reconhecimento de lipoproteínas e seus remanescentes modificados por glicação, oxidação, dessialização, agregação, tirosilação, entre outras. A expressão dessas proteínas não é regulada pelo conteúdo intracelular de colesterol. Pelo contrário, é modulada positivamente por vias de sinalização, suscitadas por sua interação com ligantes quimicamente modificados (Greaves \& Gordon, 2005).

Além de alterações celulares específicas na parede arterial, na doença inflamatória observam-se importantes alterações no metabolismo de lípides plasmáticos, que contribuem para o estabelecimento de um perfil 
aterogênico. Em parte, tais modificações são consequentes de alterações no metabolismo do tecido adiposo e muscular, nos quais as vias de sinalização da insulina são prejudicadas por componentes inflamatórios. Situação típica é oriunda da fosforilação do receptor de insulina e do substrato do receptor de insulina (IRS) em resíduos de serina, graças ao aumento da concentração do fator de necrose tumoral alfa (TNF- $\alpha$ ). Isso compete com a correta fosforilação em resíduos de tirosina, reduzindo o sinal insulínico (Draznin, 2006; Qin et al., 2008; Fernández-Veledo et al., 2009). As alterações no fluxo periférico de ácidos graxos favorecem maior aporte deste lípide ao fígado, aumentando a síntese de lipoproteínas de origem hepática, como as VLDL (Qin et al.,2008). Além disso, intermediários inflamatórios contribuem e agravam a esteatose hepática (Roden, 2006).

Aumento na concentração de VLDL associa-se, tipicamente, à redução do HDL colesterol. Além disso, há o enriquecimento das HDL em amiloide $A$ e fosfolipases secretórias, em detrimento de seu principal componente proteico, a apoA-I, a qual é deslocada da partícula (de la Llera Moya et al., 2012). O mesmo é observado em relação às proteínas antioxidantes que compõem a estrutura da HDL, como a paraoxonase (Van Der Westhuyzen et al., 2007). Em decorrência desta remodelagem estrutural, a HDL de fase aguda torna-se, caracteristicamente, uma partícula de maior tamanho, depletada em colesterol esterificado, porém enriquecida em colesterol livre, triglicérides e ácidos graxos (Van Der Westhuyzen et al., 2007).

Outras proteínas plasmáticas que participam do metabolismo da HDL ao longo do transporte reverso de colesterol estão reduzidas durante o 
processo inflamatório, como a LCAT, a CETP (de la Llera Moya et al., 2012), a proteína de transferência de fosfolípides (PLTP) e a lipoproteína lipase hepática (LH) (Khovidhunkit et al., 2000; Llera Moya et al. 2012). A diminuição da atividade da LCAT pode prejudicar a remoção de colesterol pelas HDL, tanto pela recaptação do colesterol livre pelas células, como pela menor maturação das grandes partículas de HDL (Khovidhunkit et al., 2001; de la Llera Moya et al., 2012). Além disso, a limitação na atividade da CETP e da LH reduz o trânsito de colesterol para o fígado e a regeneração de novas partículas de HDL (Feingold et al., 1999; Hardardóttir et al.,1996).

Apesar de poderem carrear diversos componentes pró-inflamatórios, as HDL enriquecidas em amiloide A são boas aceptoras de colesterol celular, por se ligarem ao ABCA-1 e SR-BI. Além disso, por se associarem à fosfolipase solúvel, as HDL sofrem maior hidrólise regenerando partículas ricas em apo-Al que reiniciam o ciclo de retirada de colesterol celular e sua remoção de sítios de inflamação (Van Der Westhuyzen et al., 2007).

O papel da inflamação sobre o fluxo de lípides celulares é assunto de grande interesse, devido à modulação da expressão de receptores scavenger e da família $\mathrm{ABC}$ e, portanto, à modulação do desenvolvimento da aterosclerose. Entretanto, estudos pontuais que avaliam a relação entre mediadores inflamatórios e fluxo de lípides celulares são contraditórios. A maior parte dos trabalhos apontam para prejuízo no fluxo de lípides celulares, com redução na expressão do receptor de HDL, ABCA-1 (Wang et al., 2002; Khovidhunkit et al., 2003; Wang et al., 2005; Chen et al., 2007; Persson et al., 2008), enquanto outros evidenciam aumento do efluxo de 
colesterol (Gerbod-Giannone, 2006; Edgel et al., 2010). (Tabela 1) Em conjunto, tais eventos parecem favorecer o maior risco de complicações macrovasculares em condições inflamatórias crônicas, como diabete melito, doença renal, artrite reumatoide, entre outras.

\section{Tabela 1. Relação entre mediadores inflamatórios e o fluxo de lípides celulares}

\begin{tabular}{|c|c|c|c|c|c|}
\hline & Tipo Celular & ABCA-1 & ABCG-1 & $\begin{array}{l}\text { Efluxo de } \\
\text { colesterol }\end{array}$ & Referência \\
\hline $\begin{array}{l}\text { Endotoxinas } \\
\text { (LPS) }\end{array}$ & $\begin{array}{c}\text { RAW/ MP } \\
\text { J774 } \\
\text { HMDM / J774 } \\
\text { MP } \\
\text { THP-1 } \\
\text { RAW }\end{array}$ & $=$ & 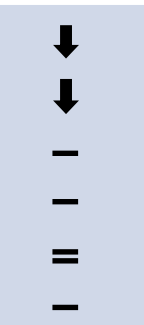 & & $\begin{array}{c}\text { Park et al.,2012 } \\
\text { Majdalawieh \& Ro, } 2009 \\
\text { McGillicuddy et al., } 2009 \\
\text { Castrilho etal., } 2003 \\
\text { Kaplan et al., } 2002 \\
\text { Baranova et al., } 2002\end{array}$ \\
\hline $\mathrm{IL}-1 \beta$ & $\begin{array}{c}\text { MP } \\
\text { THP-1 / A549 } \\
\text { HK-2 }\end{array}$ & & $=$ & & $\begin{array}{l}\text { Park et al., } 2012 \\
\text { Chen et al., } 2007 \\
\text { Wang et al., } 2005\end{array}$ \\
\hline IFN-Y & MP & & & & Wang et al., 2002 \\
\hline TGF- $\beta$ & MP & & 一 & - & Panousis et al., 2001 \\
\hline TNF- $\alpha$ & $\begin{array}{c}\text { MP } \\
\text { CaCo-2 } \\
\text { HK-2 } \\
\text { J774 } \\
\text { MP } \\
\text { MP }\end{array}$ & & - & - & $\begin{array}{c}\text { Park et al., } 2012 \\
\text { Field et al., } 2010 \\
\text { Wang et al., } 2005 \\
\text { Khovidhunkit et al., } 2003 \\
\text { Edgel et al., } 2010 \\
\text { Gerbod-Giannone et al., } 2006\end{array}$ \\
\hline IL-6 & HMDM / THP-1 & & 一 & & Frisdal et al., 2011 \\
\hline
\end{tabular}

RAW: macrófagos de linhagem tumoral; MP: macrófago de peritônio de camundongos; J774: macrófagos de linhagem tumoral; HMDM: macrófagos derivados de monócitos humanos; THP-1: monócitos humanos; A549: célula epitelial alveolar humana; HK-2: células do túbulo proximal humano; CaCo-2: célula intestinal humana. 


\subsection{Produtos de Glicação Avançada e Transporte Reverso de Colesterol}

A hiperglicemia é o principal fator envolvido na etiopatogenia das complicações micro e macrovasculares do diabete melito e, juntamente com outros componentes da síndrome metabólica, como obesidade, hipertensão, resistência à insulina, alterações hemostáticas e aumento do estresse inflamatório, acelera o acúmulo de lípides na parede arterial (Jakus e Rietbrock, 2004).

Diversas vias metabólicas são responsáveis pela relação causal entre hiperglicemia e estresse oxidativo intracelular, associados à gênese e progressão da aterosclerose. Entre elas, destacam-se: 1) a via dos polióis (Oyama et al., 2006); 2) a via glicolítica com aumento da geração de diacilglicerol e ativação de proteína cinase C (PKC) (Das Evcimen e King , 2007); 3) via das hexosaminas (Rolo e Palmeira, 2006) e 4) a geração de produtos de glicação avançada (AGE) (Brownlee, 2001).

Espécies reativas de oxigênio (ROS), como ânion superóxido e radical hidroxila, são geradas em abundância em decorrência da metabolização da glicose ao longo dessas vias, propagando o estresse oxidativo intracelular. Elas podem funcionar como segundos mensageiros, ativando vias de transdução de sinal que resultam em um amplo espectro de respostas fisiológicas, referidas como estresse oxidativo letal ou subletal. Em consequência, eleva-se a expressão de citocinas, fatores de diferenciação celular e moléculas de adesão, relacionadas ao dano vascular no diabete melito (Brownlee, 2001; Brownlee, 2005). 
O tratamento celular com inibidores da nicotinamida adenina dinucleotídeo fosfato-oxidase (NADPH oxidase) e o uso de células isoladas de animais com ablação gênica para NADPH oxidase diminuem a geração de ROS, induzida por AGE, com redução na expressão de moléculas de adesão (Basta et al., 2005; Higai et al., 2006). Estas e outras evidências apontam para importante papel da NADPH oxidase como mediadora do estresse oxidativo, induzido por AGE em macrófagos.

Du et al. (2003) demonstraram que a superprodução de ROS pela mitocôndria, induzida pela hiperglicemia, leva à ativação de isoformas da PKC, aumento da via das hexosaminas e da formação de AGE, devido à inibição da atividade da gliceraldeído fosfato desidrogenase (GAPDH). Isto ocorre em consequência da ribosilação da GAPDH pela poli (ADP-ribose) polimerase (PARP), enzima ativada pela fragmentação das fitas de DNA por radicais livres. O bloqueio da via glicolítica desvia o fluxo metabólico para as vias citadas acima, propagando a geração de ROS.

Os AGE representam a etapa final da reação de glicação ou de Maillard, caracterizada pela reação covalente não enzimática entre açúcares redutores e a porção amino terminal dos resíduos de lisina e arginina das proteínas, ácidos nucleicos e fosfolípides. A reação a partir de monossacarídeos é lenta e diretamente proporcional à concentração do açúcar no meio (controle glicêmico). Inicialmente, se forma um composto instável denominado base de Schiff, o qual progride para um produto Amadori, mais estável. A partir de ambos os compostos, ou mesmo por meio de autoxidação da glicose, ácidos graxos poli-insaturados e certos 
aminoácidos, são gerados os aldeídos bifuncionais: glioxal, glicolaldeído, metilglioxal e 3-deoxiglicosona. Estes são compostos altamente reativos que propagam a reação de glicação em sentido irreversível. A formação de AGE altera, marcadamente, a estrutura e, portanto, a função de diversas macromoléculas do meio extra e, principalmente, intracelular.

A concentração de oxoaldeídos encontra-se elevada na circulação de portadores de diabete melito tipo 1 e 2 descompensados, principalmente no período pós-prandial e em pacientes urêmicos não diabéticos (Thornalley, 2006). Nesse sentido, vias de destoxificação, prejudicadas na insuficiência renal, contribuem para redução da depuração de precursores da reação de glicação avançada (Mentink et al.,2006).

A dieta e o tabaco são, também, importantes fontes exógenas de AGE (Uribarri et al., 2005). Na dieta, a concentração de AGE depende da composição do alimento e de sua forma de cocção. AGE exógenos são absorbidos pelo trato gastrointestinal e circulam ligados à albumina e lipoproteínas (Goldberg et al., 2004).

Receptores para AGE incluem o receptor para produtos de glicação avançada (RAGE), os scavenger das classes A (SR-Al, SR-All, SR-Alll e MARCO), B (SR-B1 e CD 36), C (dSR-CI), D (CD68, macrosialin), E (LOX1), F (SREC), FEEL-1 e 2 e galectina-3 ( Horiuchi et al., 2003; Greaves \& Gordon, 2005; Rader \& Purê, 2005) e os receptores 1, 23 para produtos de glicação avançada (AGER1, AGER2 e AGER3). Todos apresentam capacidade específica de ligação à moléculas modificadas por AGE, embora a via de transdução de sinal intracelular esteja melhor elucidada para o 
RAGE, apenas. Carboximetillisina (CML), carboxietillisina, pentosidina, dímeros de glioxal e metilglioxal e pirralina (Degenhardt et al., 1998; Valencia et al., 2004a) são os principais AGE encontrados na circulação e tecidos, embora outras estruturas bastante heterogêneas também possam ser detectadas e reconhecidas pelo RAGE.

A diversidade estrutural dos ligantes de RAGE, como AGE, anfoterinas e calgranulinas, sugere que estes receptores pertençam à classe dos receptores de reconhecimento padrão, ligados à imunidade inata. A interação dos diversos ligantes com o RAGE dá-se em seu domínio extracelular V mediante oligomerização do receptor. Diversos resíduos de lisina na estrutura proteica derivatizados por AGE interagem com resíduos distintos do domínio V na superfície do RAGE. A plasticidade estrutural do domínio $\mathrm{V}$ do receptor parece conferir adaptação à ligação com diversas classes de ligantes, o que torna difícil, por muitas vezes, a exata detecção de vias de sinalização suscitadas por diferentes AGE (Xie et al., 2008)

Lu et al (2004) demonstraram que o estresse inflamatório mediado pelos AGE pode ser contrabalançado pelo receptor de AGE, AGER1, que se opõe à via de sinalização do RAGE. Neste estudo, células mesangiais que superexpressavam o receptor AGER1, em comparação com controles, apresentaram uma supressão da ativação do NF-kB (fator nuclear kappa B) e da via MAPK (proteínas cinases ativadas por mitógenos), além de redução na expressão de MCP-1 e RAGE, após estímulo com AGE. Em células de ovário de hamster transfectadas com RAGE, o estímulo por AGE levou ao 
aumento da ativação do NF-kB e da via MAPK porém, ao se cotransfectar as células com o AGER1, estas respostas foram abolidas (Lu et al., 2004).

Diversos estudos atribuem ao AGER1 a função de destoxificação dos AGE, por meio do bloqueio da geração de ROS, supressão da expressão da p66 ${ }^{\text {shc }}$, além da inibição de vias de sinalização do RAGE, fator de crescimento epitelial (EGF) e cinases reguladas por sinais extracelulares (ERK) (Lu et al., 2004; Cai et al., 2006; Cai et al., 2008). Neste sentido, em estados oxidativos crônicos, como no diabete melito e na urêmia, é verificada redução na expressão do receptor AGER1, relacionado com um aumento na concentração sérica de AGE e na expressão do RAGE (He et al., 2001; Vlassara et al., 2009).

O fluxo de colesterol ao longo do transporte reverso encontra-se alterado face à modificação de lipoproteínas por glicação. Embora a glicação precoce não afete a habilidade das HDL em remover colesterol (Passarelli et al., 2000; Rashiduni et al., 1999), a modificação de apo A-I ou HDL por glicação avançada reduz o efluxo de colesterol (Hoang, 2007 ; Matsuki et al., 2009).

O tratamento de macrófagos e fibroblastos com aldeídos bifuncionais reduz a expressão do receptor ABCA-1 com grave prejuízo na exportação de colesterol para apoA-I. Em decorrênca, acumulam-se lípides no meio intracelular. Interessante notar que a suplementação com AMP cíclico em macrófagos não é capaz de restabelecer o efluxo de colesterol, reduzido pela glicoxidação (Passarelli M, 2005). A diminuição no conteúdo de ABCA-1 
independe de variação no seu mRNA e se associa ao aumento do estresse oxidativo, evidenciado pela maior geração de ROS.

Embora a glicação de HDL esteja aumentada no diabete melito podendo concorrer para o prejuízo na retirada de colesterol celular, invariavelmente a redução de sua concentração plasmática de HDL colesterol contribui por si para a menor eficiência do transporte reverso. Além disso, aceptores inespecíficos de colesterol podem contribuir para menor remoção de lípides celulares pelas HDL. É o caso da albumina, principal proteína modificada por glicação na circulação e cuja concentração encontra-se aumentada na íntima arterial na vigência de disfunção endotelial e aterosclerose.

A albumina modificada in vitro por glicação avançada é mais captada por macrófagos e induz a geração de ROS e aumento do estresse do retículo endoplásmático, o que se vincula com a redução no conteúdo de ABCA-1 (De Souza Pinto et al., 2012; Castilho et al., 2012). Em paralelo, observa-se maior expressão de receptores CD-36 e RAGE (De Souza Pinto et al., 2012), evidenciando que a albumina-AGE favorece maior influxo de colesterol aos macrófagos em detrimento de sua remoção pelas HDL. De fato, o conteúdo de colesterol celular encontra-se aumentado, com redução e aumento, respectivamente, nas atividades da hidroximetilglutaril coenzima A redutase (HMGCoA redutase) e acil colesterol aciltransferase (ACAT) (De Souza Pinto et al., 2012).

Além disso, albumina glicada induz o aumento da expressão da proteína de ligação de ácidos graxos 4 (FABP4) em macrófagos, o que 
também está associado com maior acúmulo intracelular de colesterol total e triglicérides (Wang et al., 2011).

Redução na atividade da LCAT foi descrita, bem como aumento na atividade da CETP frente à modificação de HDL, LDL e VLDL por glicação in vivo e in vitro (Passarelli, 1997). As modificações, mediadas por metilglioxal, nos resíduos de arginina, lisina e triptofano das apoA-I são críticas para a ativação da LCAT e a atividade da enzima varia de acordo com o grau de glicação da apoA-I (Nobecourt et al., 2007).

Lipoproteínas glicadas prejudicam a função do receptor SR-BI, comprometendo a captação seletiva de colesterol esterificado no fígado (Horiuchi et al., 2003; Ohgami et al., 2003). Além disso, a atividade da lipoproteína lipase também é severamente diminuída frente à glicação de lipoproteínas (Veiraiah, 2005). Em conjunto, as alterações em etapas distintas do transporte reverso, promovidas pela glicação, contribuem para o prejuízo no fluxo centrípeto de colesterol, favorecendo seu acúmulo em células arteriais.

\subsection{Produtos de Glicação Avançada e Inflamação}

A ativação de vias de sinalização pró-inflamatórias mediadas pelo RAGE é apontada como um importante fator na gênese das complicações macro e microvasculares do diabete melito. Células da vasculatura apresentam moderada expressão basal deste receptor a qual, entretanto, é aumentada na vigência de hiperglicemia, hiperinsulinemia e inflamação (Yan et al., 2007). 
Cai et al. (2004) demonstraram que a LDL modificada por AGE, isolada de portadores de diabete melito que ingeriram dieta rica em AGE, aumentou as vias de sinalização intracelular associadas à produção de marcadores inflamatórios. Além disso, aumento da atividade da NADPH oxidase, geração de ROS, expressão dos receptores scavenger LRP1, CD36 e RAGE, expressão e secreção de $M C P-1$, além do acúmulo de lípides intracelular também foi descrito em células tratadas com LDL glicada (Sima et al.,2010; Toma et al.,2009). Ao se ligarem ao RAGE, os AGE promovem aumento da produção de ROS via NADPH oxidase, fosforilação de ERK, JNK (JUN N-terminal kinase), p38, p48 (via da MAPK) com consequente ativação de NF-kB. Este é implicado com os processos fisiopatológicos da hiperglicemia no diabete melito e relacionado ao aumento da expressão de genes pró-inflamatórios, fatores de crescimento e moléculas de adesão, além do próprio RAGE, o que cria um ciclo vicioso. Em células endoteliais, os AGE e o TNF- $\alpha$ aumentam a expressão de RAGE por meio da ativação do complexo p65/p50 do NF-kB. Nesse contexto, a exposição crônica aos AGE e ao TNF-a poderia levar a um acúmulo de AGE nos vasos, resultando em exacerbação das disfunções vasculares (Tanaka et al., 2000).

Assim como os AGE, o produto Amadori ou frutosil-lisina (intermediário precoce da reação de glicação) também induz a produção de citocina próinflamatória IL-6 e quimiocina MCP-1, além de estimular o crescimento e migração de células da musculatura lisa vascular. Neste mesmo estudo, o produto Amadori também induziu o aumento da atividade do NF-kB e da MAPK (ERK e p38), mostrando que não só o produto final da reação de 
glicação, mas os seus produtos intermediários também podem induzir aumento de mediadores inflamatórios (Hattori et al., 2002).

Além dos AGE, TNF- $\alpha$, S-100/calgranulina, $\beta$-amiloide, anfoterina (high mobility group box 1 - HMGB1) e o estresse oxidativo também podem ativar o RAGE, deixando as células mais suscetíveis à ação dos AGE e inflamação crônica (Figarola et al., 2007).

As $\$ 100 /$ calgranulinas fazem parte de uma família de 25 proteínas com baixo peso molecular (entre 10 e $12 \mathrm{kDa}$ ) sendo expressas em diversos tecidos. Elas são proteínas multifuncionais e, no meio intracelular por meio da interação com diversas proteínas efetoras, envolvem-se em uma ampla gama de processos celulares, como contração, mobilidade, crescimento e diferenciação celular, organização estrutural de membranas e dinâmica do citoesqueleto. Além disso, algumas S100 como a S100B, S100A8/A9 e S100A12 podem ser secretadas para o meio extracelular e agem como citocinas, podendo interagir com o RAGE e induzir o aumento do estresse inflamatório (Donato, 2003, Hayakawa et al., 2012). Em condições inflamatórias, diabete melito e cardiopatias, estas proteínas encontram-se em concentrações elevadas na circulação (Kosaki et al., 2004; Miyamoto et al., 2008; Hirata et al., 2012).

Tikellis et al. (2008) encontraram hipertrofia cardíaca, aumento da produção de superóxido e acúmulo de AGE e calgranulinas S100A8/A9 no tecido cardíaco de camundongos selvagens em comparação aos animais knockout para RAGE, alimentados por 16 semanas com dieta rica em gordura (a qual também contém quantidade elevada de AGE). Também se 
observou, nos animais selvagens, aumento nos marcadores inflamatórios, IL-6, TNF-a, ICAM-1, MCP-1 e p-65, no plasma, embora o peso e o acúmulo de lípides no miocárdio tenham sido similares entre os dois grupos. A administração de alagebrium, composto que reduz a concentração de AGE por desfazer o entrecruzamento de proteínas glicadas, reduziu o estresse oxidativo e inflamatório, bem como a concentração de AGE e RAGE no tecido cardíaco.

De forma similar, camundongos, simultaneamente, knockout para RAGE e receptor de LDL, alimentados por 12 semanas com dieta rica em gordura, apresentaram redução no tamanho da lesão aterosclerótica, no conteúdo de macrófagos arteriais, além de diminuição no estresse oxidativo e inflamatório (VCAM-1 e ICAM-1) quando comparados com animais knockout para receptor de LDL apenas (Sun et al., 2009).

Harja et al. (2008) evidenciaram papel crítico do RAGE na disfunção endotelial, desenvolvimento da placa aterosclerótica e aumento da inflamação vascular em camundongos knockout para apoE. Além disso, neste mesmo estudo, a calgranulina S100B levou ao aumento da expressão de mediadores inflamatórios, via ativação da JNK-MAPK.

Monócitos THP-1, incubados com calgranulina S100B (Huang at al., 2006; Shanmugam et al.,2003), com AGE ou com alta concentração de glicose (Shanmugan et al., 2003 a,b) apresentaram aumento da expressão e secreção de citocinas pró-inflamatórias, quimiocinas, moléculas de adesão, integrinas e ciclooxigenase-2 (COX-2). Além disso, o uso de inibidores de NF-kB, estresse oxidativo, PKC, ERK e MAPK bloquearam o aumento da 
expressão desses genes. De forma análoga, em fibroblastos da adventícia, incubados com albumina-AGE, observou-se aumento da resposta inflamatória (MCP-1, IL-6 e VCAM-1) e da capacidade migratória mediante ativação da via RAGE-MAPK-NF-kB (Liu et al., 2010).

A resposta inflamatória suscitada por AGE é atenuada por inibidores de glicação avançada, como metformina (Isoda et al., 2006), tiazolidinedionas (Marx et al., 2004), o composto LR-90 (Figarola et al., 2007), ciprofloxacina (Mori et al., 2010) e irbesartan (Matsui et al., 2011).

Por outro lado, alguns estudos demonstram que a ligação de albuminaAGE, isenta de endotoxinas, ao RAGE não é suficiente para induzir a liberação de moléculas pró-inflamatórias, como VCAM-1 e TNF-a e pode não ter um papel na ativação celular (Valencia et al., 2004b; Valencia et al., 2004c). Desta forma, o potencial inflamatório suscitado pelos AGE nos demais estudos poderiam ser atribuídos à presença de endotoxinas nas amostras processadas em laboratório.

Embora referida como parte do mecanismo aterogênico suscitado pelos AGE, a resposta inflamatória atribuída aos mesmos ainda é incerta e pode decorrer da interação entre vários receptores celulares, como o RAGE e aqueles que medeiam a resposta imunológica inata, como os receptores símiles ao Toll (TLR) (Lin, 2006; van Beijnum et al., 2008;Qin et al., 2009; van Zoelen et al., 2009). Além disso, o estresse inflamatório celular tem sido apontado como consequência da sensibilização prévia, pela incubação com AGE, a estímulos subsequentes, como as calgranulinas/S100 (Ehlermann et al., 2006). 
Células endoteliais da veia umbilical humana (HUVEC) pré-tratadas com albumina-AGE, em comparação com células controles, apresentaram maior secreção de IL-6, ICAM-1, VCAM-1 e MCP-1 de forma dosedependente, quando incubadas com S100A8/S100A9. Esse efeito foi reduzido por inibidores da via MAPK (ERK1/2 e p38) (Ehlermann et al., 2006). Assim, fica evidente que os AGE podem, previamente, sensibilizar as células a outros estímulos inflamatórios (Herold et al., 2007).

Contrariamente aos estudos anteriores, Aneja et al. (2008) demonstrou que o pré-condicionamento de monócitos, THP-1, com HMGB1 leva à diminuição na secreção de TNF- $\alpha$ e ativação do NF-kB induzido por LPS. O mesmo foi verificado, in vivo, quando ao injetar HMGB1 1h antes da injeção de LPS, houve redução no TNF- $\alpha$ circulante, sugerindo que o précondicionamento com HMGB1 induz tolerância ao LPS.

Neste sentido, Yamamoto et al. (2011) demonstraram que o LPS, um clássico indutor inflamatório, é capaz de induzir o estresse inflamatório tanto via TLR4 e 2 quanto via RAGE. O LPS interage com o RAGE no mesmo sítio de ligação que os $A G E$, levando à ativação de NF-kB e secreção de citocinas inflamatórias como o TNF-a e IL-6. Assim como o LPS, a S100A8/S100A9, também parecem ser capazes de interagir tanto com o RAGE quanto com os TLR (Boyd et al.,2008; Vogl et al., 2007).

Interessantemente, esses estudos fortalecem a ideia de uma ação sinérgica entre os vários ligantes dos RAGE e outros receptores celulares durante processos inflamatórios crônicos. 
A proposta do presente estudo baseou-se na íntima associação entre inflamação e aterosclerose no diabete melito. Mediadores inflamatórios alteram o fluxo de lípides, favorecendo o acúmulo destes em macrófagos arteriais. Por outro lado, produtos de glicação avançada também interferem sobre as vias de captação e remoção de lípides e são importantes mediadores da resposta inflamatória e do estresse oxidativo. A glicação prejudica o efluxo de lípides celulares, por reduzir a expressão de ABCA-1 e ABCG-1 em macrófagos, associada ao aumento do estresse oxidativo e estresse do retículo endoplasmático (De Souza Pinto et al., 2012; Castilho et al, 2012).

Os mecanismos celulares que envolvem a participação dos produtos de glicação avançada sobre o estresse inflamatório e sobre o fluxo de lípides celulares em macrófagos não estão totalmente esclarecidos. Há evidências de que os AGE, por si, não são capazes de induzir o aumento do estresse inflamatório, mas sensibilizam as células a posterior estimulação inflamatória por outros ligantes de RAGE. A grande heterogeneidade dos AGE e a característica do seu principal receptor - RAGE - também tornam difícil a exata determinação dos efeitos biológicos promovidos pelos AGE.

Do ponto de vista da inflamação, a grande maioria dos dados da literatura acerca da modulação do efluxo de colesterol resulta da adição direta de citocinas pró e anti-inflamatórias às células em cultura, não refletindo a interação entre células da parede arterial. A sensibilização de macrófagos com albumina controle ou albumina-AGE, seguido do estímulo inflamatório por calgranulina S100B ou LPS, permitiu avaliar a secreção de 
citocinas, quimiocinas e moléculas de adesão, e seu reflexo sobre a remoção de colesterol (Figura 2).

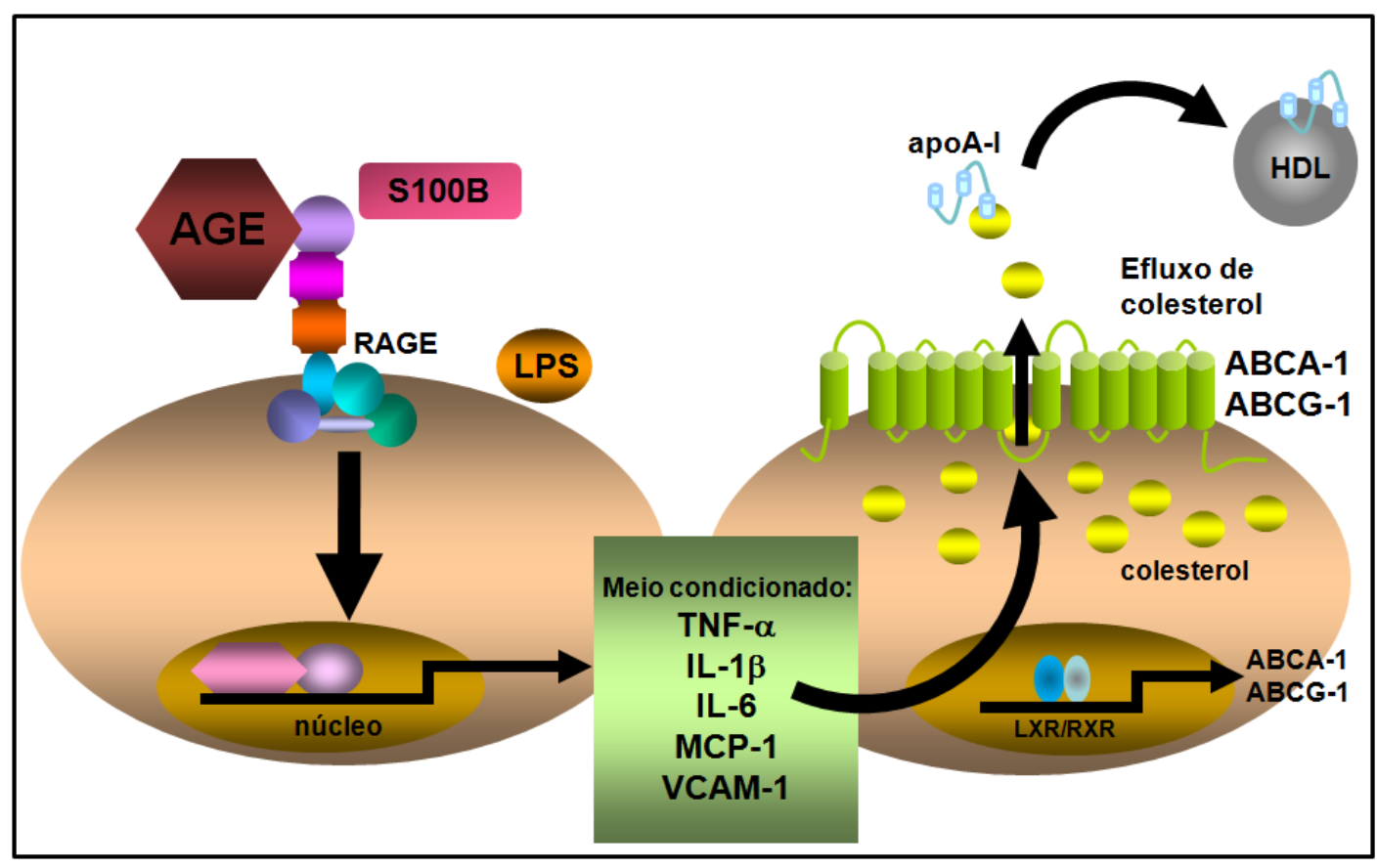

\section{Figura 2. Hipótese experimental}

Meio condicionado, contendo citocinas, produzido por macrófagos expostos à albumina-AGE e, posteriormente, a S100B ou LPS, quando utilizado para tratar macrófagos não estimulados, podem alterar o efluxo de colesterol mediado por subfrações de HDL e apo A-I, além da expressão dos receptores de HDL e LXR, refletindo prejuízo ao transporte reverso de colesterol e maior risco de aterosclerose no diabete melito. 


\section{OBJETIVO}

O objetivo deste estudo é avaliar se citocinas, quimiocinas e moléculas de adesão produzidas por macrófagos estimulados por albumina-AGE, na presença ou ausência de estímulos subsequentes (calgranulina S100B e LPS), são capazes de modular a remoção de colesterol celular por subfrações de HDL e apo A-I.

Desta forma, foram avaliados:

- a secreção de citocinas pró-inflamatórias (IL-1 $\beta$, IL-6, TNF- $\alpha$ ), quimiocinas (MCP-1) e molécula de adesão (VCAM-1);

- o efluxo de ${ }^{14} \mathrm{C}$-colesterol, em macrófagos saudáveis, mediado por apo A-I e por subfrações de HDL, mediante incubação com meio condicionado, contendo citocinas

- o papel anti-inflamatório da HDL em macrófagos submetidos ao tratamento com albumina-AGE e subsequente estímulo inflamatório (S100B ou LPS) 


\section{MÉTODOS}

O protocolo para utilização de animais foi de acordo com os Princípios Éticos na Experimentação Animal adotados pelo Colégio Brasileiro de Experimentação Animal (COBEA), e todos os precedimentos experimentais deste projeto, foram aprovados pela Comissão de Ética para Análise de Projetos de Pesquisa do HCFMUSP (CAPPesq - 0220/08).

\subsection{Preparo da albumina glicada in vitro}

Albumina bovina isenta de ácidos graxos e com concentração de endotoxina inferior a $0,1 \mathrm{ng} / \mathrm{mg}$ (Sigma-Aldrich, Steinheim, Alemanha) foi incubada na presença de $10 \mathrm{mM}$ de glicolaldeído (Sigma-Aldrich, FlukaBuchs, Alemanha) dissolvido em tampão fosfato (PBS) ( $\mathrm{NaCl} 137 \mathrm{mmol} / \mathrm{L}$; $\left.\mathrm{Na}_{2} \mathrm{HPO}_{4} 4 \mathrm{mmol} / \mathrm{L} ; \mathrm{KCl} 2 \mathrm{mmol} / \mathrm{L} ; \mathrm{K}_{2} \mathrm{PO}_{4} 1 \mathrm{mmol} / \mathrm{L}\right)$ com EDTA $(\mathrm{pH}=7,4)$. Albumina controle (C) foi preparada na presença de PBS, apenas. As incubações foram realizadas sob condições estéreis, atmosfera de nitrogênio, banho de água a $37^{\circ} \mathrm{C}$, com agitação por 4 dias. A seguir, as amostras foram dialisadas contra PBS e esterilizadas em filtro $0,22 \mu \mathrm{m}$. A concentração final de proteína das amostras foi determinada pelo método de LOWRY et al. (1951) e todas as amostras foram congeladas a $-70^{\circ} \mathrm{C}$ até o seu uso. 


\subsection{Dosagem de endotoxina das albuminas controle e glicada in vitro}

A quantidade de endotoxina das albuminas $C$ AGE, in vitro, foi determinada pelo ensaio da Limulus Amebocyte Lysate (LAL) (Cape Cod, Falmouth, MA, USA). Em todas as amostras, a concentração de endotoxinas inferior a $50 \mathrm{pg} / \mathrm{mL}$, a qual é referida como não sendo capaz de induzir resposta inflamatória em estudos de cultura celualr (Valencia et al., 2004).

\subsection{Obtenção de lipoproteínas}

Lipoproteína de densidade baixa (LDL; $d=1,019-1,063 \mathrm{~g} / \mathrm{mL}$ ) e as subfrações de $\mathrm{HDL}_{2}(\mathrm{~d}=1,063-1,125 \mathrm{~g} / \mathrm{mL})$ e $\mathrm{HDL}_{3}(\mathrm{~d}=1,125-1,21$ $\mathrm{g} / \mathrm{mL}$ ) foram isoladas do plasma humano por ultracentrifugação sequencial e purificação por gradiente descontínuo de densidade (Havel et al., 1955; Redgrave et al., 1975).

\subsection{Acetilação de LDL}

A LDL foi acetilada segundo protocolo descrito por Basu et al. (1976). Para cada $16 \mathrm{mg}$ de proteína de LDL, foram adicionados $1 \mathrm{~mL}$ de solução saturada de acetato de sódio e $1 \mathrm{~mL}$ de cloreto de sódio ( $\mathrm{NaCl}-0,15 \mathrm{M}$ ), sob constante agitação e banho de gelo. Anidrido acético em pequenas e multiplas quantidades foi adicionado por um período de $1 \mathrm{~h}$, seguido de 30 
min de agitação em banho de gelo. O volume de anidrido acético utilizado foi de 1,5 vezes a massa de proteína de LDL.

A seguir, a LDL acetilada foi dialisada contra tampão fosfato (PBS) com EDTA $(\mathrm{pH}=7,4)$ por $24 \mathrm{~h}$ a $4^{\circ} \mathrm{C}$ e esterilizada em filtro $0,22 \mu \mathrm{m}$. A concentração final de proteína da amostra foi determinada pelo método de LOWRY et al. (1951)

\subsection{Obtenção e cultivo dos macrófagos de peritônio de camundongos}

Os camundongos da linhagem suiça foram obtidos do Departamento Técnico de Apoio ao Ensino e Pesquisa (DTAEP) da Faculdade de Medicina da Universidade de São Paulo. Macrófagos foram isolados da cavidade peritoneal dos camundongos, lavando-se o peritônio com solução de tampão fosfato (PBS) estéril, pH 7,4, acrescido com penicilina G potássica e sulfato de estreptomicina. Após obtenção do botão celular, as células foram ressuspensas em meio RPMI (Gibco, Grand Island, Nova lorque, EUA) contendo $10 \%$ de soro fetal bovino (SFB) (Cultilab, Campinas, Brasil), antibióticos $(100 \mu \mathrm{g} / \mathrm{mL}$ de estreptomicina e $100 \mathrm{U} / \mathrm{mL}$ de penicilina - Gibco) e glutamina (2 mM - Gibco); colocados em placas de cultura com 24 cavidades $\left(1,8 \times 10^{6}\right.$ células por cavidade) ou em garrafas de cultura de 75 $\mathrm{cm}^{2}$ (30 × $10^{6}$ células por garrafa) e mantidas em incubadora de $\mathrm{CO}_{2} 5 \%$ a $37^{\circ} \mathrm{C}$. Após $48 \mathrm{~h}$ as placas foram lavadas com PBS contendo albumina isenta em ácidos graxos (FAFA) (Sigma) para remoção de células não aderidas. 


\subsection{Meio condicionado sem e com sobrecarga de colesterol}

Macrófagos de peritônio de camundongos foram incubados apenas com meio de cultura, DMEM contendo baixa concentração de glicose (Gibco) acrescido de $1 \%$ de albumina isenta em ácidos graxos (FAFA) (Sigma) (situação controle), na presença de albumina-controle (2 mg albumina $\mathrm{C} / \mathrm{mL}$ de meio), albumina-AGE (2mg albumina $A G E / m L$ de meio), calgranulina/S100B (20 $\mathrm{gg} / \mathrm{mL}$ de meio) (Sigma-Aldrich, St. Louis - MO, EUA) ou lipopolissacarídeo (LPS serotipo E. Coli, $1 \mu \mathrm{g} / \mathrm{mL}$ de meio Sigma), por 24 h, para avaliar a secreção de citocinas pró-inflamatórias (Figura 3).

\section{Macrófagos de peritônio de camundongo}

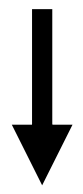

\section{DMEM}

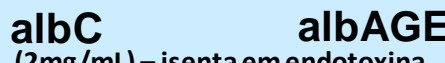

\section{$24 h$}

IL-6, TNF- $\alpha$, IL-1 $\beta$,

MCP-1 e VCAM-1

Figura 3. Protocolo experimental 1 
Em outro protocolo experimental (Figura 4), macrófagos foram incubados por $72 \mathrm{~h}$ apenas com meio de cultura (DMEM/FAFA), albumina-C ou albumina-AGE, na presença ou ausência de sobrecarga de colesterol

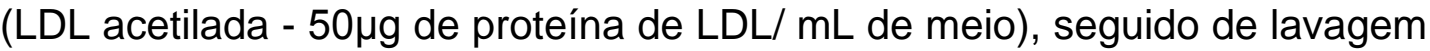
com PBS/FAFA e subsequente incubação apenas com meio de cultura (DMEM/FAFA), na presença de calgranulina/S100B ou LPS por 24h. O LPS foi utilizado como controle positivo de indução inflamatória (Baranova et al., 2002) e a proteína S100B como controle positivo de sinalização pelo RAGE (Donato, 2003).

Após os períodos de incubação, este meio isolado de tratamento com albumina-C ou albumina-AGE e S100B ou LPS, que denominamos, meio condicionado, foi centrifugado a $1500 \mathrm{rpm}$ por 10 min e congelado a $-70^{\circ} \mathrm{C}$, para posterior determinação da concentração de citocinas.

Em outros experimentos (Figura 4) o meio condicionado foi centrifugado para remoção de debris celulares e utilizado para tratar macrófagos não estimulados, nos quais foi determinado o efluxo de ${ }^{14} \mathrm{C}$ colesterol. 
Macrófagos de peritônio de camundongo

\pm Sobrecarga de

$$
\text { colesterol }
$$

(LDL acetilada)

Lavagem

$\downarrow$

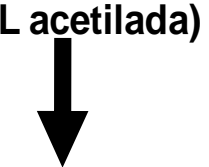

$72 \mathrm{~h}$

\section{$24 \mathrm{~h}$}

DMEM, albC ou albAGE

DMEM, S100B ou LPS

( $2 \mathrm{mg} / \mathrm{mL}$ - isenta em endotoxinas)

$(20 \mathrm{mg} / \mathrm{mL}) \quad(1 \mathrm{mg} / \mathrm{mL})$

Coleta do meio

condicionado

- IL-6, TNF- $\alpha$, IL-1 $\beta$, MCP-1 e VCAM-1

- Tratamento de macrófagos não estimulados (meio condicionado, 24 h):

- determinação do efluxo de colesterol, mediado por $\mathrm{HDL}_{2}, \mathrm{HDL}_{3}$, e apoA-I

Figura 4. Protocolo experimental 2

3.7. Determinação do papel da HDL em modular a resposta inflamatória induzida por albumina-AGE, S100B e LPS

Após confluência, macrófagos de peritônio de camundongo foram incubados com albumina-C (2 mg/mL de meio) ou albumina-AGE (2 mg/mL de meio) por 72 h, na presença ou ausência de HDL (100 ㅆg de proteína de $\mathrm{HDL} / \mathrm{mL}$ de meio). Após esse período de incubação, as células foram cuidadosamente lavadas com PBS/FAFA e incubadas, por mais $24 \mathrm{~h}$, com calgranulina/S100B (20 $\mathrm{\mu g} / \mathrm{mL}$ de meio) ou LPS (1 $\mu \mathrm{g} / \mathrm{mL}$ de meio) na presença ou ausência de HDL (100 $\mu \mathrm{g}$ de proteína de HDL/mL de meio). 
O meio foi, então, centrifugado a 1500 rpm, por 10 min e congelado a $70^{\circ} \mathrm{C}$, para posterior determinação da concentração de mediadores inflamatórios.

\subsection{Determinação do papel do inibidor de NF-kB em modular a resposta inflamatória induzida por albumina-AGE, S100B e LPS}

Após confluência, macrófagos de peritônio de camundongo foram incubados com albumina-C (2 mg albC/mL de meio) ou albumina-AGE (2 mg albAGE/mL de meio) por $72 \mathrm{~h}$, na presença ou ausência do inbidor de NF-kB (SN50 - $50 \mu \mathrm{g} / \mathrm{mL}$ de meio, Sigma). Após esse período de incubação, as células foram cuidadosamente lavadas com PBS/FAFA e incubadas, por mais $24 \mathrm{~h}$, com calgranulina/S100B (20 $\mathrm{gg} / \mathrm{mL}$ de meio) ou LPS $(1 \mu \mathrm{g} / \mathrm{mL}$ de meio) na presença ou ausência do inibidor de NF-kB (SN50 - $50 \mu \mathrm{g} / \mathrm{mL}$ de meio).

O meio foi, então, centrifugado a 1500 rpm por 10 min e utilizado para incubar, por 24 h, macrófagos não estimulados para avaliação do efluxo de colesterol mediado por apoA-I.

3.9. Quantificação de citocinas pró-inflamatórias (IL-1 $\beta$ e IL-6, TNF- $\alpha$ ), quimiocina MCP-1 e molécula de adesão VCAM-1

A concentração de citocinas pró-inflamatórias (IL-6, TNF- $\alpha$ e IL-1 $\beta$ ), quimiocina (MCP-1) e molécula de adesão (VCAM-1) foram determinadas por ELISA (R\&D System - Duo Set, Minneapolis, EUA). 


\subsection{Efluxo de ${ }^{14} \mathrm{C}$-colesterol, mediado por $\mathrm{HDL}_{3}, \mathrm{HDL}_{2}$ e apoA-I mediante incubação com meio condicionado, contendo citocinas}

O efeito de mediadores inflamatórios sobre o efluxo de colesterol celular foi avaliado pela utilização de meio condicionado de macrófagos tratados com albumina $\mathrm{C}$ ou albumina $\mathrm{AGE}$.

Macrófagos foram incubados em placas de cultura com 24 cavidades $\left(1,8 \times 10^{6}\right.$ células por cavidade). As células foram mantidas em estufa a $37^{\circ} \mathrm{C}$ com atmosfera de $\mathrm{CO}_{2} 5 \%$. Após confluência celular, os macrófagos foram incubados com DMEM/FAFA, acrescido com LDL acetilada (50 $\mathrm{\mu g}$ de proteína de LDL/mL de meio) e ${ }^{14} \mathrm{C}$-colesterol $(0,3 \mu \mathrm{Ci} / \mathrm{mL}$ de meio), por $48 \mathrm{~h}$. Após este período, as células foram lavadas duas vezes com PBS/FAFA e incubadas com DMEM contendo 0,5 mM de 8-Bromoadenosine 3', 5'- cyclic monphosphate (8-Br AMPc) por $24 \mathrm{~h}$.

Seguindo a lavagem cuidadosa das cavidades, as células foram incubadas com meio condicionado por 24 h. Após esse período, esses macrófagos foram incubados por mais $5 \mathrm{~h}$ na presença ou ausência de $\mathrm{HDL}_{3}$ (50 $\mu \mathrm{g}$ de $\left.\mathrm{HDL}_{3} / \mathrm{mL}\right)$ ou $\mathrm{HDL}_{2}\left(50 \mu \mathrm{g}\right.$ de $\left.\mathrm{HDL}_{2} / \mathrm{mL}\right)$ ou por 8h na presença ou ausência de apoA-I (30 $\mu \mathrm{g}$ de apoA-l/mL). O meio de cultura foi, então, recolhido para tubos de vidro, centrifugado a $1500 \mathrm{rpm}$ durante $10 \mathrm{~min}$ a $4^{\circ} \mathrm{C}$, para a remoção de debris celulares e, transferido para frascos de cintilação, seguindo-se a adição de solução contadora (Perkin Elmer, Turko, Finlândia). As cavidades das placas foram lavadas com solução fisiológica gelada $\left(4^{\circ} \mathrm{C}\right)$. A quantidade de radioatividade presente no meio, ao final do 
período de incubação, indicou o efluxo basal de colesterol e o mediado pela $\mathrm{HDL}_{3}, \mathrm{HDL}_{2}$ ou apoA-I

Os lípides celulares foram extraídos com solução de hexana:isopropanol (3:2) (Merck, Darmastadt, Alemanha) e a radioatividade determinada, após evaporação do solvente. As células foram incubadas com $250 \mu \mathrm{L}$ de $\mathrm{NaOH} 0,2 \mathrm{~N}$, durante $3 \mathrm{~h}$, a temperatura ambiente, para lise celular e determinação da concentração de proteína, pelo método de Lowry (Lowry et al., 1951).

Os valores obtidos em incubações na presença de $\mathrm{HDL}_{3}$ ou $\mathrm{HDL}_{2}$ ou apoA-I e albumina foram subtraídos daqueles obtidos apenas com albumina, de maneira a refletir o efluxo mediado somente por $\mathrm{HDL}_{3}$ ou $\mathrm{HDL}_{2}$ ou apoA-I.

A porcentagem de efluxo foi calculada como:

$\frac{{ }^{14} \mathrm{C} \text {-colesterol no meio }}{{ }^{14} \mathrm{C} \text {-colesterol no meio }+{ }^{14} \mathrm{C} \text {-colesterol na célula }} \times 100$

\subsection{Teste de viabilidade celular}

Ao final das incubações, alíquotas do meio de cultura foram removidas e centrifugadas a $250 \mathrm{~g}$ por $4 \mathrm{~min}$, para a remoção de debris celulares. Após centrifugação, esse meio foi utilizado para medir a viabilidade celular através da liberação da lactato desidrogenase (LDH) utilizando-se kit colorimétrico para ensaio toxicológico (Sigma). 


\subsection{Análise estatística}

As análises estatísticas foram realizadas com a utilização do programa GraphPad Prism 4 (GraphPad Software, Inc. 2003). As comparações entre os grupos foram feitas por análise de variância (ANOVA) de um fator com pós teste de Newman Keuls ou por teste t de Student, não pareado. Em todos os casos, foram consideradas significantes todas as situações nas quais o nível descritivo de significância foi inferior a 5\%. 


\section{RESULTADOS}

A concentração das citocinas pró-inflamatórias - IL-6, TNF- $\alpha$-, da quimiocina MCP-1 e da molécula de adesão VCAM-1 foram determinadas no meio de cultura, após incubação dos macrófagos com albumina-C, albumina-AGE, S100B ou LPS, por 24 h. Macrófagos incubados com albumina-AGE apresentaram perfil semelhante de secreção de marcadores inflamatórios quando comparados aqueles expostos à albumina- $\mathrm{C}$ ou apenas ao meio de cultura (DMEM). Conforme esperado, o tratamento com LPS (utilizado como controle positivo) promoveu aumento na secreção de IL6, TNF-a, MCP-1 e VCAM-1, em comparação às demais incubações; enquanto a calgranulina S100B apenas elevou a produção de IL-6 e VCAM1 (Figura 5, painéis A, B, C e D).

A

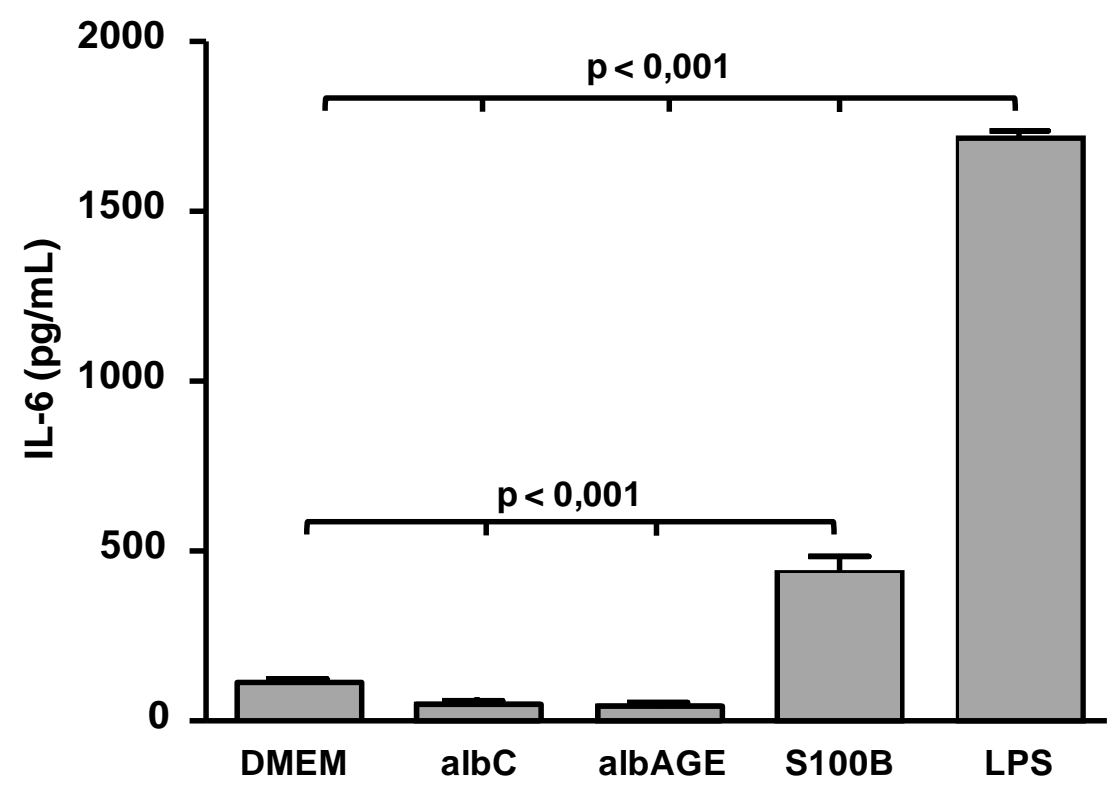


B

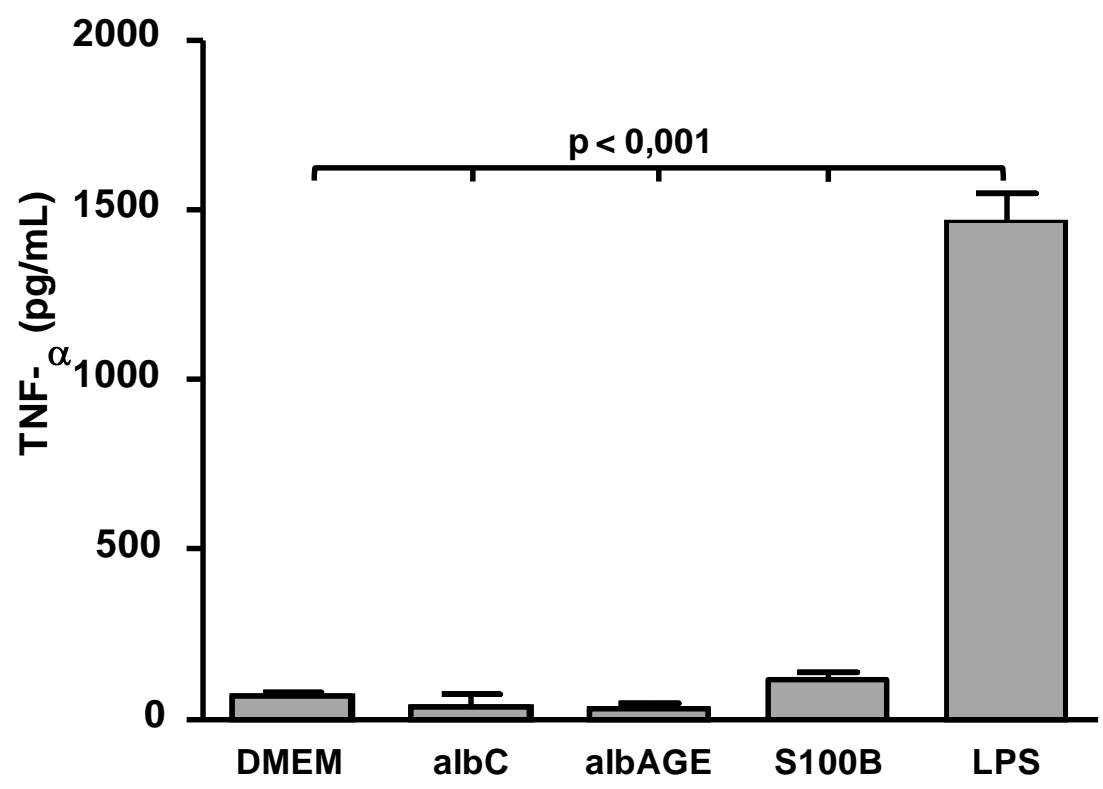

C

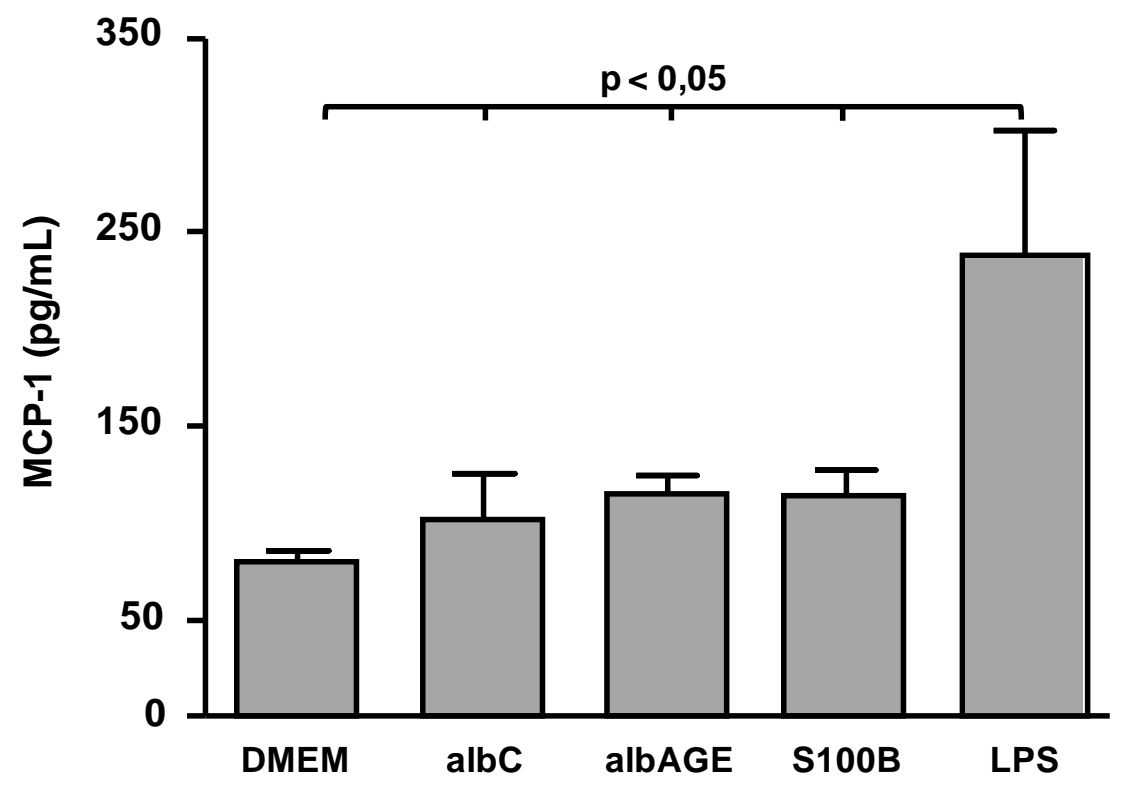


D

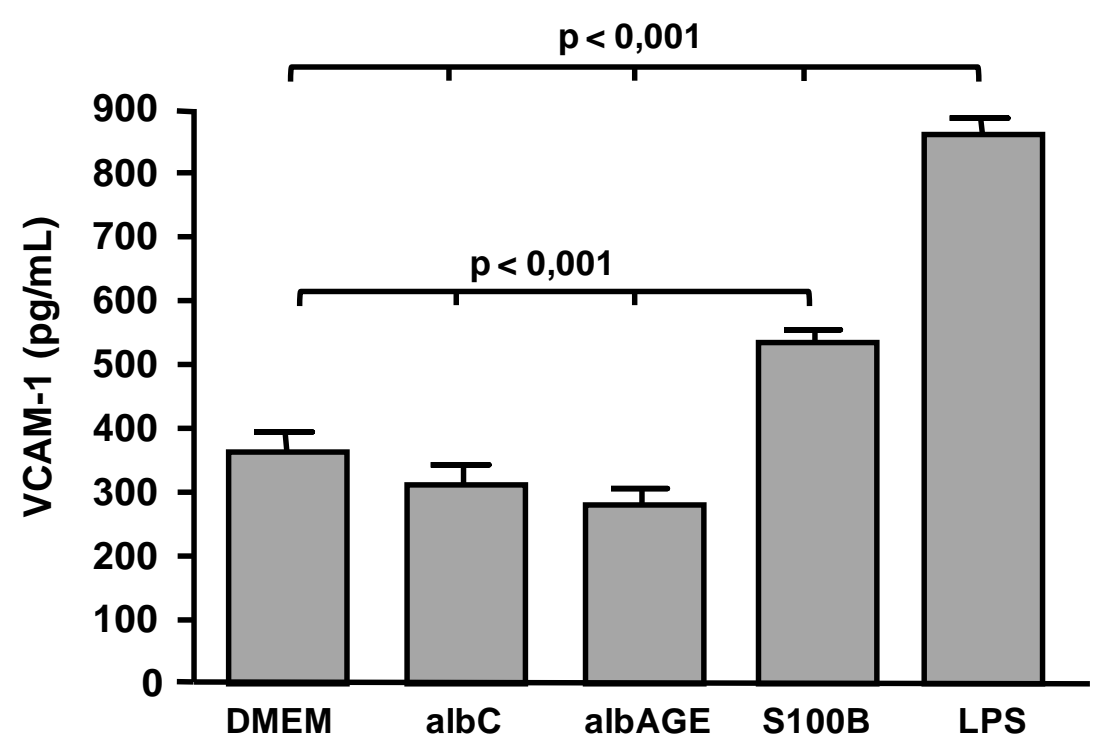

Figura 5. Albumina-AGE não altera a produção de citocinas inflamatórias por macrófagos.

Macrófagos de peritônio de camundongo foram incubados, por 24h na presença albumina-C (albC; $2 \mathrm{mg} / \mathrm{mL}$ ), albumina-AGE (albAGE; 2 $\mathrm{mg} / \mathrm{mL})$, S100B (20 $\mu \mathrm{g} / \mathrm{mL})$ ou LPS ( $1 \mu \mathrm{g} / \mathrm{mL})$. Incubações controles foram feitas apenas na presença de meio de cultura (DMEM). A concentração de IL-6 (painel A), TNF- $\alpha$ (painel B), MCP-1 (painel C) e VCAM-1 (painel D) no meio foi determinada por ELISA $(n=5)$. As comparações foram feitas pela análise de variância (ANOVA) de um fator, com pós- teste de Newman Keuls. 
Incubações de macrófagos com albumina-C ou albumina-AGE por 72 h, seguidas de lavagem e subsequente exposição, por 24h, à S100B ou LPS, evidenciaram que o pré-tratamento com albumina-AGE favoreceu maior secreção de marcadores inflamatórios. A produção de IL-6, TNF-a, MCP-1, IL-1 $\beta$ e VCAM-1 foi, respectivamente, 17, 7, 4, 4 e 13 vezes maior em células tratadas com albumina-AGE e S100B em comparação com aquelas incubadas com albumina-C e S100B (Figura 6, painéis A, B, C, D e E). De forma similar, a secreção destas mesmas citocinas foi maior nos macrófagos tratados com albumina-AGE e, posteriormente, com LPS (IL-6, 4 vezes; TNF-a, 3 vezes; MCP-1, 4 vezes; IL-1 $\beta, 3$ vezes e VCAM-1, 17 vezes) quando comparados a incubação com albumina-C e LPS (Figura 6, painéis $\mathbf{A}, \mathbf{B}, \mathbf{C}, \mathbf{D}$ e E). Estes resultados demonstram que a exposição crônica prévia aos AGE é capaz de sensibilizar macrófagos à posterior estimulação inflamatória, neste caso, por S100B e LPS (Figura 6, painéis A, B, C, D e E). 
A

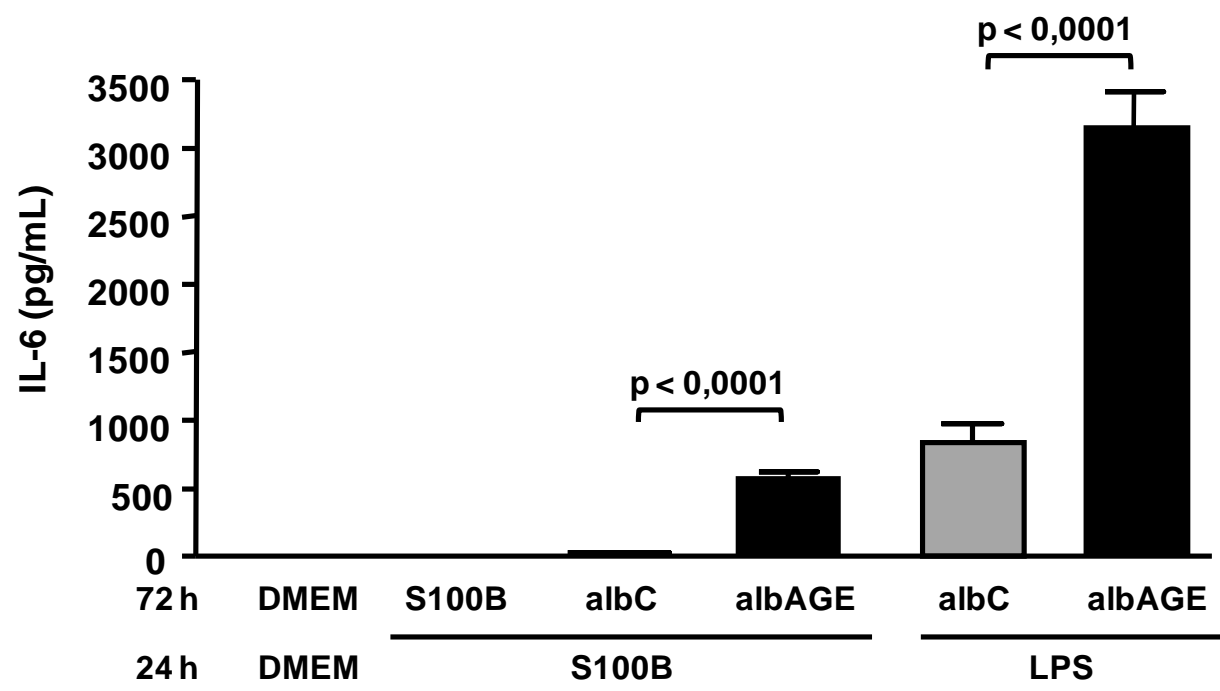

B

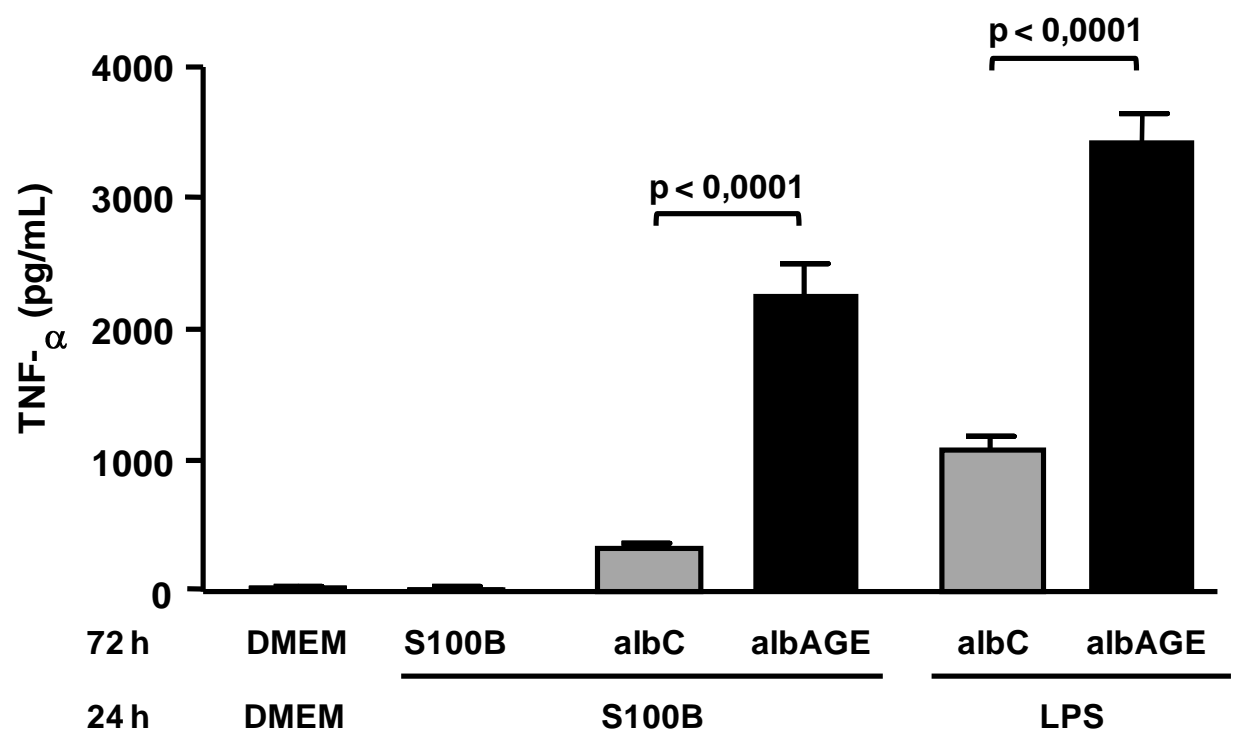


C

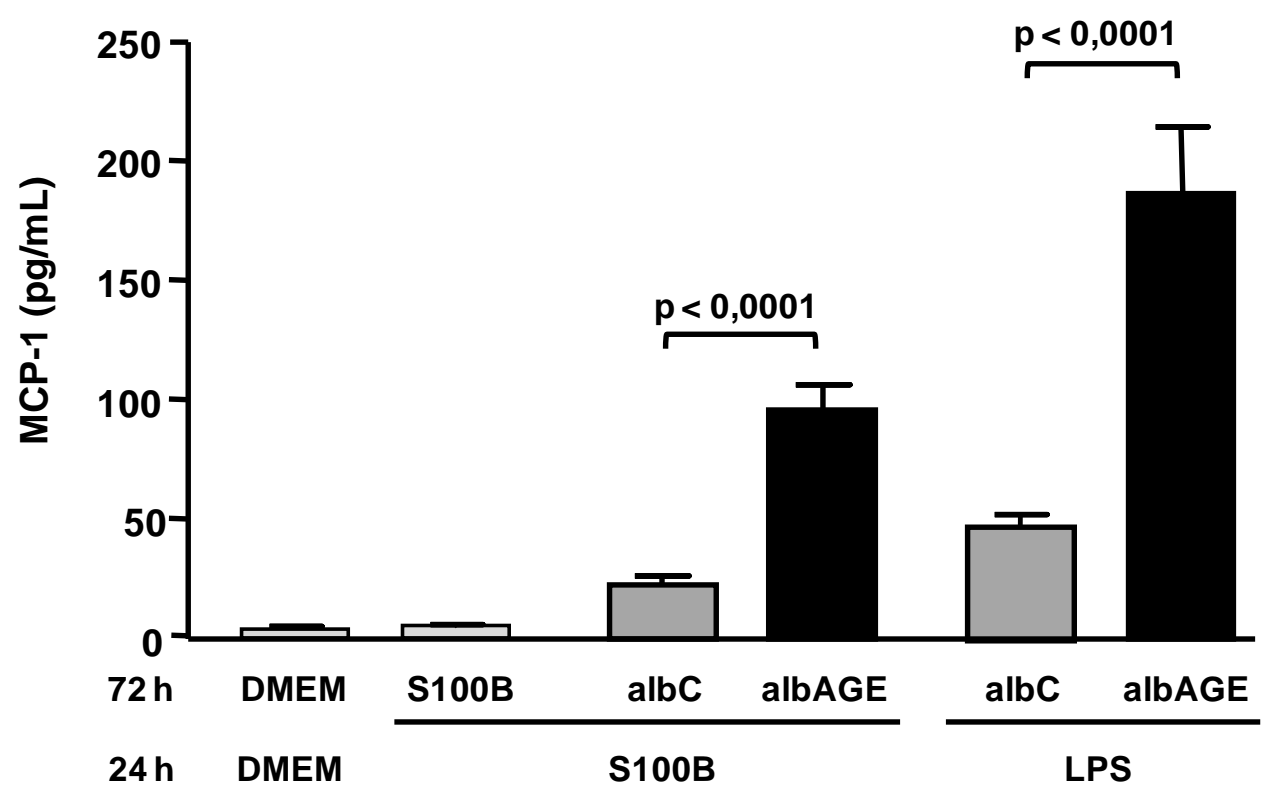

D

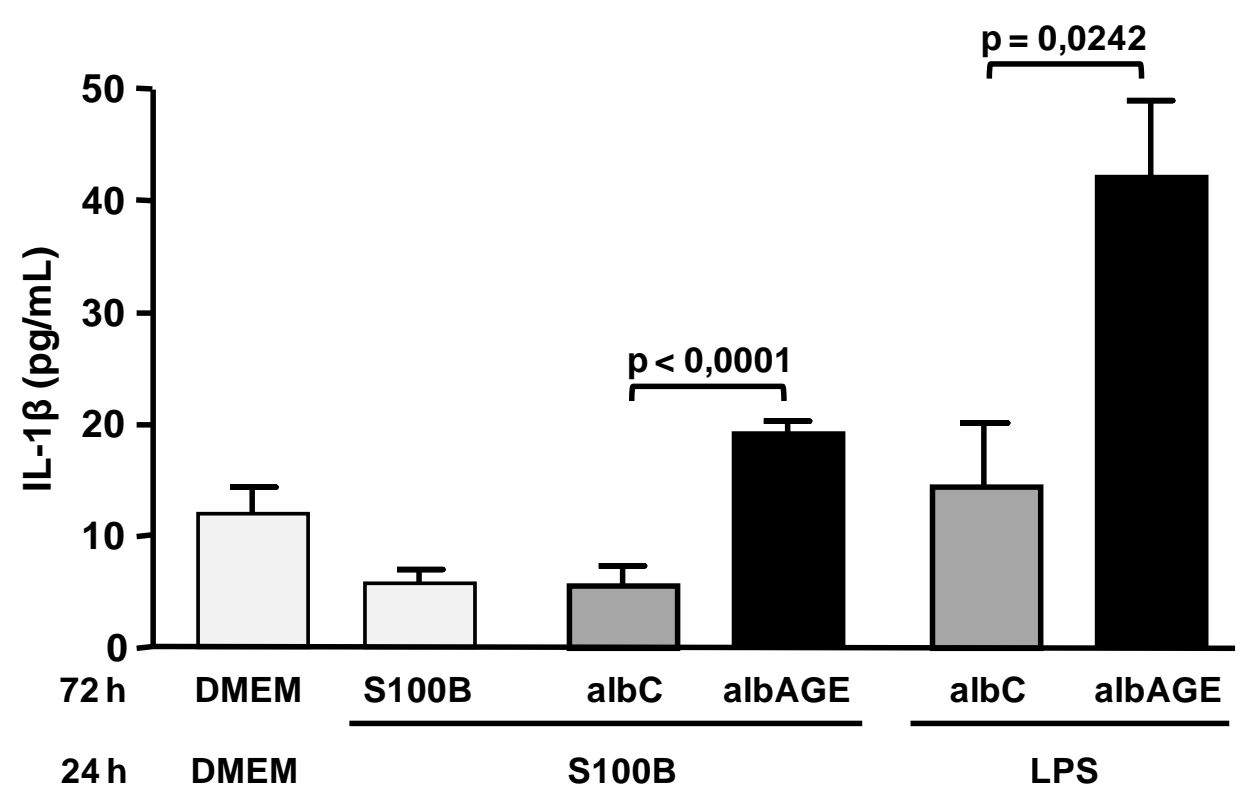


$\mathbf{E}$

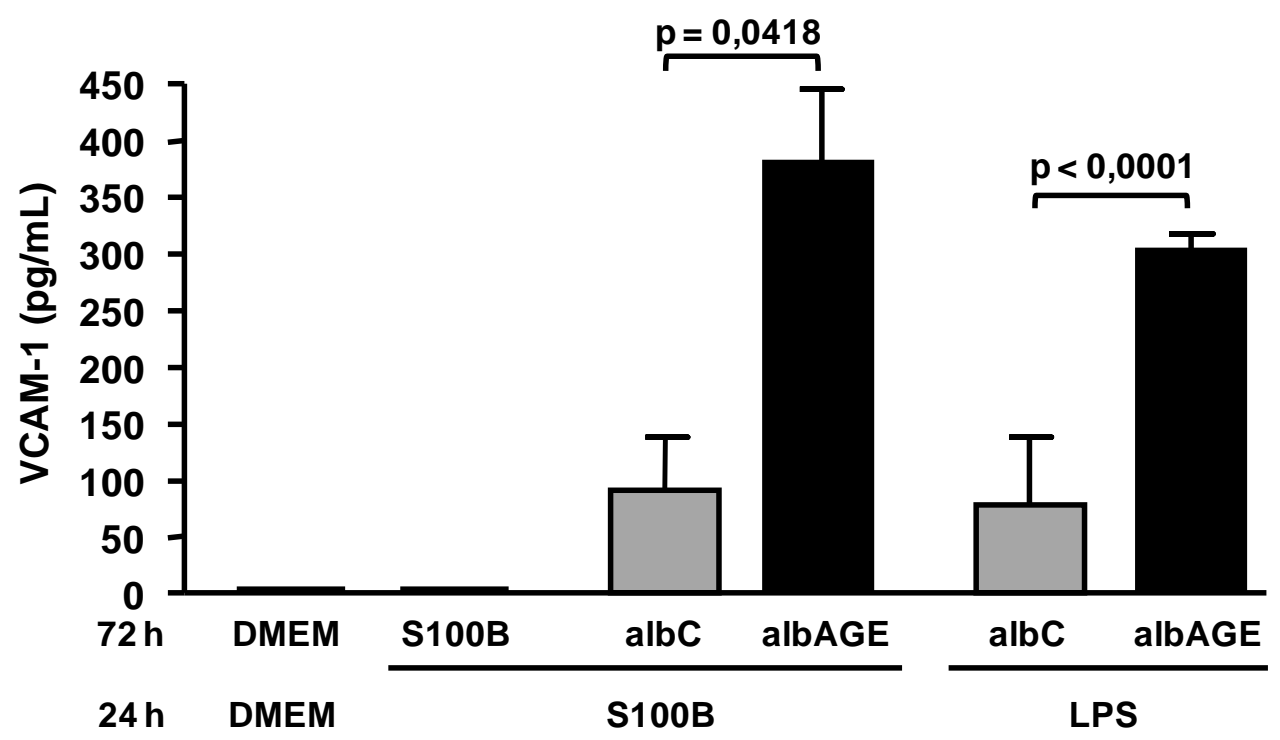

Figura 6. Calgranulina S100B e LPS induzem maior secreção de citocinas inflamatórias em macrófagos sensibilizados por albumina-AGE.

Macrófagos de peritônio de camundongo foram pré-incubados, por $72 \mathrm{~h}$, com albumina-C (albC) ou albumina-AGE (albAGE), $2 \mathrm{mg} / \mathrm{mL}$. Após lavagem, as células foram incubadas, por $24 \mathrm{~h}$, com S100B (20 $\mu \mathrm{g} / \mathrm{mL})$ ou LPS $(1 \mu \mathrm{g} / \mathrm{mL})$. Incubações controles foram feitas apenas na presença de meio de cultura (DMEM). A concentração IL-6 (painel A), TNF- $\alpha$ (painel B), MCP-1 (painel C), IL-1 $1 \beta$ (painel D) e VCAM-1 (painel E) foi determinada no meio de cultura por ELISA $(n=14)$. As comparações foram feitas pelo teste $t$ de Student, não pareado. 
Em etapas posteriores, avaliamos a contribuição do enriquecimento celular com colesterol sobre a sensibilização de macrófagos por albuminaAGE à estimulação com S100B ou LPS. Para tanto, macrófagos foram sobrecarregados com colesterol (incubação com $50 \mu \mathrm{g} / \mathrm{mL}$ de LDLacetilada), juntamente com a exposição à albumina-C ou albumina-AGE, por 72 h. A seguir, conforme descrito anteriormente, foram lavados e expostos, por $24 \mathrm{~h}$, à S100B ou LPS.

O enriquecimento dos macrófagos com colesterol levou à uma maior produção de citocinas inflamatórias em comparação aos macrófagos sem sobrecarga de LDL-colesterol. Este evento foi observado mesmo nas incubações controles com meio de cultura ou S100B apenas (Figura 7, painéis $A, B$ e C).

A incubação com albumina-C na presença de colesterol, seguida de tratamento com S100B foi capaz de induzir maior produção de IL-6, TNF- $\alpha$ e MCP-1 em comparação à incubação com albumina-C sem sobrecarga lipídica (Figura 7, painéis A, B e C). Estes achados evidenciam que o acúmulo de colesterol potencializa a resposta inflamatória em macrófagos, após tratamento com albumina-C e S100B.

A presença de colesterol também incrementou a produção de IL-6 (Figura 7, painel A) e MCP-1 (Figura 7, painel C) em macrófagos tratados com albumina-AGE e S100B, porém em menor magnitude. Isto reitera a ação da albumina-AGE na sensibilização de macrófagos ao estímulo inflamatório por S100B, independentemente do colesterol. 
Assim como nos macrófagos que não foram enriquecidos em colesterol, aqueles enriquecidos apresentaram uma maior secreção de citocinas próinflamatórias quando pré-tratados com albumina-AGE e S100B em comparação com o pré-tratamento com albumina-C e S100B (Figura 7, painéis $A, B$ e $C$ ).

No tratamento com albumina-C e LPS observou-se maior produção de IL-6, TNF-a e MCP-1 frente ao enriquecimento celular com colesterol. Entretanto, isto não foi observado para o tratamento com albumina-AGE, no qual o acúmulo de colesterol não potencializou a secreção de citocinas. Diferentemente do observado com S100B, a concentração de IL-6 e MCP-1 não variou entre macrófagos tratados com sobrecarga de colesterol, albumina-AGE e LPS em comparação à macrófagos com sobrecarga lipídica, albumina-C e LPS (Figura 7, painéis A, B e C). 
A

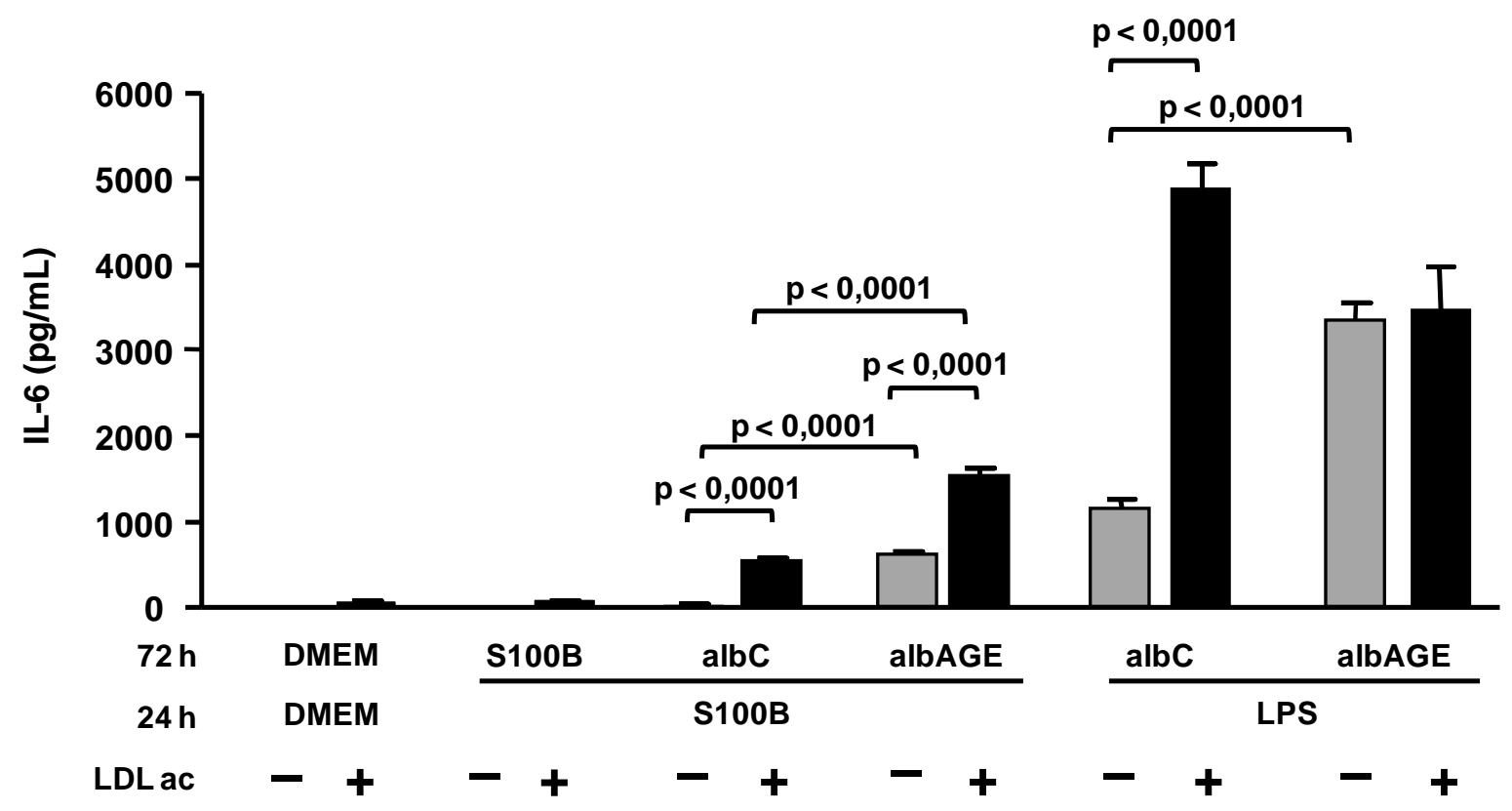

B

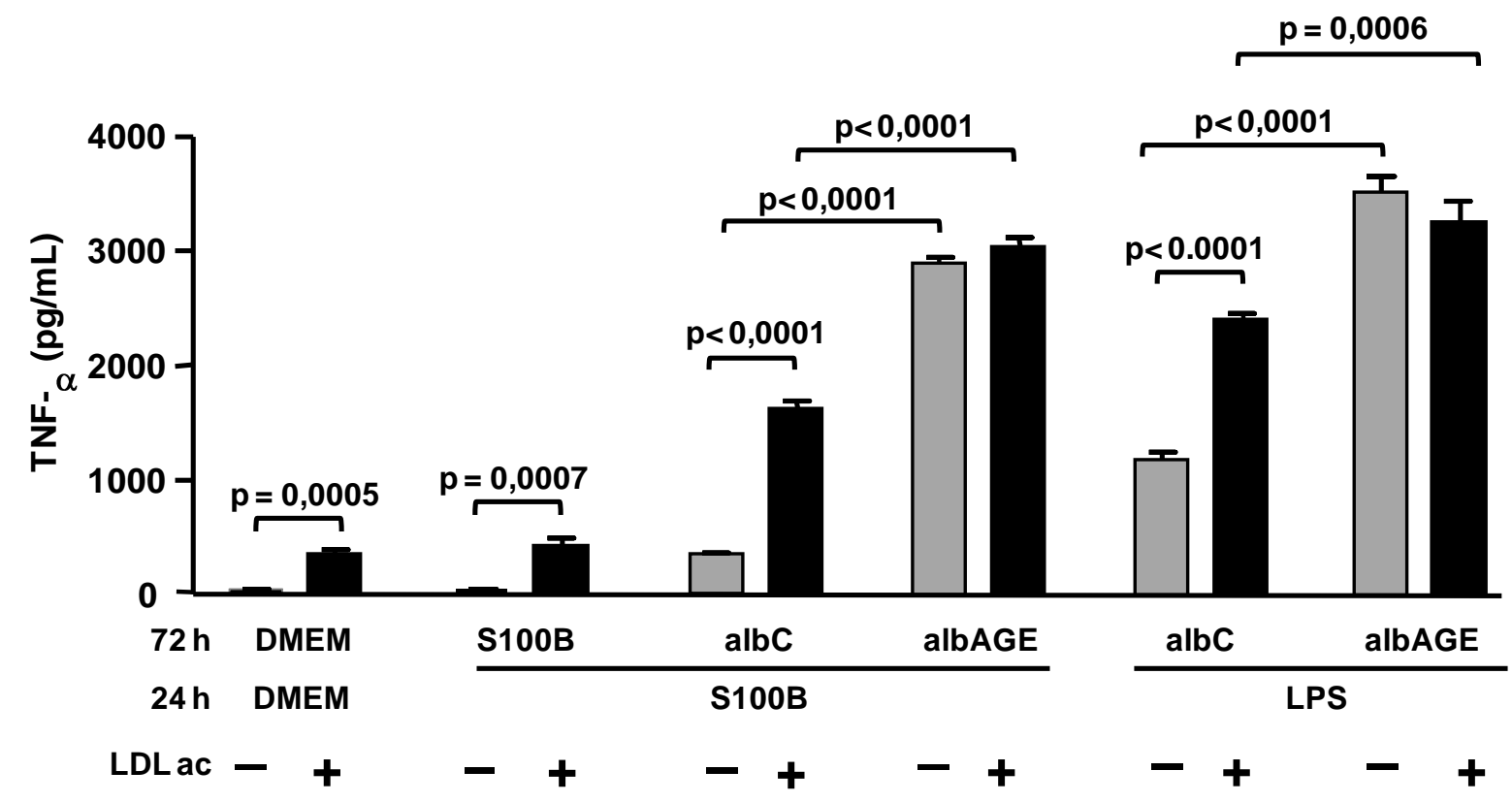


C

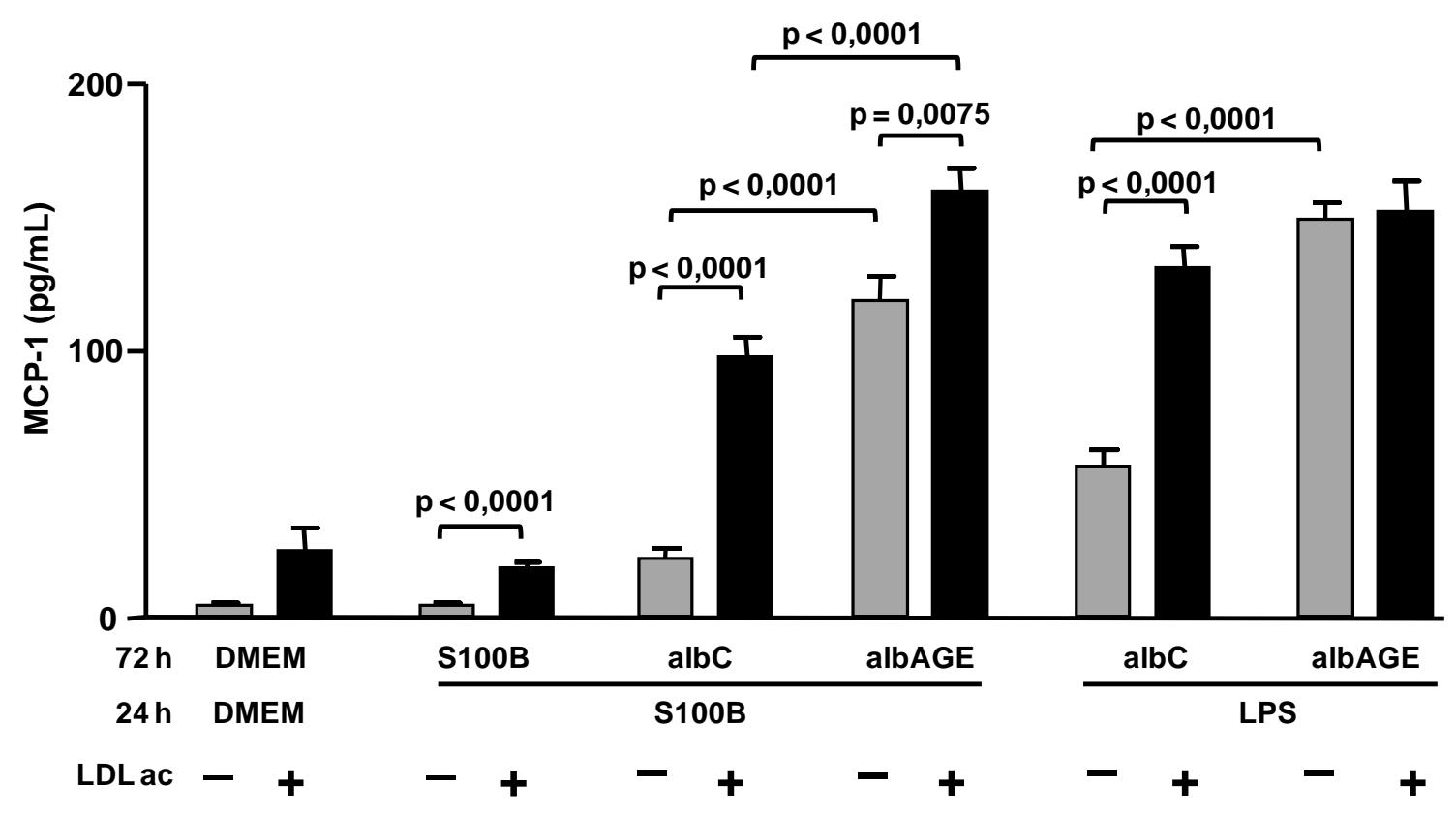

Figura 7. Sobrecarga de colesterol potencializa a resposta inflamatória induzida pela calgranulina $\mathrm{S100B}$, mas não por LPS, em macrófagos sensibilizados por albumina-AGE.

Macrófagos de peritônio de camundongo foram pré-incubados, por $72 \mathrm{~h}$, na presença de LDL acetilada $(50 \mu \mathrm{g} / \mathrm{mL})$ e albumina-C (albC; $2 \mathrm{mg} / \mathrm{mL}$ ) ou LDL-acetilada e albumina-AGE (albAGE; $2 \mathrm{mg} / \mathrm{mL}$ ). Após lavagem, as células foram incubadas, por 24 h, com S100B (20 $\mu \mathrm{g} / \mathrm{mL}$ ) ou LPS ( $1 \mu \mathrm{g} / \mathrm{mL})$. Incubações controles foram feitas apenas na presença de meio de cultura (DMEM) ou S100B. A concentração de IL-6 (painel A), TNF- $\alpha$ (painel B) e MCP-1 (painel C) foi determinada no meio de cultura por ELISA $(n=9)$. As comparações foram feitas pelo teste t de Student, não pareado. 
O meio isolado das diferentes incubações de macrófagos com sobrecarga de colesterol foi utilizado para o tratamento de macrófagos recém isolados do peritônio de camundongos. Avaliou-se, então, o efluxo de ${ }^{14} \mathrm{C}$-colesterol mediado por $\mathrm{HDL}_{2}, \mathrm{HDL}_{3}$, e apoA-I.

O meio condicionado isolado de macrófagos tratados com albuminaAGE e S100B levou à uma redução de respectivamente, $43 \%, 20 \%$, e $23 \%$ no efluxo de colesterol mediado por $\mathrm{HDL}_{2}$ (Figura 8), $\mathrm{HDL}_{3}$ (Figura 9) e apoA-I (Figura 10), quando comparado com o meio condicionado de macrófagos tratados com albumina-C e S100B. Isto se associou à maior concentração de citocinas no meio obtido dos tratamentos com albuminaAGE e S100B.

De forma semelhante, o efluxo de colesterol mediado por $\mathrm{HDL}_{2}$ (Figura 8), $\mathrm{HDL}_{3}$ (Figura 9) e apoA-I (Figura 10) nos macrófagos não estimulados tratados com meio condicionado, contendo citocinas induzidas pelo tratamento com albumina-AGE e LPS foi respecitvamente, 47\%, 8,5\% e 37\% menor quando comparado com os macrófagos tratados com meio condicionado do tratamento com albumina-C e LPS. A concentração de todas as citocinas, foi superior no meio condicionado com albumina-AGE e LPS em comparação ao meio condicinado com albumina-C e LPS. 


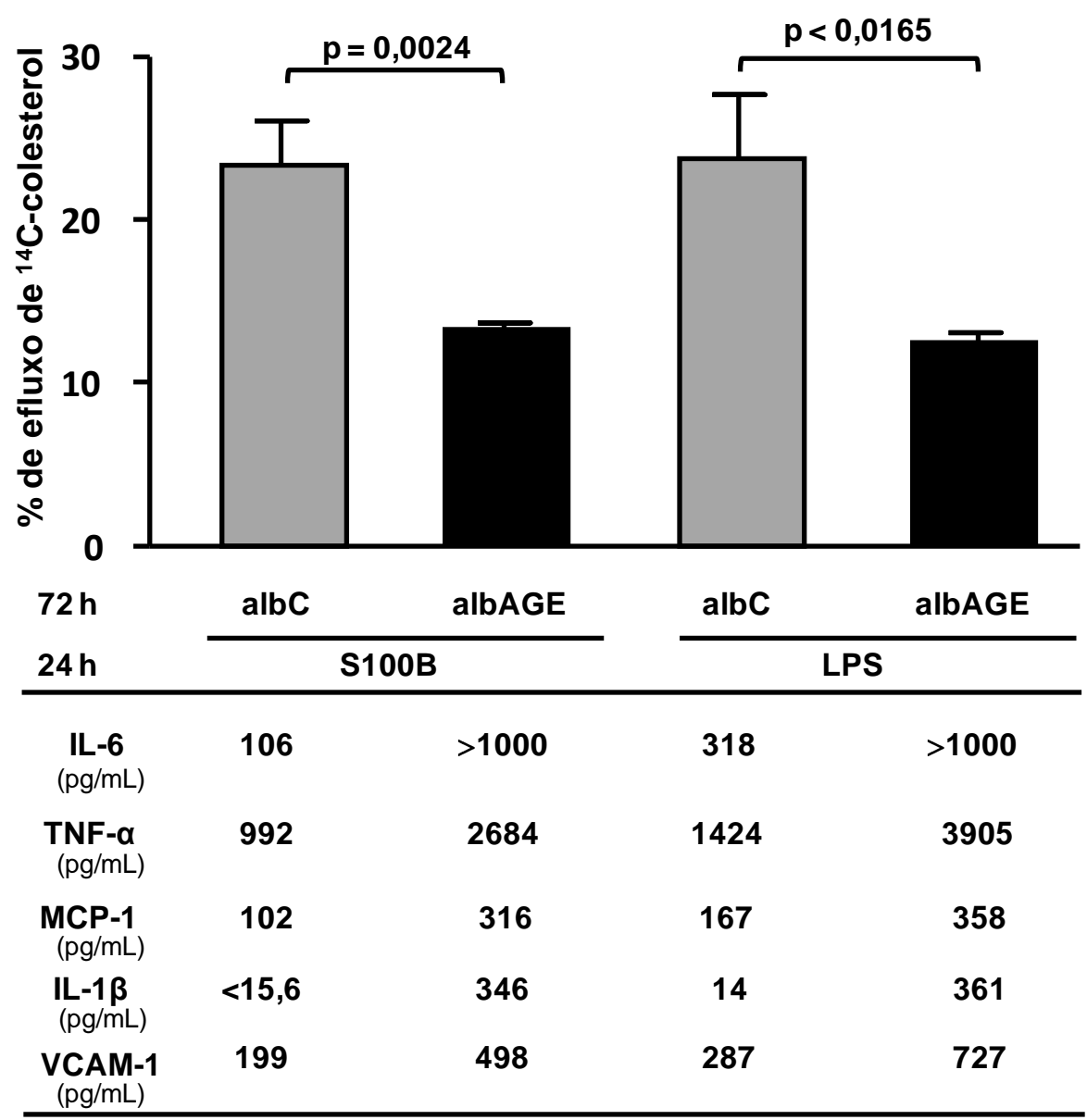

Figura 8. Meio condicionado rico em citocinas, isolado de macrófagos tratados com albumina-AGE e S100B ou albumina-AGE e LPS, reduz o efluxo de colesterol celular mediado por $\mathrm{HDL}_{2}$.

Macrófagos de peritônio de camundongo foram pré-incubados, por $72 \mathrm{~h}$ na presença de LDL acetilada e albumina-C (albC; $2 \mathrm{mg} / \mathrm{mL}$ ) ou LDL acetilada e albumina-AGE (albAGE; $2 \mathrm{mg} / \mathrm{mL}$ ) em garrafas de cultura de $75 \mathrm{~cm}^{2}$. Após lavagem, as células foram incubadas, por 24 h com S100B $(20 \mu \mathrm{g} / \mathrm{mL})$ ou LPS $(1 \mu \mathrm{g} / \mathrm{mL})$, . O meio condicionado contendo citocinas foi, então, utilizado para incubar, por $24 \mathrm{~h}$, macrófagos saudáveis, previamente enriquecidos com ${ }^{14} \mathrm{C}$-colesterol e LDL acetilada. $\mathrm{O}$ efluxo de ${ }^{14} \mathrm{C}$-colesterol foi determinado mediante incubação por $5 \mathrm{~h}$ com $\mathrm{HDL}_{2}(50 \mu \mathrm{g} / \mathrm{mL} ; \mathrm{n}=6)$. As comparações foram feitas pelo teste t de Student, não pareado. 


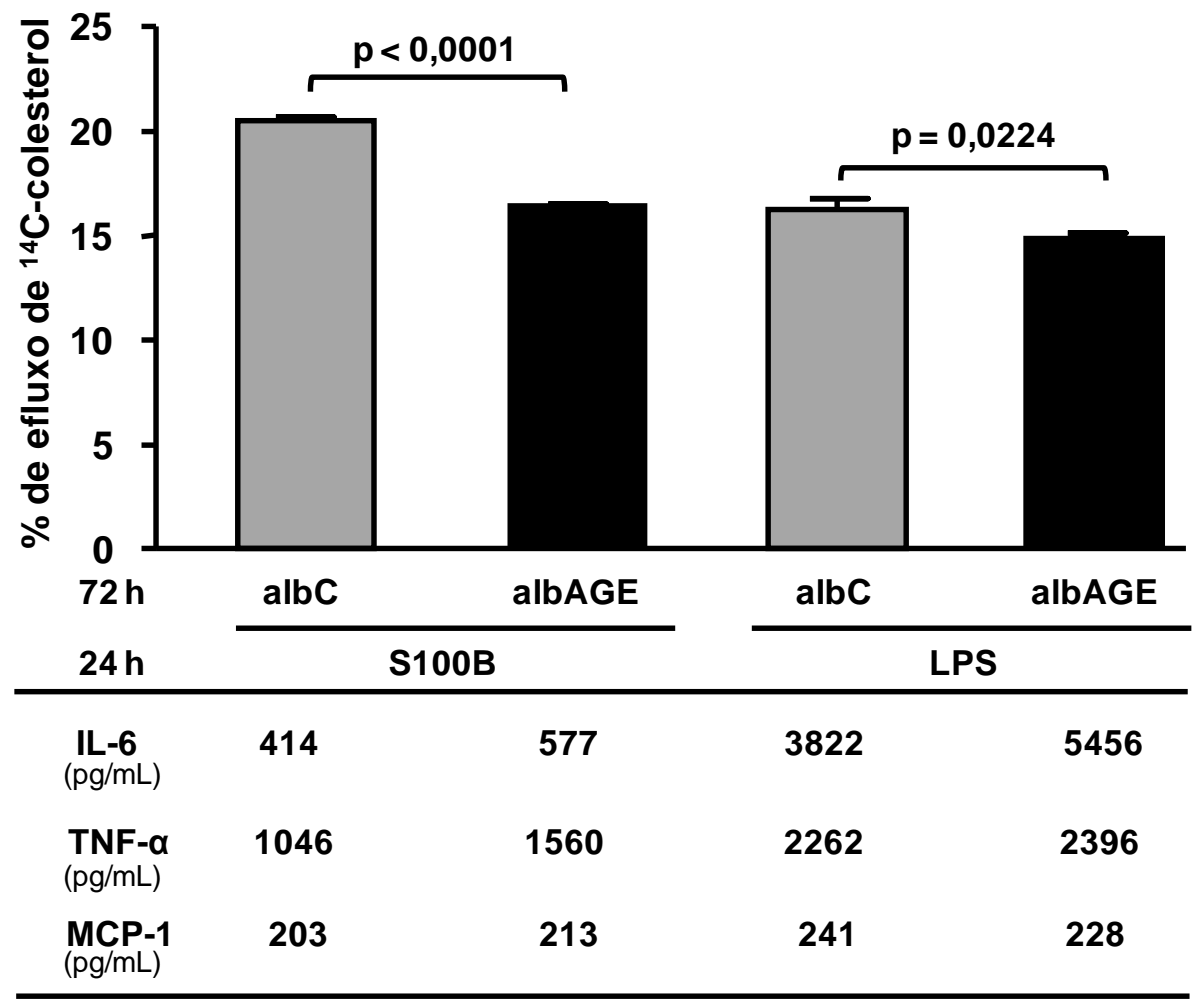

Figura 9. Meio condicionado rico em citocinas, isolado de macrófagos tratados com albumina-AGE e S100B ou albumina-AGE e LPS, reduz o efluxo de colesterol celular mediado por $\mathrm{HDL}_{3}$.

Macrófagos de peritônio de camundongo foram pré-incubados, por $72 \mathrm{~h}$ na presença de LDL acetilada e albumina-C (albC; $2 \mathrm{mg} / \mathrm{mL}$ ) ou LDL acetilada e albumina-AGE (albAGE; $2 \mathrm{mg} / \mathrm{mL}$ ) em garrafas de cultura de $75 \mathrm{~cm}^{2}$. Após lavagem, as células foram incubadas, por 24 h com S100B $(20 \mu \mathrm{g} / \mathrm{mL})$ ou LPS $(1 \mu \mathrm{g} / \mathrm{mL})$, . O meio condicionado contendo citocinas foi, então, utilizado para incubar, por $24 \mathrm{~h}$, macrófagos saudáveis, previamente enriquecidos com ${ }^{14} \mathrm{C}$-colesterol e LDL acetilada. O efluxo de ${ }^{14} \mathrm{C}$-colesterol foi determinado mediante incubação por $5 \mathrm{~h}$ com $\mathrm{HDL}_{3}(50 \mu \mathrm{g} / \mathrm{mL} ; \mathrm{n}=6)$ As comparações foram feitas pelo teste $\mathrm{t}$ de Student, não pareado. 


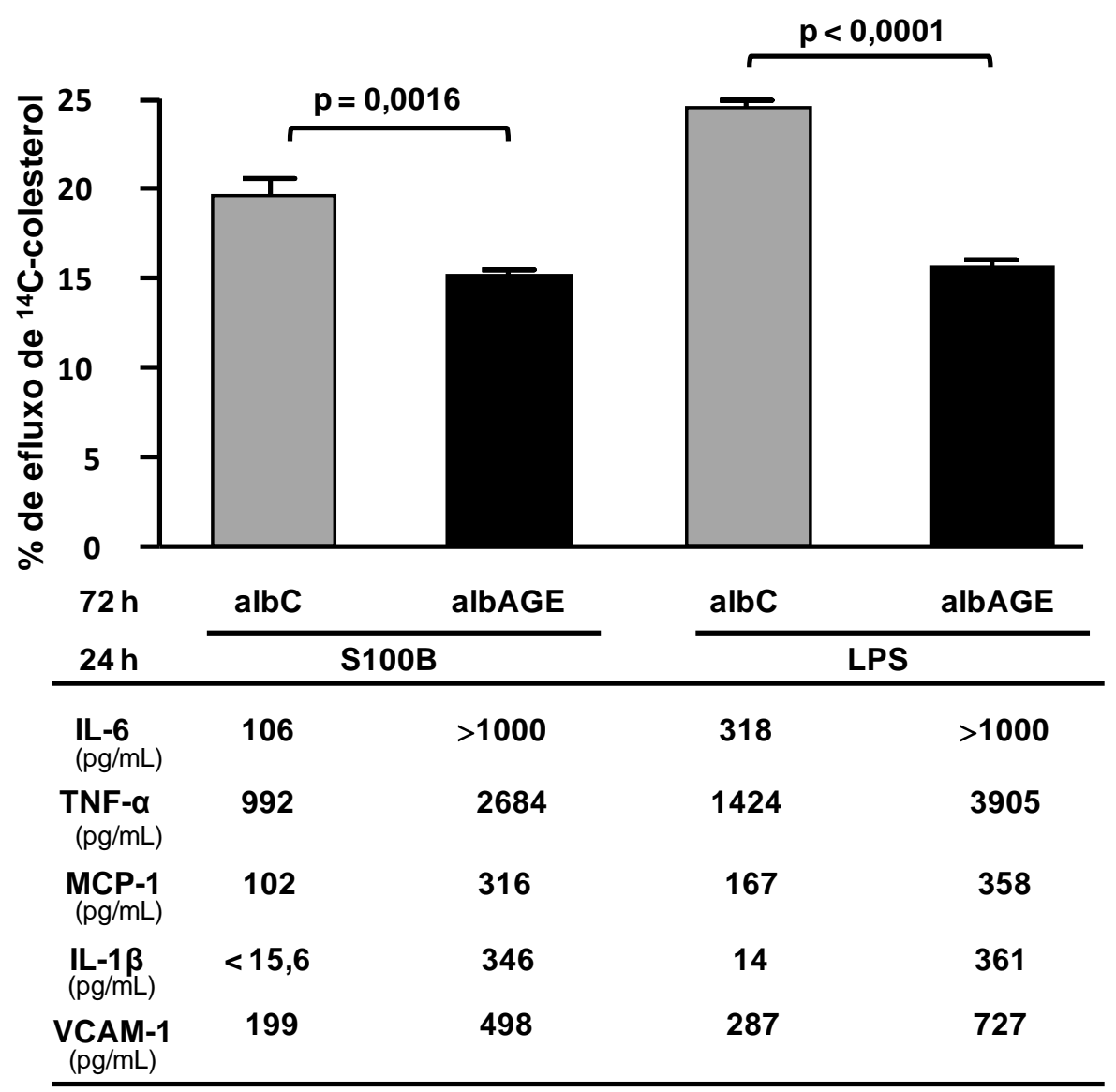

Figura 10. Meio condicionado rico em citocinas, isolado de macrófagos tratados com albumina-AGE e S100B ou albumina-AGE e LPS, reduz o efluxo de colesterol celular mediado por apoA-I.

Macrófagos de peritônio de camundongo foram pré-incubados, por $72 \mathrm{~h}$ na presença de LDL acetilada e albumina-C (albC; $2 \mathrm{mg} / \mathrm{mL}$ ) ou LDL acetilada e albumina-AGE (albAGE; $2 \mathrm{mg} / \mathrm{mL}$ ) em garrafas de cultura de $75 \mathrm{~cm}^{2}$. Após lavagem, as células foram incubadas, por 24 h com S100B $(20 \mu \mathrm{g} / \mathrm{mL})$ ou LPS $(1 \mu \mathrm{g} / \mathrm{mL})$, O meio condicionado contendo citocinas foi, então, utilizado para incubar, por $24 \mathrm{~h}$, macrófagos saudáveis, previamente enriquecidos com ${ }^{14} \mathrm{C}$-colesterol e LDL acetilada. $O$ efluxo de ${ }^{14} \mathrm{C}$-colesterol foi determinado mediante incubação por $8 \mathrm{~h}$ com apoA-I $(30 \mu \mathrm{g} / \mathrm{mL} ; \mathrm{n}=6)$. As comparações foram feitas pelo teste t de Student, não pareado. 
A fim de avaliar melhor a ligação entre insulto inflamatório e prejuízo no efluxo de lípides de macrófagos, protocolo muito similar ao anterior foi realizado, porém durante a incubação com albumina-C ou albumina-AGE, ou durante a incubação com LPS ou S100B, os macrófagos foram tratados

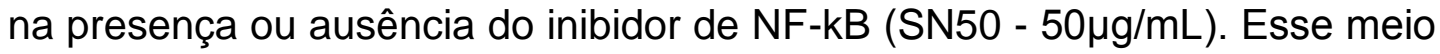
condicionado das diferentes condições experimentais foi, então utilizado para tratar macrófagos não estimulados e avaliar o efluxo de colesterol mediado por apoA-I.

Não foram encontradas diferenças no efluxo de colesterol em macrófagos tratados com meio condicionado advindo de incubações com albumina-C e S100B, na presença ou ausência do inibidor de NF-kB, SN-50 (Figura 11, painel A).

Como já era esperado, macrófagos tratados com meio condicionado advindo de incubações com albumina-AGE e S100B apresentaram uma redução significativa no efluxo de colesterol mediado por apoA-I quando comparado a albumina-C e S100B (Figura 11, painel A).

Nas células tratadas com albumina-AGE, a incubação simultânea do S100B com o inibidor de NF-kB recuperou o efluxo de colesterol, não sendo mais observada diferença entre macrófagos pré-tratados com albumina-AGE e albumina-C. Quando o inibidor foi incubado juntamente com albuminaAGE, não se observou melhora no efluxo de colesterol mediado por apoA-I (Figura 11, painel A).

No tratamento com LPS, observou-se pequeno aumento no efluxo de colesterol nos macrófagos tratados com meio condicionado advindo de 
incubação com albumina-C e LPS na presença do inibidor de NF-kB juntamente com o LPS, comparado a mesma incubação sem o inibidor de NF-kB (Figura 11, painel B).

De forma similar ao encontrado com S100B, macrófagos tratados com meio condicionado advindo de incubação com albumina-AGE e LPS apresentaram redução no efluxo de colesterol comparado ao tratamento com albumina-C e LPS, e assim como no caso anterior, o inbidor de NF-kB foi incapaz de corrigir o efluxo de colesterol mediado por apoA-I, quando incubado simultaneamente com albumina-AGE (Figura 11, painel B).

Neste caso, verificamos uma recuperação parcial do efluxo de colesterol mediado por apoA-I nos macrófagos tratados com meio condicionado advindo de incubações com albumina-AGE, apenas quando o inbidor de NFkB foi incubado juntamente com o LPS porém, mantendo a diferença entre o tratamento com albumina-C comparado com albumina-AGE (Figura 11, painel B). 
A

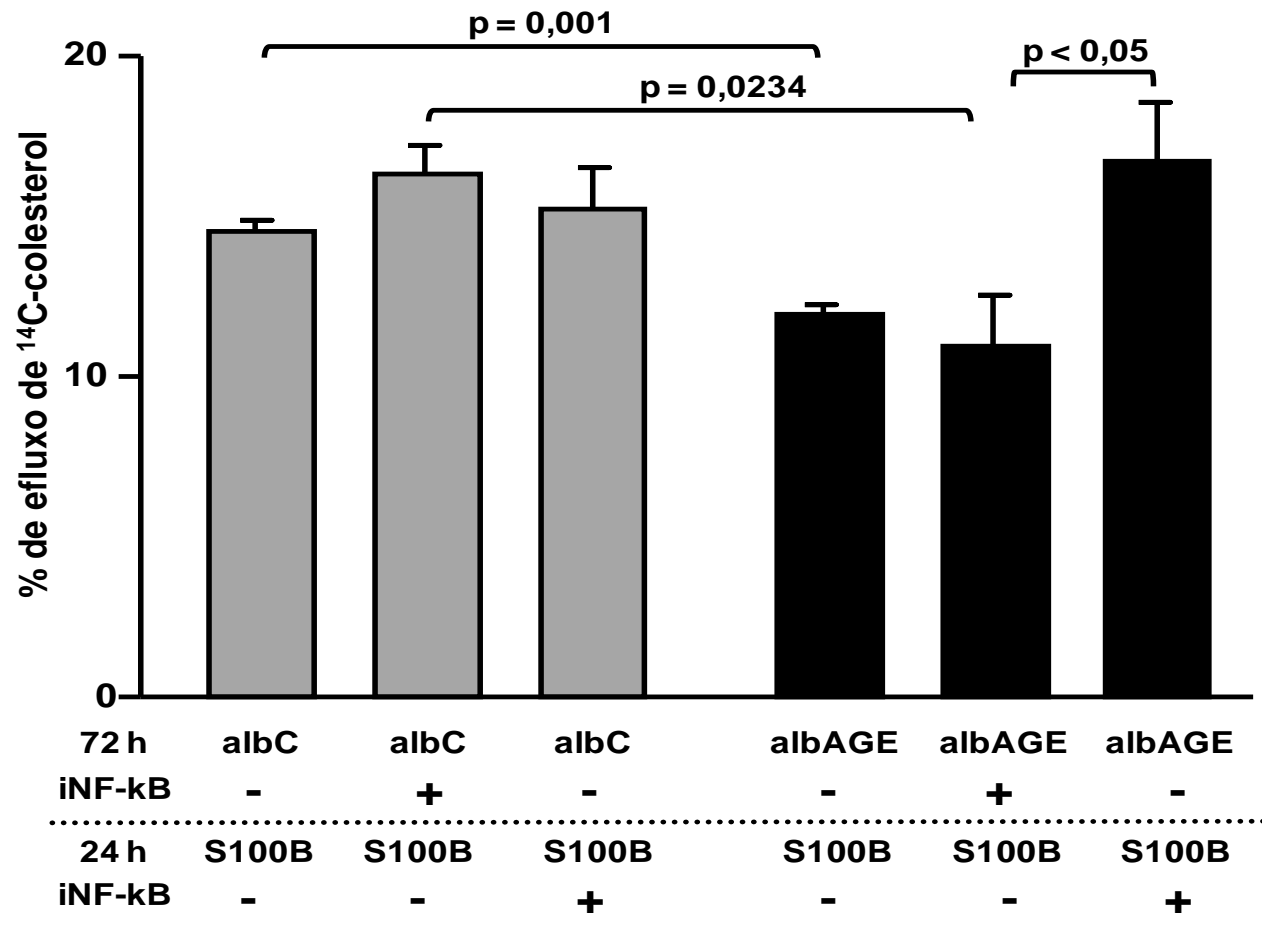


B

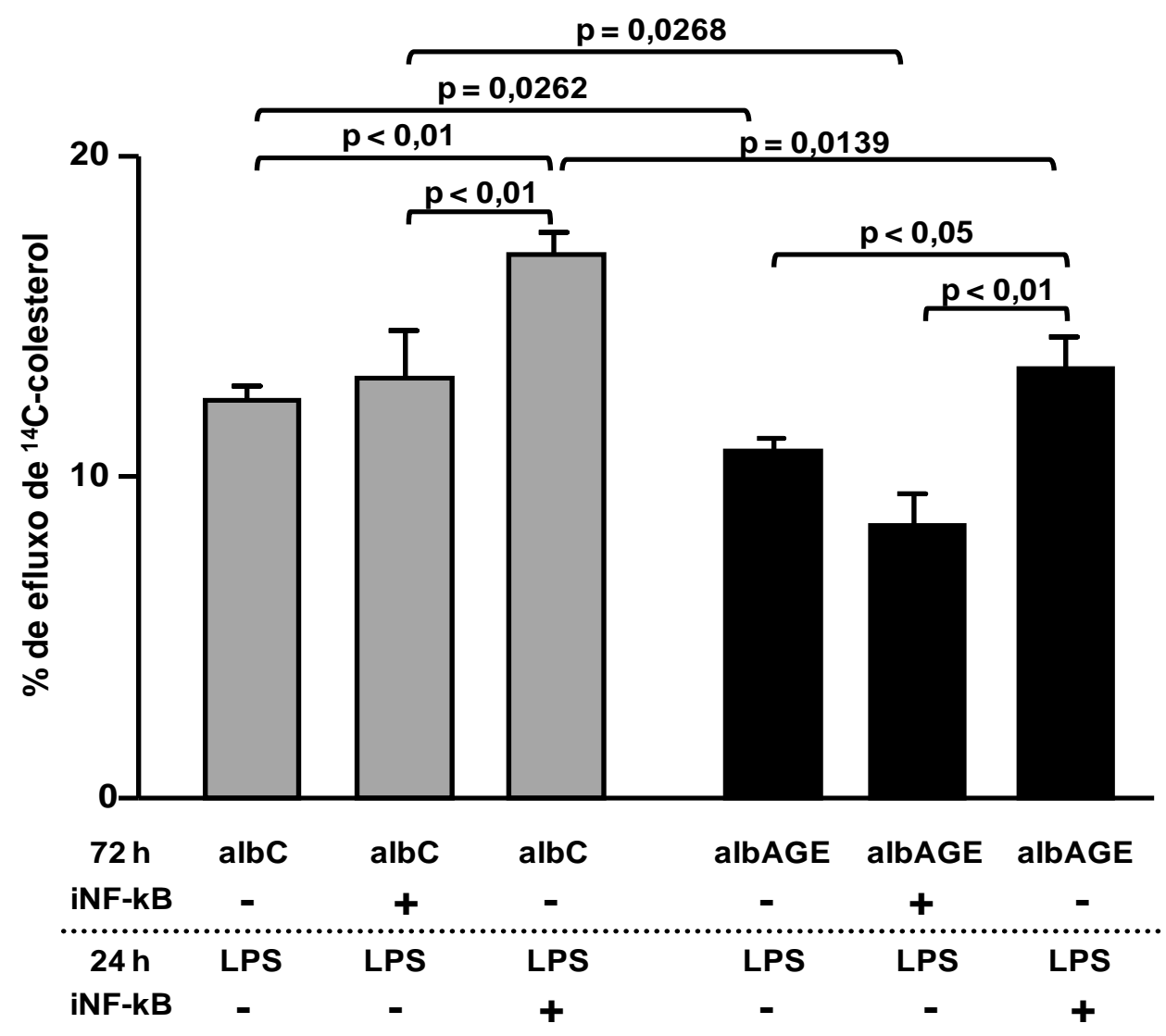

Figura 11. Meio condicionado, isolado de macrófagos tratados com albumina-AGE e S100B ou albumina-AGE e LPS, na presença de inibidor de NF-kB melhora o efluxo de colesterol celular mediado por apoA-I.

Macrófagos de peritônio de camundongo foram pré-incubados, por $72 \mathrm{~h}$ na presença de LDL acetilada e albumina-C (albC; $2 \mathrm{mg} / \mathrm{mL}$ ) ou LDL acetilada e albumina-AGE (albAGE; $2 \mathrm{mg} / \mathrm{mL}$ ), na presença ou ausência do inibidor de NF-kB (SN50- $50 \mu \mathrm{g} / \mathrm{mL}$ ). Após lavagem, as células foram incubadas, por $24 \mathrm{~h}$ com S100B $(20 \mu \mathrm{g} / \mathrm{mL})$ ou LPS (1 $\mu \mathrm{g} / \mathrm{mL}$ ), na presença ou ausência do inibidor de NF-kB (SN50- $50 \mu \mathrm{g} /$ $\mathrm{mL}$ ). O meio condicionado contendo citocinas foi, então, utilizado para incubar, por $24 \mathrm{~h}$, macrófagos não estimulados, previamente enriquecidos com ${ }^{14} \mathrm{C}$-colesterol e LDL acetilada. O efluxo de ${ }^{14} \mathrm{C}$ colesterol foi determinado mediante incubação por $8 \mathrm{~h}$ com apoA-I $(30 \mu \mathrm{g} / \mathrm{mL} ; \mathrm{n}=6)$. As comparações foram feitas pelo teste $\mathrm{t}$ de 
Student, não pareado e pela análise de variância (ANOVA) de um fator, com pós- teste de Newman Keuls.

Para determinação da capacidade anti-inflamatória da HDL, utilizaramse macrófagos sobrecarregados com colesterol (LDL acetilada) e expostos, por 72h, à albumina-C ou albumina-AGE na presença ou ausência de HDL. A seguir foram incubados, por mais $24 \mathrm{~h}$, com S100B ou LPS na presença ou ausência de HDL.

Nas células incubadas com S100B, o pré-tratamento com albumina-C e HDL reduziu a secreção de IL-6, TNF- $\alpha$, MCP-1 e VCAM-1, respectivamente, $72 \%, 57 \%, 50 \%$ e $41 \%$ quando comparado com macrófagos tratados apenas com albumina-C e S100B. Esta redução foi ainda maior nos macrófagos incubados, ao mesmo tempo, com S100B e HDL (Figura 12, painéis A,B,C,D e E).

Resultados semelhantes foram encontrados no tratamento com LPS. O pré-tratamento com albumina-C, na presença de HDL, levou à uma redução de $58 \%, 54 \%, 42 \%, 74 \%$ e $45 \%$, respectivamente, na secreção de IL-6, TNF- $\alpha$, MCP-1, IL-1 $\beta$ e VCAM-1 em comparação a incubações semelhantes porém sem a presença de HDL. Assim como no experimento anterior, a incubação simultânea da HDL com LPS levou à uma redução maior na secreção dos mediadores inflamatórios (Figura 13, painéis A,B,C,D e E).

No tratamento com albumina-AGE e S100B, a HDL foi incapaz de reduzir a secreção de TNF- $\alpha$, IL-1 $1 \beta$ e VCAM-1 porém aumentou a secreção de IL-6 e MCP-1, respectivamente, 54\% e 20\% quando incubada juntamente com a albumina-AGE. Redução na secreção de IL-6, TNF- $\alpha$, MCP-1, IL-1 $\beta$ e 
VCAM-1 foi observada apenas quando a HDL foi incubada simultaneamente com o S100B (Figura 12, painéis A, B, C, D e E).

Além disso, a HDL foi incapaz de reduzir a secreção de TNF- $\alpha$, MCP-1 e IL-1ß e aumentou a secreção de IL-6 (16\%) e VCAM-1 (20\%) em macrófagos pré-tratados com albumina-AGE e HDL, sendo encontrada redução na secreção desses mediadores inflamatórios, apenas, nos macrófagos incubados, ao mesmo tempo, com LPS e HDL (Figura 13, painéis $A, B, C, D$ e E). 
A

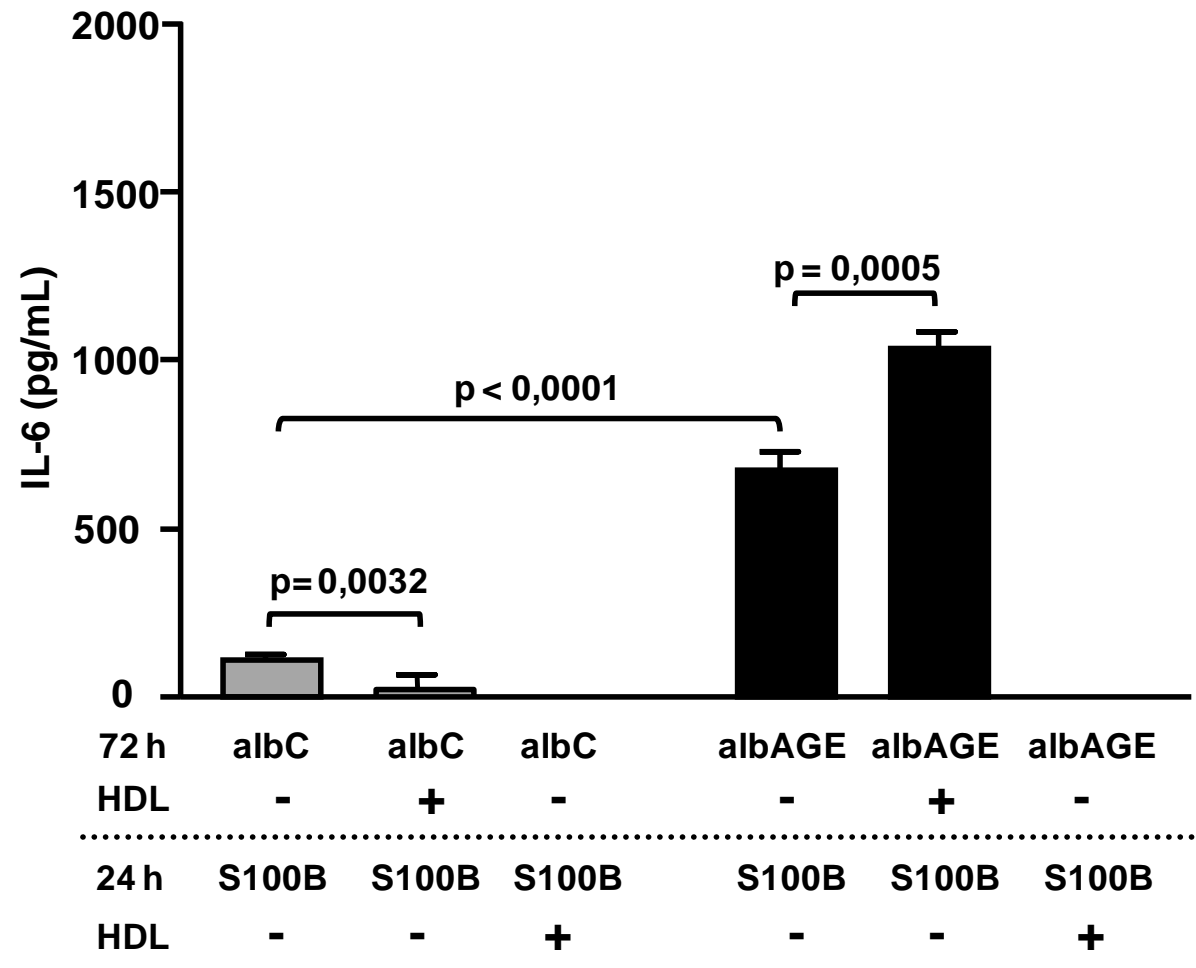

B

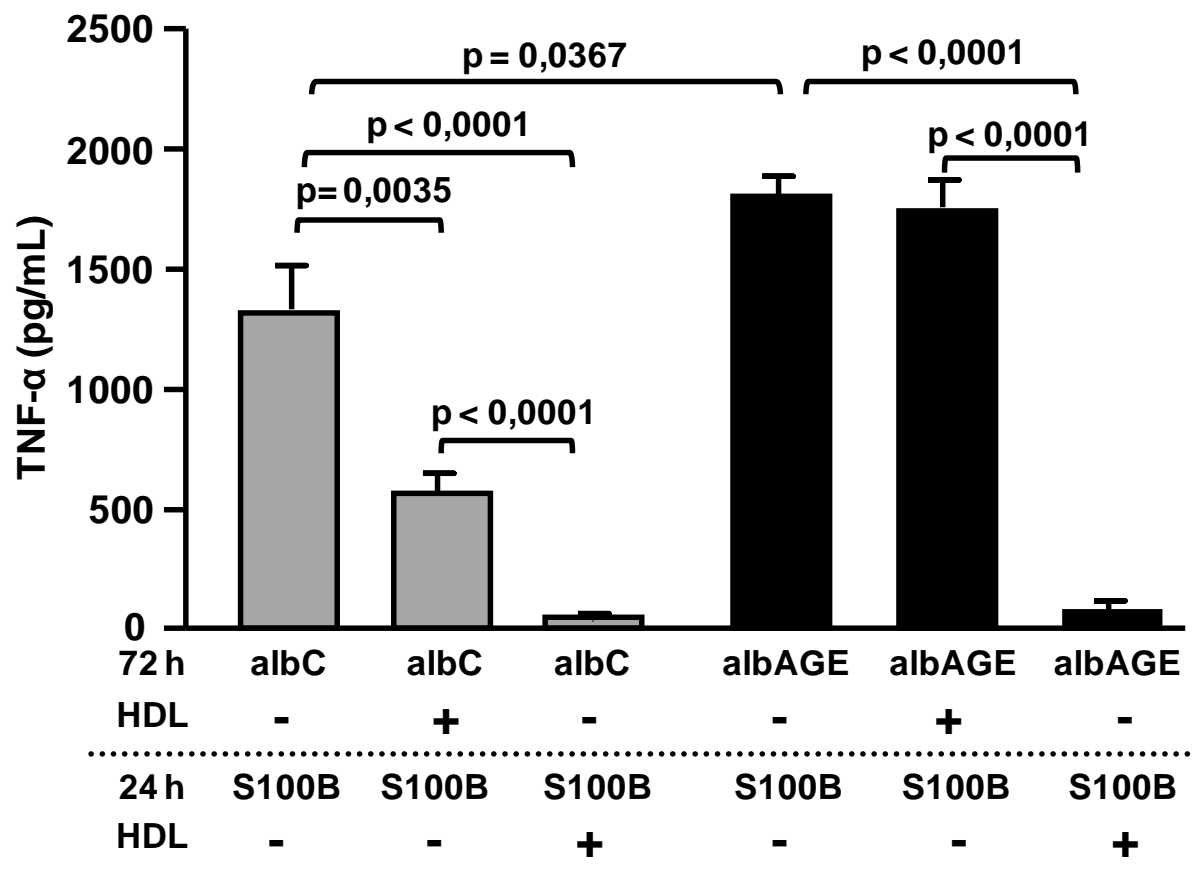


C

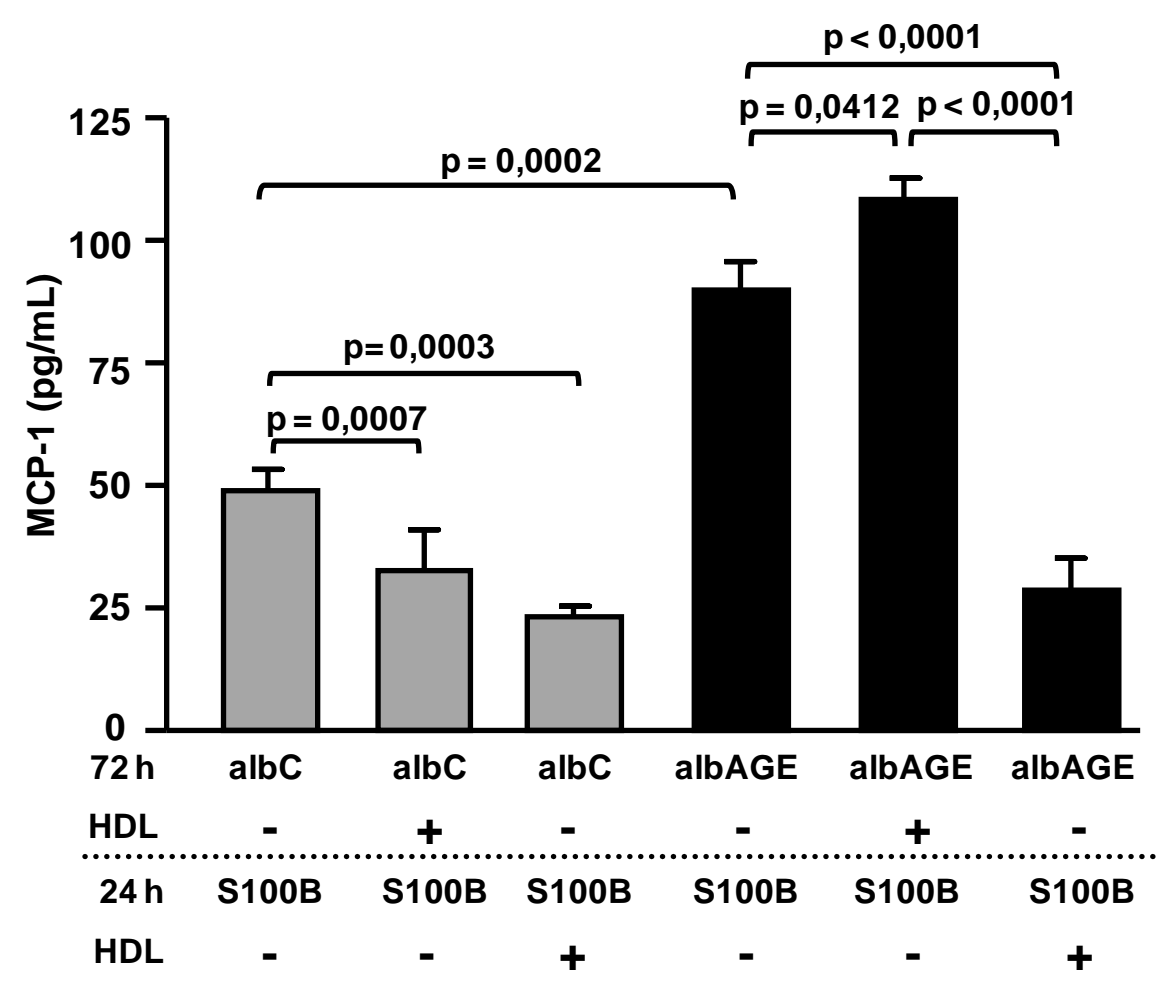

D

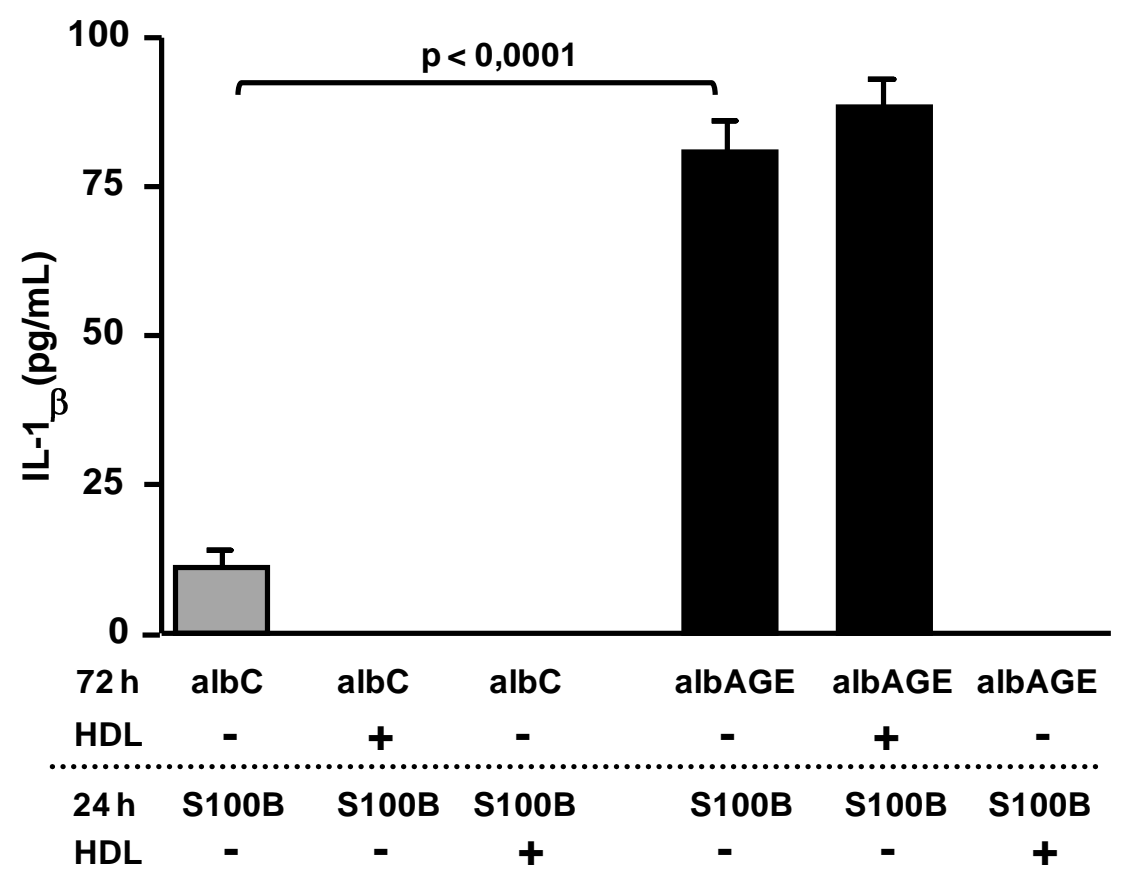


E

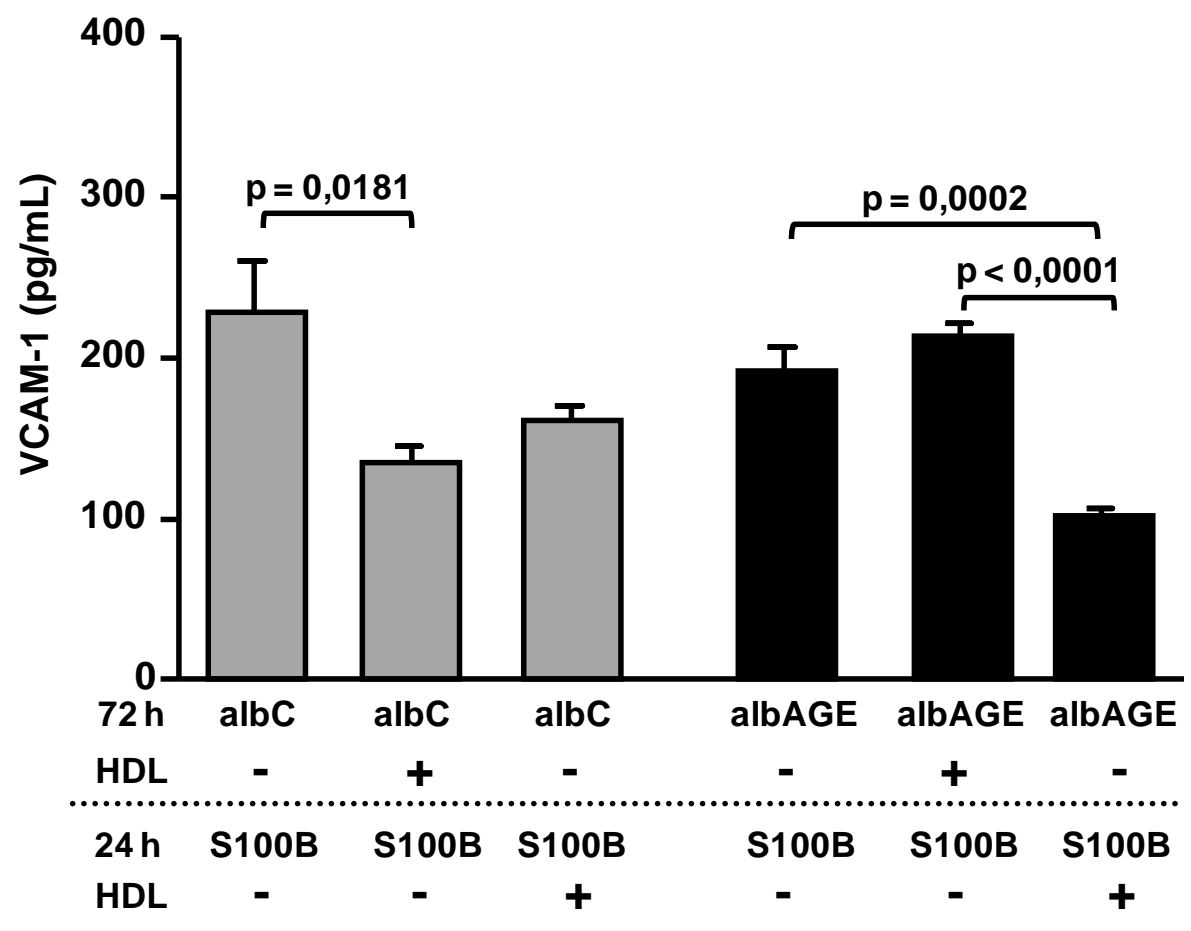

Figura 12. HDL é incapaz de reduzir, e até piora, a resposta inflamatória induzida pela $\mathrm{S100B}$ calgranulina em macrófagos sensiblilizados por albumina-AGE.

Macrófagos de peritônio de camundongo foram pré-incubados, por $72 \mathrm{~h}$ na presença de LDL acetilada e albumina- $\mathrm{C}$ (albC; $2 \mathrm{mg} / \mathrm{mL}$ ) ou LDL acetilada e albumina-AGE (albAGE; $2 \mathrm{mg} / \mathrm{mL}$ ), na presença ou ausência de HDL $(100 \mu \mathrm{g} / \mathrm{mL})$ em placas de cultura de 24 wells. Após lavagem, as células foram incubadas, por $24 \mathrm{~h}$ com S100B (20 $\mu \mathrm{g} / \mathrm{mL})$, na presença ou ausência de $\mathrm{HDL}(100 \mu \mathrm{g} / \mathrm{mL})$. A concentração de IL-6, TNF- $\alpha$, MCP-1, IL-1 $\beta$ e VCAM-1 foi determinada no meio de cultura por ELISA $(n=6)$. As comparações foram feitas pelo teste t de Student, não pareado. 
A

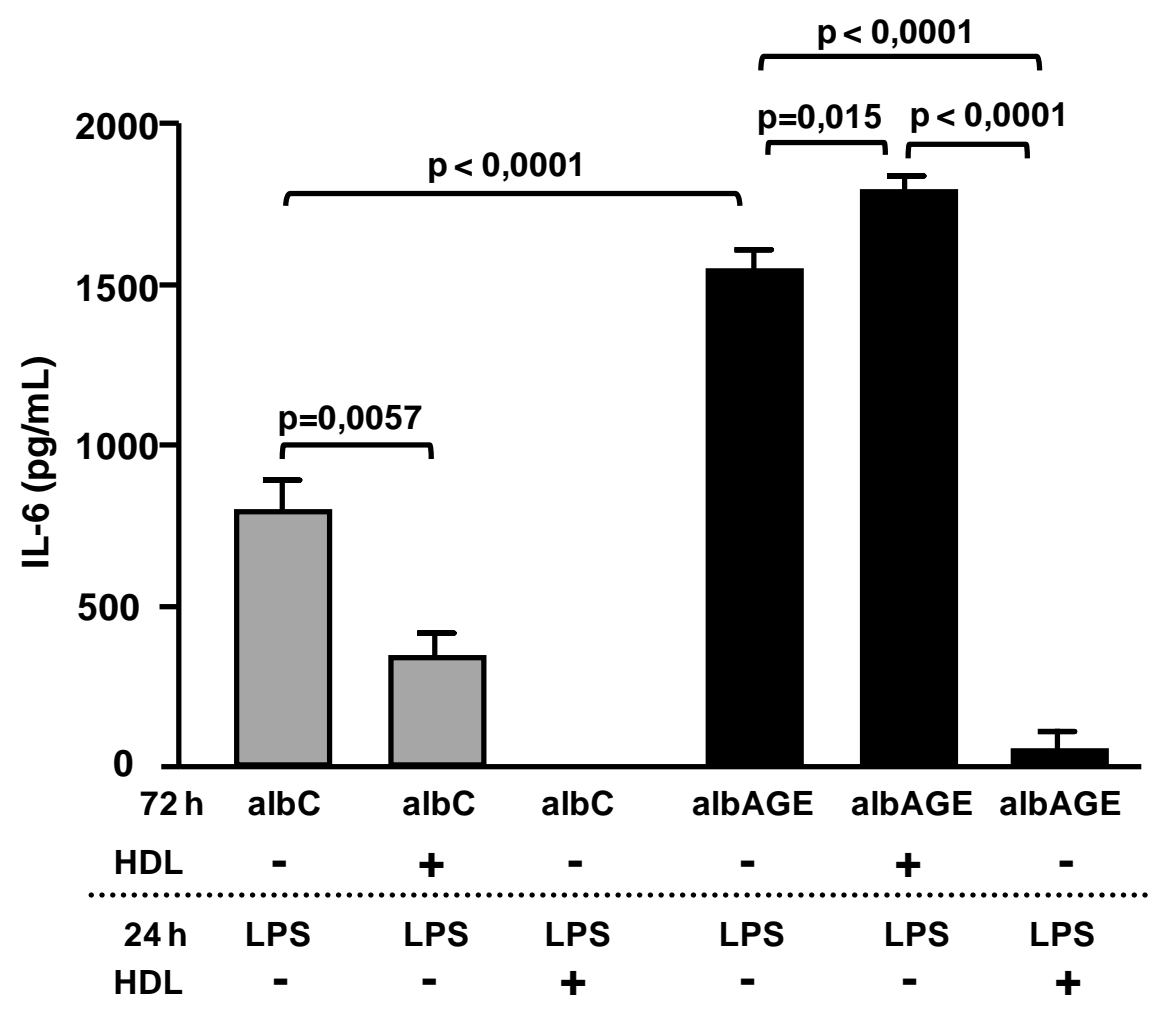

B

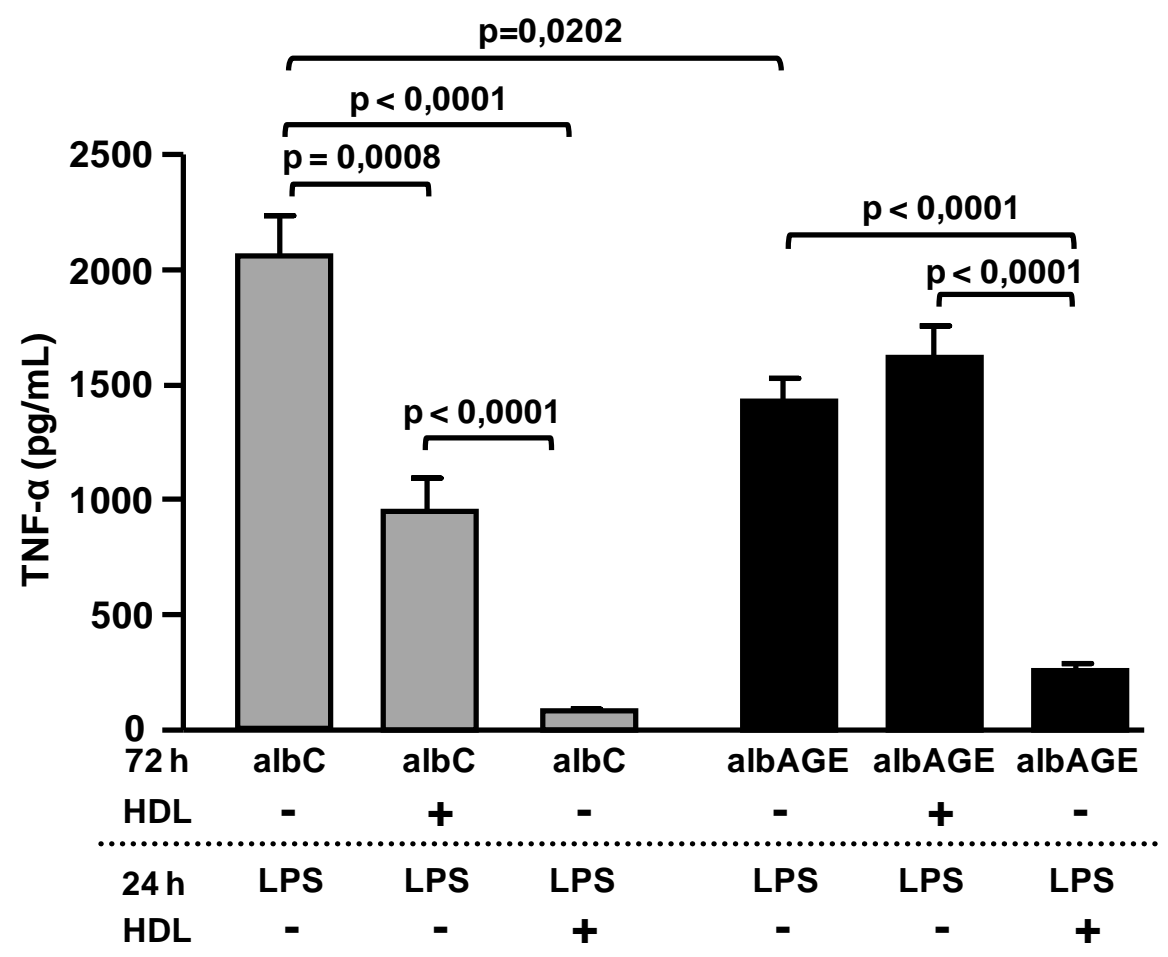


C

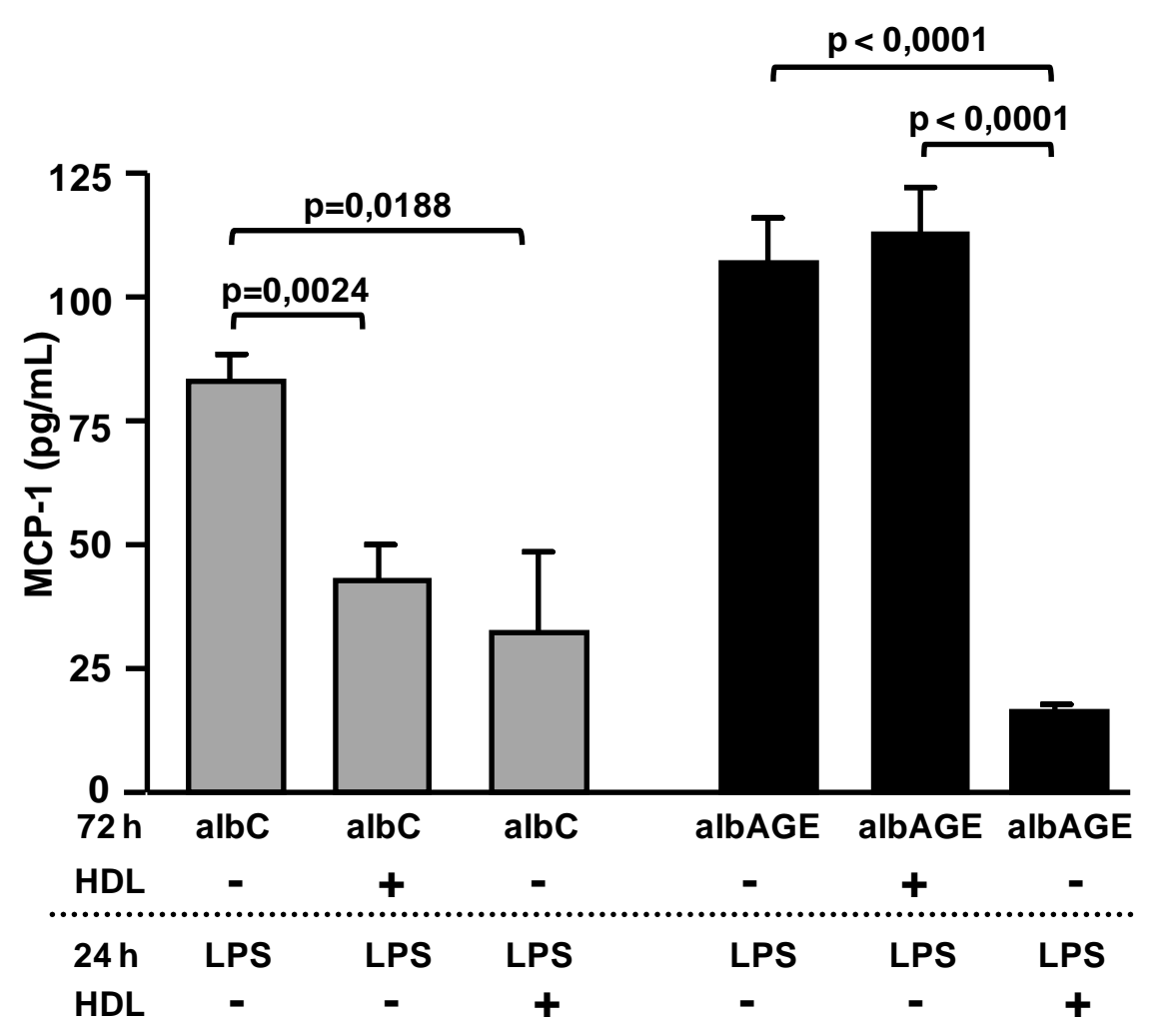

D

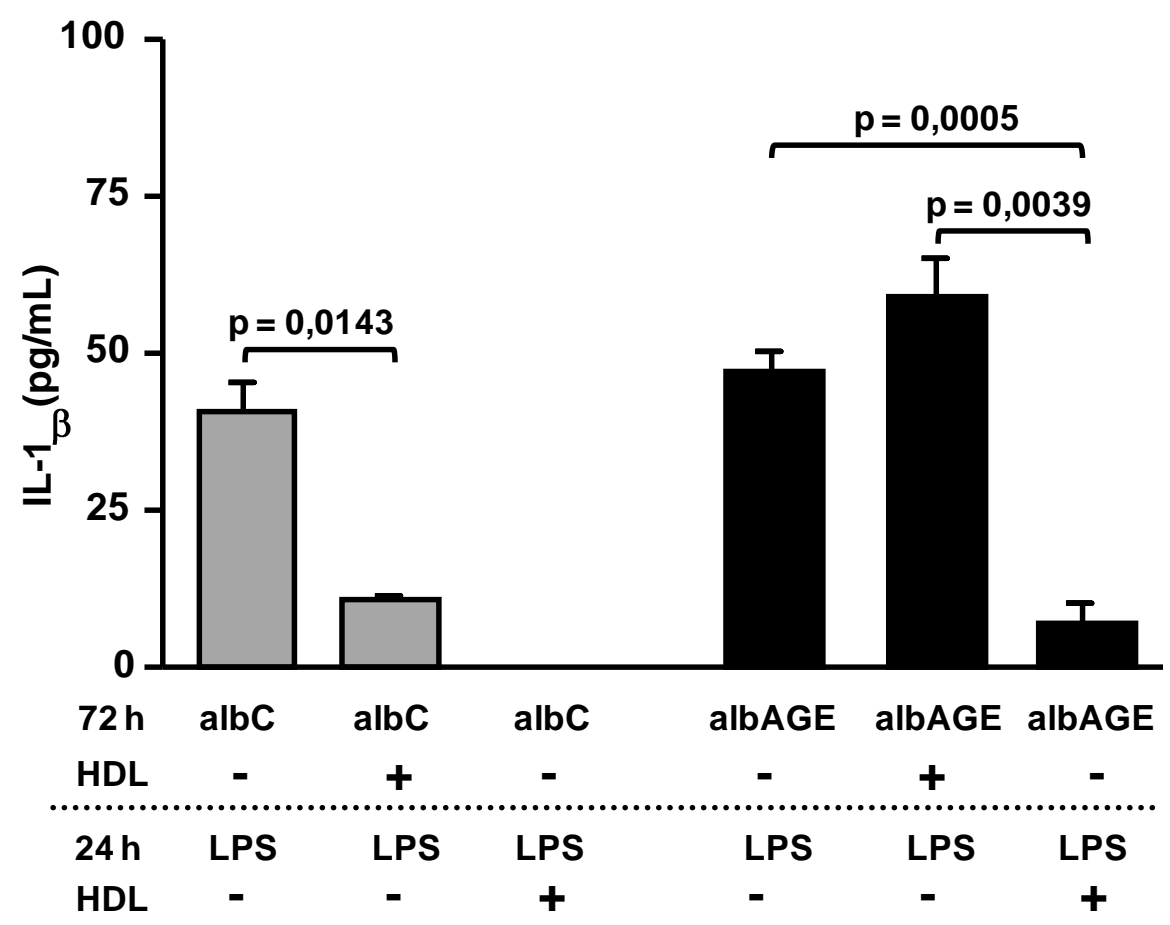




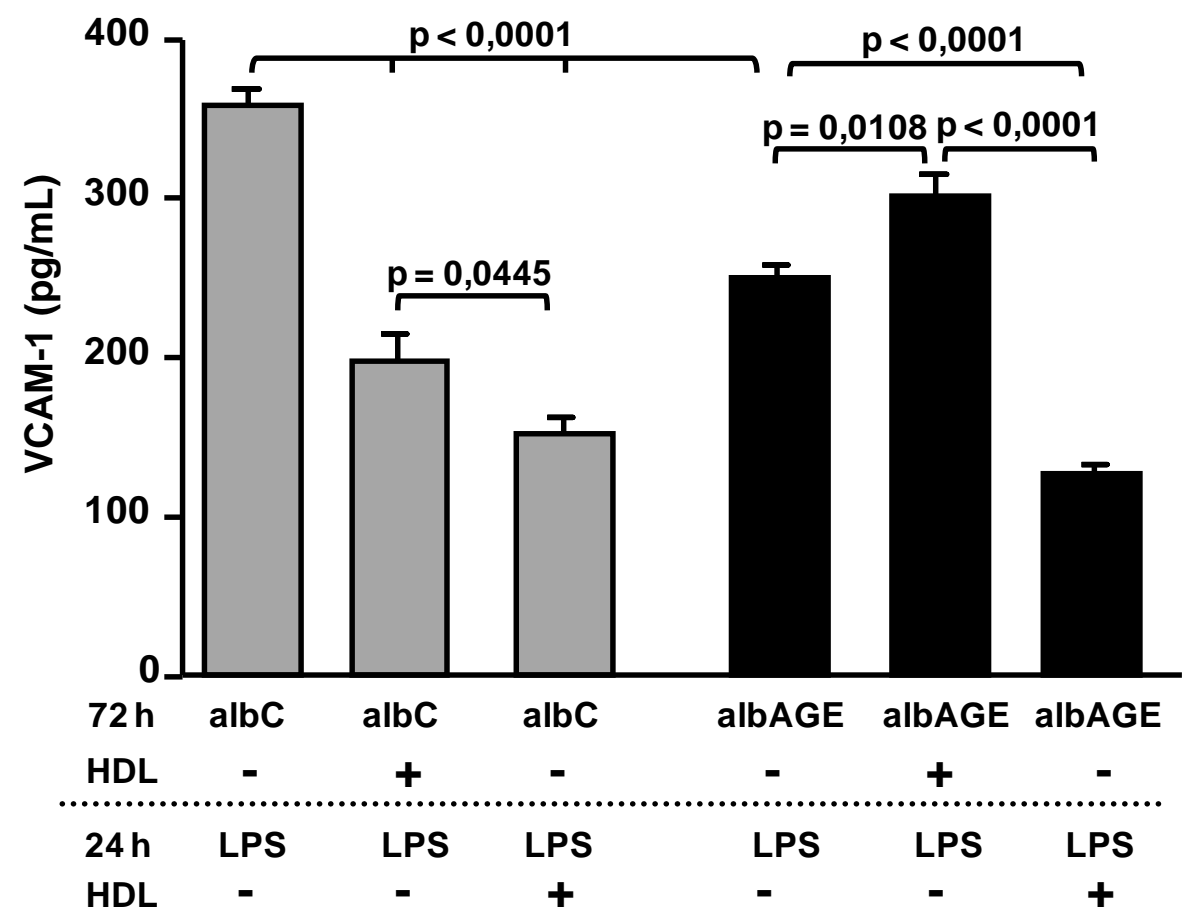

Figura 13. HDL é incapaz de reduzir, e até piora, a resposta inflamatória induzida pelo LPS em macrófagos sensibilizados por albumina-AGE.

Macrófagos de peritônio de camundongo foram pré-incubados, por $72 \mathrm{~h}$ na presença de LDL acetilada e albumina-C (albC; $2 \mathrm{mg} / \mathrm{mL}$ ) ou LDL acetilada e albumina-AGE (albAGE; $2 \mathrm{mg} / \mathrm{mL}$ ), na presença ou ausência de HDL $(100 \mu \mathrm{g} / \mathrm{mL})$ em placas de cultura de 24 wells. Após lavagem, as células foram incubadas, por $24 \mathrm{~h}$ com LPS $(1 \mu \mathrm{g} / \mathrm{mL})$, na presença ou ausência de $\mathrm{HDL}(100 \mu \mathrm{g} / \mathrm{mL})$. A concentração de IL6. TNF- $\alpha$, MCP-1, IL-1 $\beta$ e VCAM-1 foi determinada no meio de cultura por ELISA $(n=6)$. As comparações foram feitas pelo teste $t$ de Student, não pareado. 


\section{DISCUSSÃO}

Produtos de glicação avançada (AGE) reduzem a expressão dos receptores ABCA-1 e ABCG-1 e, desta forma, prejudicam o efluxo de colesterol celular (Isoda et al., 2007; Passarelli et al.,2005). Além disso, os AGE associam-se ao aumento do estresse inflamatório, o qual se apresenta intimamente relacionado à gênese e progressão da aterosclerose. Neste estudo, avaliamos se citocinas, quimiocinas e moléculas de adesão produzidas por macrófagos estimulados por albumina-AGE, na presença ou ausência de estímulos subsequentes (calgranulina S100B ou LPS), são capazes de modular a remoção de colesterol por subfrações de HDL e apo A-I em macrófagos não estimulados, além de avaliar o papel antiinflamatório da HDL em macrófagos expostos à albumina glicada.

A albumina-AGE, isoladamente, não afetou a secreção de citocinas por macrófagos, à semelhança dos resultados obtidos por Valencia et al (2004b) que também utilizaram albumina isenta em endotoxinas. Reznikov et al. (2004) demonstraram que, na ausência de endotoxinas, o AGE é incapaz de estimular a secreção de citocinas em células mononucleares do sangue periférico de doadores saudáveis. Entretanto, a associação de AGE com LPS aumentou a síntese e a liberação de citocinas pró-inflamatórias, em comparação com as células que sofreram ação do LPS isoladamente. De forma semelhante, Qin et al. (2009) evidenciaram que a atividade inflamatória da HMGB1 é determinada pelo conteúdo de endotoxinas. Porém, a associação entre HMGB1 e LPS, à semelhança do estudo anterior, 
aumentou a secreção de citocinas pró-inflamatórias em comparação à incubação isolada com LPS.

Embora, isoladamente, a albumina-AGE não aumente a produção de mediadores inflamatórios por macrófagos, demonstramos no presente estudo que ela foi capaz de sensibilizar estas células à posterior estimulação por S100B ou LPS, o que já havia sido demonstrado em células endoteliais do cordão umbilical tratadas com albumina-AGE e o dímero S100A8/S100A9, mas não com S100B (Ehlermann et al., 2006).

A sensibilização celular ao LPS pela albumina-AGE parece reforçar a interação entre o RAGE e os TLR, embora estes aspectos não tenham sido investigados no presente estudo.

Yamamoto et al. (2011) demonstraram que o LPS, sabidamente um ligante de TLR, também é capaz de interagir com o RAGE e induzir aumento do estresse inflamatório. Macrófagos de peritônio de camundongos $\mathrm{RAGE}^{+/+}$ secretaram maior quantidade de TNF- $\alpha$ após estímulo com LPS comparado a macrófagos de camundongos $\mathrm{RAGE}^{-/}$. Além disso, células $\mathrm{C} 6$ extraídas de glioma de ratos que expressavam RNA de silenciamento para RAGE, TLR2 e TLR4 ou a combinação dos três foram incubados com LPS para avaliar a ativação do NF-kB e nessas situações, a ativação do NF-kB foi inibida $37,2 \%, 17,6 \%, 41,1 \%$ e $57,1 \%$ respectivamente, sugerindo que, tanto RAGE, quanto o TLR4 contribuem de forma significante para a ativação do NF-kB neste tipo celular. Neste mesmo estudo, camundongos RAGE ${ }^{-/}$ sobreviveram por um período mais longo comparado com camundongos $\mathrm{RAGE}^{+/+}$após receberem injeção de LPS. Além disso, os camundongos 
RAGE $^{-/-}$apresentaram menor concentração de TNF-a, IL-6 e endotelina 1 (ET-1) no plasma, comparado com RAGE ${ }^{+/+}$(Yamamoto et al., 2011).

Convergência e amplificação de resposta inflamatória suscitada pela ativação de ambos os receptores é também demonstrada com a HMGB1 (van Beijnum et al., 2008; Qin et al.,2009). A administração de HMGB1 no peritônio de camundongos selvagens ou knockout para TLR-2, TLR-4 ou RAGE promoveu redução na concentração de citocinas pró-inflamatórias no lavado peritoneal apenas dos animais knockout para TLR-4 e RAGE, comparados com os selvagens. Ao contrário, aumento na concentração de citocinas inflamatórias foi observada nos animais knockout TLR-2, evidenciando que a HMGB1 induz a liberação de citocinas pró-inflamatórias, in vivo, por meio de mecanismos que dependem, pelo menos em parte, da ativação do TLR-4 e RAGE (van Zoelen et al., 2009).

O tratamento de macrófagos com HMGB1 e LPS levou ao aumento da expressão de RAGE, TLR-4 e TLR-2, ativação do NF-kB e fosforilação da p38MAPK, com aumento da secreção de IL-6 e TNF-a. Inibição da resposta inflamatória foi obtida apenas mediante incubação com anticorpo anti-TLR-4 e anti-RAGE, mas não com anti-TLR-2 (Qin et al., 2009). O mesmo é observado com LDL modificadas por glicação avançada, as quais interagem com o RAGE, TLR-4 e CD36, induzindo a secreção de citocinas próinflamatórias (Hodgkinson et al., 2008).

Neste sentido, mais recentemente, Sakaguchi et al., (2011) demonstraram que, após interação com seus ligantes, o domínio

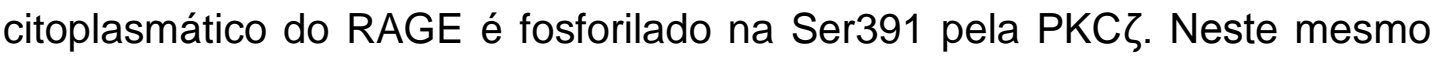


estudo, verificou-se que TIRAP e MyD88, conhecidos como proteínas adaptadoras de TLR2 e 4, também ligam-se ao RAGE fosforilado induzindo uma transdução de sinais que culmina na ativação do NF-kB e secreção de mediadores inflamatórios. Desta forma, a interação funcional de RAGE e TLR parece ter um papel importante na regulação da resposta inflamatória.

O meio condicionado, isolado de macrófagos sobrecarregados com colesterol e tratados com albumina-AGE e S100B ou albumina-AGE e LPS mostrou-se mais enriquecido em citocinas, prejudicando, de fato, o efluxo de colesterol mediado por apo A-I, $\mathrm{HDL}_{3}$ e $\mathrm{HDL}_{2}$ em macrófagos não estimulados. Os achados evidenciam que a albumina-AGE aumenta o potencial inflamatório de macrófagos frente à estimulação com S100B, sendo este efeito potencializado pelo excesso de colesterol celular e capaz de modular negativamente o efluxo de colesterol em macrófagos não estimulados.

Em macrófagos tratados com albumina-AGE e LPS, a sobrecarga de colesterol não incrementou a secreção de citocinas, o que pode estar relacionado ao fato do LPS, por si, ser um potente estimulador inflamatório. Não obstante, a albumina-AGE potencializou a resposta inflamatória dos macrófagos ao LPS, promovendo redução do efluxo de colesterol.

A concentração de citocinas no meio condicionado foi bastante inferior àquela utilizada na literatura em incubações diretas com macrófagos (Chen et al 2007; Wang et al., 2005; Khovidhunkit et al., 2004; Wang et al., 2002). Além disso, parece melhor refletir o estado inflamatório de macrófagos 
estimulados por AGE e seu efeito parácrino na modulação do fluxo de lípides.

Sabe-se que a combinação entre o acúmulo de colesterol intracelular e o estresse inflamatório contribui para o desenvolvimento da atersoclerose. Yehuda et al. (2011) demonstraram que o colesterol e a fração rica em oxisteróis presentes no extrato lipídico obtido da lesão aterosclerótica da carótida pode induzir a expressão de mediadores inflamatórios em macrófagos. Neste sentido, dados recentes do nosso grupo demonstraram que o tratamento de macrófagos com albumina-AGE leva ao acúmulo intracelular de 7-cetocolesterol, o qual tem sido relacionado com toxicidade e morte celular por induzir inflamação e estresse do retículo endoplasmatico (Iborra et al., 2011).

De fato, o enriquecimento celular em colesterol favorece seu tráfego ao retículo endoplasmático, com respostas adaptativas a proteínas não enoveladas que podem culminar no aumento da expressão de citocinas, bem como apoptose (Li et al.,2005).

Recentemente, Castilho et al. (2012) demonstraram que a albuminaAGE aumenta a expressão de chaperonas marcadoras do estresse do retículo endoplasmático e de proteínas efetoras da via de resposta a proteínas mal enoveladas em macrófagos. Interessante que o tratamento com a chaperona química PBA (4-ácido fenil butírico), que previne o estresse do retículo endoplasmático, foi capaz de restaurar a expressão de ABCA-1 em macrófagos expostos à albAGE e o efluxo de colesterol, mediado por ApoA-I (Castilho et al., 2012). 
Menor remoção de colesterol celular por subfrações de HDL e apo A-I, condicionada ao conteúdo reduzido de ABCA-1 e alteração na expressão diferencial de genes envolvidos no metabolismo lipídico foi observada em macrófagos expostos à albumina purificada do plasma de portadores de diabete melito tipo 1 e 2 com controle glicêmico inadequado (Lima, 2010). Tais resultados demonstram que a albumina glicada, in vivo, é capaz de alterar o fluxo de lípides celulares e inteferir no transporte reverso de colesterol, independentemente da concentração de HDL-colesterol e funcionalidade da partícula de HDL. Além disso, as alterações observadas em macrófagos tratados com albumina isolada de diabéticos foram semelhantes àquelas encontradas mediante incubação com albumina-AGE, produzida in vitro pela incubação com glicolaldeído. Isto valida a utilização de albumina-AGE, obtida pelo tratamento com oxoaldeídos, no estudo da fisiopatologia das complicações cardiovasculares do diabete melito.

Para melhor avaliar o prejuizo encontrado no efluxo de colesterol em macrófagos não estimulados, incubados com meio condicionado advindo de tratamento com albumina-AGE (rico em citocinas), utilizou-se, nas diferentes condições experimentais, o inibidor de NF-kB (SN50).

Tratamento com SN50 recuperou o efluxo de colesterol mediado pela apoA-I em macrófagos tratados com meio condicionado advindo de incubação com albumina-AGE e S100B comparado a sua situação controle, e melhorou significativamente o efluxo no tratamento com albumina-AGE e LPS comparado a albumina-C e LPS. 
Por outro lado, não verificamos melhora no efluxo de colesterol mediado por apoA-I quando o inibidor foi incubado juntamente com a albumina-AGE, o que está de acordo com nosso dados anteriores, já que a albumina-AGE, por si, não foi capaz de induzir a secreção de mediores inflamatórios mas sim, sensibilizou os macrófagos à posterior estimulo inflamatório por S100B ou LPS.

Em conjunto, tais resultados fortalecem nossos dados anteriores que demonstram prejuízo no efluxo de colesterol em macrófagos não estimulados tratados com meio condicionado contendo mediadores inflamatórios. Porém os mecanismos pelos quais a albumina-AGE prejudica, de forma parácrina o efluxo de colesterol em macrófagos não estimulados não foi abordado neste estudo e precisa ser melhor detalhado futuramente.

Neste estudo, verificou-se que macrófagos pré-tratados com albuminaC na presença de HDL apresentaram menor secreção de TNF-a, IL-6, MCP1, IL-1 $\beta$ e VCAM-1 quando comparados com sua situação controle sem a presença de HDL, tanto nos macrófagos que foram posteriormente estimulados com S100B quanto com LPS. Tais resultados sugerem que a HDL é capaz de prevenir o insulto inflamtório, embora os mecanismos celulares envolvidos não estejam ainda elucidados.

Estudo realizado por Van Linthout et al. (2011) demonstraram redução na expressão do TLR4, do mRNA da MyD88 e atividade do NF-kB em células humanas endoteliais pré-incubadas, por 24h, com HDL ou apoA-I e posteriormente expostas ao LPS. 
Li et al. (2008) demonstraram que camundongos que superexpressam apoA-I, apresentam diminuição no dano agudo no pulmão e rim, além de diminuição da concentração de TNF- $\alpha$, IL-6 e IL-1ß no plasma após injeção de LPS (Li et al., 2008).

Di Bartolo et al. (2011a), infundiram HDL reconstituída (rHDL) e peptidio mimético de apoA-I (ETC-642) após inserção colar não-oclusivo na carótida de coelhos e verificaram redução dose-dependente na expressão de moléculas de adesão, ICAM-1 e VCAM-1 na artéria destes animais comparado aos coelhos que receberam infusão de salina. Neste mesmo estudo, células endoteliais da carótida humana (HCAECS) pré-tratadas com rHDL ou ETC-642 e, posteriormente estimuladas com TNF- $\alpha$, apresentaram redução da adesão de monócitos, e do mRNA de VCAM-1, MCP-1 e p65. A infusão de rHDL ou ETC-642 também foi capaz de reduzir a expressão de ICAM-1 e VCAM-1 na aorta de coelhos que receberam dieta suplementada com colesterol por 6 semanas (Di Bartolo et al., 2011b). Em conjuntos tais estudos evidenciam o papel protetor da HDL frente ao estresse inflamatório.

Interessantemente, a HDL foi incapaz de reduzir a secreção e até piorou o estresse inflamatório quando incubado juntamente com albumina-AGE. Esses resultados evidenciam que a albumina-AGE altera a funcionalidade da HDL, inibindo e piorando sua função anti-inflamatória.

Nobécourt et al. (2010) infundiram, em coelhos, apoA-I isolada de indivíduos saudáveis, apoA-I isolada de indivíduos diabéticos (glicada in vivo) ou apoA-I glicada in vitro, $24 \mathrm{~h}$ antes de induzir inflamação vascular aguda, por meio da inserção de colar não oclusivo periarterial na carótida. 
Verificaram, nos animais que receberam infusão de apoA-I normal, diminuição de $89 \%$, 90\% e 66\% na infiltração de neutrófilos e expressão de VCAM-1 e ICAM-1, respectivamente, comparado aos animais que receberam salina. Já, os animais que receberam apoA-I glicada in vitro, apresentaram redução na infiltração de neutrófilos porém, sem alteração na expressão de VCAM-1 e ICAM-1; enquanto que a infusão de apoA-I glicada, in vivo, foi incapaz de reduzir, tanto a infiltração de neutrófilos, quanto a expressão das moléculas de adesão, evidenciando que a glicação não enzimática prejudica as propriedades anti-inflamatórias da apoA-I.

Em outro estudo realizado por Park et al. (2011), verificou-se severa senescência celular em fibroblastos dérmicos humanos e maior formação de células espumosas, além de maior influxo de colesterol em macrófagos tratados com HDL isolada de indivíduos idosos ou HDL reconstituída com apoA-I glicada in vitro comparado ao tratamento com HDL isolado de individuos jovens ou HDL reconstituída.

Redução na secreção de citocinas inflamatórias em macrófagos expostos à albumina-AGE foi obeservada apenas quando a HDL foi incubada juntamente com o S100B ou LPS. Porém, a diminuição na secreção de mediadores inflamatórios nessa situação pode estar relacionado à capacidade da HDL se ligar a porção lipídio A do LPS e, dessa forma, inibir seu efeito inflamatório (Brandenburg et al., 2002; Gupta et al.,2005). 


\section{CONCLUSÃo}

Os resultados deste estudo permitem concluir que a albumina modificada por glicação avançada aumenta o potencial inflamatório de macrófagos enriquecidos em colesterol, frente à estimulação com S100B ou LPS, o que prejudica o efluxo de colesterol em macrófagos não estimulados. Além disso, a exposição crônica à albumina-AGE prejudica as propriedades anti-inflamatórias da HDL. Neste contexto, o presente estudo ajuda a esclarecer o papel do estresse inflamatório induzido pela albumina-AGE no agravamento do desenvolvimento da aterosclerose no diabete mellitus. 


\section{REFERÊNCIAS}

Adorni MP, Zimetti F, Billheimer JT, Wang N, Rader DJ, Phillips MC, Rothblat $\mathrm{GH}$. The roles of different pathways in the release of cholesterol from macrophages. J Lipid Res. 2007; 48: 2453-62

Aneja RK, Tsung A, Sjodin H, Gefter JV, Delude RL, Billiar TR, Fink MP. Preconditioning with high mobility group box 1 (HMGB1) induces lipopolysaccharide (LPS) tolerance. J of Leukoc Biol. 2008; 84:1326-34.

Asztalos BF, Schaefer EJ, Horvath KV, Yamashita S, Miller M, Franceschini G, Calabresi L. Role of LCAT in HDL remodeling: investigation of LCAT deficiency states. J Lipid Res. 2007; 48: 592-9.

Bandeali S, Farmer J. High density lipoprotein and atherosclerosis: the role of antioxidant activity. Curr Atheroscler Rep. 2012; 14:101-7.

Baranova I, Vishnyakova T, Bocharov A, Chen Z, Remaley AT, Stonik J, Eggerman TL, Patterson AP. Lipopolysaccharide down regulates both scavenger receptor B1 and ATP binding cassette transporter A1 in raw cells. Infect Immun. 2002; 70: 2995-3003.

Barter PJ, Nicholls S, Rye KA, Anantharamiah GM, Navab M, Folgeman AM. Antiinflammatory properties of HDL. Circulation Res. 2004; 95: 764-72.

Basta G, Lazzerini G, Del Turco S, Ratto GM, Schimdt AM, De Caterina R. At least two distinct pathways generating reactive oxygen species mediate vascular cell adhesion molecule-1 induction by advanced glycation end products. Arterioscler Thromb Vasc Biol. 2005; 25: 1401-7.

Borthwick F, Warnakula S, Mangat R, Uwiera RR, Russell JC, Kelly SE, Lee CY, Hryshko L, Mamo JCL, Rye KA, Lopaschuk GD, Proctor SD. ApoA-I 
infusions reduces arterial cholesterol and myocardial lesions in a rat model of cardiac dysfunction and insulin resistance. Atherosclerosis. In Press 2012.

Boyd JH, Kan B, Roberts H, Wang Y, Walley KR. S100A8 and S100A9 mediate endotoxin-induced cardiomyocyte dysfunction via the receptor for advanced glycation end products. Circulation Res. 2008; 102:1239-46.

Brandeburg K, Jurgens G, Andra J, Lindner B, Koch MH, Blume A, Garidel P. Biophysical characterization of the interaction of high density lipoprotein (HDL) with endotoxins. Eur J Biochem. 2002, 269:5821-9.

Briand $F$, Tréguier M, André A, Grillot D, Issandou M, Ouguerram K, Sulpice $\mathrm{T}$. Liver $\mathrm{X}$ Receptor activation promotes macrophage - to - feces reverse cholesterol transport in a dyslipidemic hamster model. J Lipid Res. 2010; 51: 763-70.

Brownlee M. Biochemistry and molecular cell biology of diabetic complications. Nature. 2001; 414: 813-20.

Brownlee M. The pathobiology of diabetic complications. A unifying mechanism. Diabetes. 2005; 54: 1615-25.

Cai W, He JC, Zhu L, Chen X, Striker GE, Vlassara H. AGE-receptor 1 counteracts cellular oxidant stress induced by AGE via negative regulation of p66shc - dependent FKHRL1 phosphorylation. Am J Physiol Cell Physiol. 2008; 294:C145-52.

Cai W, He JC, Zhu L, Lu C, Vlassara H. Advanced glycation end product (AGE) receptor 1 supresses cell oxidant stress and activation signaling via EGF receptor. Proc Natl Acad Sci USA. 2006; 103: 13801-6.

Cai W, He JC, Zhu L, Peppa M, Lu C, Uribarri J, Vlassara H. High levels of dietary advanced glycation end products transform low-density lipoprotein into a potent redox-sensitive mitogen-activated protein kinase stimulant in diabetic patients. Circulation. 2004; 110: 285-91. 
Castilho G, Okuda LS, Pinto RS, Iborra RT, Nakandakare ER, Santos CX, Laurindo FR, Passarelli M. ER stress is associated with reduced ABCA-1 protein levels in macrophages treated with advanced glycated albumin reversal by a chemical chaperone. Int J Biochem Cell Biol. In Press 2012.

Castrillo A, Joseph SB, Vaidya SA, Haberland M, Fogelman AM, Cheng G, Tontonoz P. Crosstalk between LXR and toll-like receptor signaling mediates bacterial and viral antagonism of cholesterol metabolism. Mol cell. 2003; 12 : 805-16.

Cavelier C, Lorenzi I, Rohrer L, Eckardstein AV. Lipid efflux by ATP-binding cassette transporters ABCA1 and ABCG1. Biochim Biophys Acta. 2006; 1761: 655-66.

Chen M, Li W, Wang N, Zhu Y, Wang X. ROS and NF-kB but not LXR mediate $\mathrm{IL}-1 \beta$ signaling for the downregulation of ATP-binding cassette transporter A1. Am J Physiol Cell Physiol. 2007; 292:c1493-c1501.

Das Evcimen N, King GL. The role of protein kinase $\mathrm{C}$ activation and vascular complications of diabetes. Pharmacol Res. 2007; 55:498-510.

de la Llera Moya M, Mc Gillicuddy FC, Hinkle CC, Byrne M, Joshi MR, Nguyen V, Tabita-Martinez J, Wolfe ML, Badellino K, Pruscino L, Mehta NN, Asztalos BF, Reilly MP. Inflammation modulates human HDL composition and function in vivo. Atherosclerosis. In Press 2012.

De Souza Pinto R, Castilho G, Paim BA, Machado-Lima A, Inada NM, Nakandakare ER, Vercesi AE, Passarelli $M$. Inhibition of macrophage oxidative stress prevents the reduction of $A B C A-1$ transporter induced by advanced glycated albumin. Lipids. 2012; 47: 443-50.

Degenhardt TP, Thorpe SP, Baynes JW. Chemical modifications of proteins by methylglyoxal. Cell Mol Biol. 1998; 44: 1139-45. 
Di Bartolo BA, Nicholls SJ, Bao S, Rye KA, Heather AK, Barter PJ, Bursill C. The apolipoprotein A-I mimetic peptide ETC-642 exhibits anti-inflammatory properties that are comparable to high density lipoproteins. Atherosclerosis. 2011; 217: 395-400.

Di Bartolo BA, Vanags LZ, Tan JTM, Bao S, Rye KA, Barter PJ, Bursill CA. The apolipoprotein A-I mimetic peptide, ETC-642, reduces chronic vascular inflammation in the rabbit. Lipids Health Dis. 2011a; 10: 224.

Donato R. Intracellular and extracellular roles of S100 proteins. Microsc Res Tech. 2003; 60: 540-51.

Draznin B. Molecular mechanisms of insulin resistance: serine phosphorylation of insulin receptor substrate-1 and increased expression of p85a: the two sides of a coin. Diabetes. 2006; 55: 2392-7.

Drew BG, Duffy SJ, Formosa MF, Natoli AK, Henshidge DC, Penfold SA, Thomas WG, Mukhamedova N, De Courten B, Forbes JM, Yap FY, Kaye DM, van Hall G, Febbravo MA, Kemp BE, Sviridov D, Steinberg GR, Kingwell BA. High density lipoprotein modulates glucose metabolism in patients with type 2 diabetes mellitus. Circulation. 2009; 119: 2103-11.

Drew BG, Rye KA, Duffy SJ, Barter P, Kingwell BA. The emerging role of HDL in glucose metabolism. Nat Rev Endocrinol. 2012; 8: 237-45.

Du X, Matsumura T, Edelstein D, Rosseti L, Zsengellér Z, Szabó C, Brownlee M. Inhibition of GAPDH activity by poli(ADP-ribose) polymerase activates three major pathways of hyperglycemic damage in endothelial cells. J Clin Invest. 2003; 112: 1049-57.

Edgel KA, LeBoeuf R, Oram JF. Tumor necrosis factor- $\alpha$ and lymphotoxin- $\alpha$ increase macrophage ABCA1 by gene expression and protein stabilization via different receptors. Atherosclerosis. 2010; 209: 387-92. 
Ehlermann P, Eggers K, Bierhaus A, Most P, Weichenhan D, Greten J, Nawroth PP, Katus HA, Remppis A. Increased proinflammatory endothelial response to $S-100 A 8 / A 9$ after preactivation through advanced glycation end products. Cardiovasc Diabetol. 2006; 5: 6-14.

Feingold KR, Memon RA, Moser AH, Shigenaga JK, Grunfeld C. Endotoxin and interleukin-1 decrease hepatic lipase mRNA levels. Atherosclerosis. 1999; 142:379-87.

Field FJ, Watt K, Mathur SN. TNF-alpha decreases ABCA1 expression and attenuates HDL cholesterol efflux in the human intestinal cell line Caco-2. $J$ Lipid Res. 2010; 51:1407-15.

Figarola JL, Shanmugam N, Natarajan R, Rahbar S. Anti-inflammatory effects of the advanced glycation end product inhibitor LR-90 in human monocyte. Diabetes. 2007; 56: 647-55.

Frisdal E, Lesnik P, Olivier M, Robillard P, Chapman MJ, Huby T, Guerin M, Le Goff W. Interleukin-6 protects human macrophages from cellular cholesterol accumulation and attenuates the proinflammatory response. $J$ Biol Chem. 2011; 286: 30926-36.

Gerbod-Giannone MC, Li Y, Holleboom A, Han S, Hsu LC, Tabas I, Tall AR. TNFa induces ABCA1 through NF-kB in macrophages and in phagocytes ingesting apoptotic cells. Proc Natl Acad Sci USA. 2006; 103: 3112-7.

Goldberg T, Cai W, Peppa M, Dardaine V, Baliga B, Uribarri J, Vlassara H. Advanced glycoxidation end products in commonly consumed foods. J Am Diet Assoc. 2004; 104: 1287-91.

Greaves DR, Gordon S. Thematic review series: the immune system and atherogenesis. Recent insights into biology of macrophage scavenger receptors. J Lipid Res. 2005; 46: 11-20. 
Gupta H, Dai L, Datta G, Garber GW, Grenett H, Li Y, Mishra V, Palqunachari MN, Handattu S, Gianturco SH, Bradley WA, Anantharamaiah GM, White CR. Inhibition of lipopolyssacharide-induced inflammatory responses by an apolipoprotein A-I mimetic peptide. Circulation Res. 2005; 97:236-43.

Hardardottír I, Moser AH, Fuller J, Fielding C, Feingold KR, Grunfeld C. Endotoxin and cytokines decrease serum levels and extra hepatic protein and mRNA levels of cholesteryl ester transfer protein in Syrian hamsters. $J$ Clin Invest. 1996; 87:370-4.

Harja E, Bu D, Hudson BI, Chang JS, Shen X, Hallam K, Kalea AZ, Lu Y, Rosario RH, Oruganti S, Nikolla Z, Belov D, Lalla E, Ramasamy R, Yan SF, Schmidt AM. Vascular and inflammatory stresses mediate atherosclerosis via RAGE and its ligands in apo E -/- mice. J Clin Invest. 2008; 118: 183-94.

Hattori Y, Suzuki M, Hattori S, Kasai K. Vascular smooth muscle cell activation by glycated albumin (Amadori adducts). Hypertension. 2002; 39: 22-8.

Havel RJ, Eder HA, Bragdon JH. The distribution and chemical composition of ultracentrifugally separated lipoproteins in human serum. J Clin Invest. 1955; 34:1345-53.

Hayakawa E, Yoshimoto T, Sekizawa N, Sugiyama T, Hirata Y. Overexpression of receptor for advanced glycation end products induces monocyte chemoattractant protein-1 expression in rat vascular smooth muscle cell line. J Atheroscler Thromb. 2012; 19: 13-22.

He C, Koschinsky T, Buenting C, Vlassara H. Presence of diabetic complications in type 1 diabetic patients correlates with low expression of mononuclear cell AGE-receptor-1 and elevated serum AGE. Mol Med. 2001; 7:159-68. 
Herold K, Moser B, Chen Y, Zeng S, Yan SF, Ramasamy R, Emond J, Clynes R, Schmidt AM. Receptor for advanced glycation end products (RAGE) in a dash to the rescue: inflammatory signals gone awry in the primal response to stress. J Leukoc Biol. 2007; 82: 1-9.

Higai K, Shimamura A, Matsumoto K. Amadori-modified glycated albumin predominantly induces E-selectin expression on human umbilical vein endothelial cells through NADPH oxidase activation. Clin Chim Acta. 2006; 367: 137-43.

Hirata A, Kishida K, Nakatsuji H, Hiuge-Shimizu A, Funahashi T, Shimomura I. High serum S100A8/A9 levels and high cardiovascular complication rate in type 2 diabetics with ultrasonographic low carotid plaque density. Diabetes Res Clin Pract. In Press 2012.

Hoang A, Murphy AJ, Coughlan MT, Thomas MC, Forbes JM, O'Brien R, Cooper ME, Chin-Dusting JP, Sviridov D. Advanced glycation of apolipoprotein A-I impairs its anti-atherogenic properties. Diabetologia. 2007; 50:1770-9.

Hodgkinson CP, Laxton RC, Patel K, Ye S. Advanced glycation end-product of low density lipoprotein activates the toll-like 4 receptor pathway implications for diabetic atherosclerosis. Arterioscler Thromb Vasc Biol. 2008; 28:2275-81.

Horiuchi S, Sakamoto Y, Sakai M. Scavenger receptor for oxidized and glycated proteins. Amino Acids. 2003; 25: 283-92.

Hozoji M, Munehira Y, Ikeda Y, Makishima M, Matsuo M, Kioka N, Ueda K. Direct interation of nuclear liver $X$ receptor- $\beta$ with $A B C A 1$ modulates cholesterol efflux. J Biol Chem. 2008; 283: 30057-63. 
Huang SM, Wu CH, Yen GC. Effects of flavonoids on the expression of the pro-inflammatory response in human monocytes induced by ligation of the receptor for AGEs. Mol Nutr Food Res. 2006; 50: 1129-39.

Iborra RT, Machado-Lima A, Castilho G, Nunes VS, Abdalla DS, Nakandakare ER, Passarelli M. Advanced glycation in macrophages induces intracellular accumulation of 7-ketocholesterol and total sterols by decreasing the expression of ABCA-1 and ABCG-1. Lipids Health Dis. 2011; 10: 172.

Isoda K, Folco EJ, Shimizu K, Libby P. AGE-BSA decrease ABCG1 expression and reduces macrophage cholesterol efflux to $\mathrm{HDL}$. Atherosclerosis. 2007; 192: 298-304.

Isoda K, Young JL, Zirlik A, MacFarlane LA, Tsuboi N, Gerdes N, Schönbeck $\mathrm{U}$, Libby $\mathrm{P}$. Metformin inhibits proinflammatory responses and nuclear factorkB in human vascular wall cells. Arterioscler Thromb Vasc Biol. 2006; 26: 611-7.

Jakus V, Rietbrock N. Advanced Glycation End-Products and The Progress of Diabetic Vascular Complications. Physiol Res. 2004; 53: 131-42.

Kaplan R, Gan X, Menke JG, Wright SD, Cai TQ. Bacterial lipopolysacharide induces expression of ABCA1 but not ABCG1 via an LXR-independent pathway. J Lipid Res. 2002; 43: 952-9.

Khovidhunkit W, Kim MS, Memon RA, Shigenaga JK, Moser AH, Feingold $\mathrm{KR}$, Grunfeld C. Effects of infection and inflammation on lipid and lipoprotein metabolism: mechanism and consequences to the host. J Lipid Res. 2004; 45: 1169-96.

Khovidhunkit W, Moser AH, Shigenaga JK, Grunfeld C, Feingold KR. Endotoxin down-regulates $A B C G 5$ and $A B C G 8$ in mouse liver and $A B C A 1$ and ABCG1 in J774 murine macrophages: differential role of LXR. J Lipid Res. 2003; 44:1728-36. 
Khovidhunkit W, Shigenaga JK, Moser AH, Feingold KR, Grunfeld C. Cholesterol efflux by acute-phase high density lipoprotein: role of lecithin cholesterol acyltransferase. J Lipid Res. 2001; 42:967-75.

Koh KK, Han SH, Quon MJ. Inflammatory markers and the metabolic syndrome. Insights from therapeutic interventions. J Am Coll Cardiol. 2005; 46:1978-85.

Kontush A, Therond P, Zerrad A, Couturrier M, Négre-Salvayre A, de Souza JA, Chantepie S, Chapman MJ. Preferential sphingosine-1-phosphate enrichment and sphingomyelin depletion are key features of small dense HDL3 particles: relevance to antiapoptotic and antioxidative activity. Arterioscler Thromb Vasc Biol. 2007; 27: 1843-9.

Kosaki A, Hasegawa T, Kimura T, lida K, Hitomi J, Matsubara H, Mori Y, Okigaki M, Toyoda N, Masaki H, Inoue-Shibata M, Mishikawa M, Iwasaka T. Increased plasma S100A12 (EN-RAGE) levels in patients with type 2 diabetes. J Clin Endocrinol Metab. 2004; 89: 5423-8

Larrede S, Quinn CM, Jessup W, Frisdal E, Olivier M, Hsieh V, Kim MJ, Van Eck M, Couvert P, Carrie A, Giral P, Chapman MJ, Guerin M, Le Goff W. Stimulation of cholesterol effluc by LXR agonists in cholesterol-loaded human macrophage is ABCA1-dependent but ABCG1-independent. Arterioscler Thromb Vasc Biol. 2009; 29(11): 1930-6.

Lee CM, Chien CT, Chang PY, Hsieh MY, Jui HY, Liau CS, Hsu SM, Lee YT. High density lipoprotein antagonizes oxidized low density lipoprotein by suppressing oxygen free-radical formation and preserving nitric oxide bioactivity. Atherosclerosis. 2005; 183: 251-8.

Li Y, Dong JB, Wu MP. Human apoA-I overexpression diminishes LPSinduced systemic inflammation and multiple organ damage in mice. Eur $J$ Pharmacol. 2008; 590(1-3):417-22. 
Li Y, Schwabe RF, DeVries-Seimom T, Yao PM, Gerbod-Giannone MC, Tall AR, Davis RJ, Flavell R, Brenner DA, Tabas I. Free cholesterol-loaded macrophage are abundant source of tumor necrosis factor-alpha and interleukin-6: model of NF-kappaB and map-kinase dependent inflammation in advanced atherosclerosis. J Biol Chem. 2005; 280: 21763-72.

Libby P, Ridker PM, Maseri A. Inflammation and Atherosclerosis. Circulation. 2002; 105: 1135-43.

Lima, Adriana Machaddo Saldiba De. Albumina modificada por glicação avanaçada no diabete melito tipo 1 e 2 prejudica o transporte reverso de colesterol e favorece o acúmulo de lípides em macrófagos [tese]. São Paulo: Faculdade de Medicina da Uniersidade de São Paulo; 2010.

Lin L. RAGE on the toll road? Cell Mol Immunol. 2006; 3: 351-8.

Liu YY, Liang C, Liu X, Liao B, Pan X, Ren Y, Fan M, Li M, He Z, Wu J, Wu $Z$. AGEs increased migration and inflammatory responses of adventitial fibroblasts via RAGE, MAPK and NF-kB pathways. Atherosclerosis. 2010; 208:34-42.

Lowry OH, Rosenbrough NJ, Farr AL, Randall RJ. Protein measurement with the folin-phenol reagent. J Biol Chem. 1951; 193: 265-75.

Lu C, He JC, Cai H, Liu H, Zhu L, Vlassara H. Advanced glycation endproduct (AGE) receptor 1 is a negative regulator of the inflammatory response to AGE in mesangial cells. Proc Natl Acad Sci USA. 2004; 101: 11767-72.

Majdalawieh A, Ro HS. LPS-induced suppression of macrophage cholesterol efflux is mediated by adipocyte enhancer-binding protein-1. Int $J$ Biochem Cell Biol. 2009; 41: 1518-25.

Marx N, Walcher D, Ivanova N, Rautzenberg K, Jung A, Friedl R, Hombach V, Caterina R, Basta G, Wautier MP, Wautiers JL. Thiazolidinediones reduce 
endothelial expression of receptors for advanced glycation end products. Diabetes. 2004; 53: 2662-8.

Matsui T, Nishino Y, Maeda S, Takeuchi M, Yamagishi SI. Irbesartan inhibits advanced glycation end products (AGE)-induced up-regulation of vascular cell adhesion molecule-1 (VCAM-1) mRNA levels in glomerular endothelial cells. Microvasc Res. 2011; 81:269-73.

Matsuki K, Tamasawa N, Yamashita M, Tanabe J, Murakami H, Matsui J, Imaizumi T, Satoh K, Suda T. Metformin restores impaired HDL-mediated cholesterol efflux due to glycation. Atherosclerosis. 2009; 206: 434-8.

McGillicuddy FC, de la Llera Moya M, Hinkle CC, Joshi MR, Chiquoine EH, Bilheimer JT, Rothblat GH, Reilly MP. Inflammation impairs reverse cholesterol transport in vivo. Circulation. 2009; 119:1135-45.

Mentink CJ, Kilhovd BK, Rondas-Colbers GJ, Torjesen PA, Wolffenbuttel BH. Time course of specific AGEs during optimized glycaemic control in type 2 diabetes. Neth J Med. 2006; 64: 10-6.

Miyamoto S, Ueda M, Ikemoto M, Naruko T, Itoh A, Tamaki S, Nahara R, Teresaki F, Sasayama S, Fujita M. Increased serum levels and expression of S100A8/A9 complex in infiltrated neutrophils in atherosclerotic plaque of unstable angina. Heart. 2008; 94:1002-7

Mori S, Takahashi HK, Liu K, Wake H, Zhang J, Liu R, Yoshino T, Nishibori M. Ciprofloxacin inhibits advanced glycation end products-induced adhesion molecule expression $n$ human monocytes. Br J Pharmacol. 2010; 161 :22940.

Naik SU, Wang X, Da Silva JS, Jaye M, Macphee CH, Reilly MP, Billheimer JT, Rothblat GH, Rader DJ. Pharmaclogical activation of Liver X Receptors promotes reverse cholesterol transport in vivo. Circulation. 2006; 113: 90-7. 
Nobecourt E, Davies MJ, Brown BE, Curtiss LK, Bonnet DJ, Charlton F, Januszewski AS, Jenkins AJ, Barter PJ, Rye KA. The impact of glycation on apoliprotein A-1 structure and its ability to activate lecithin:cholesterol acyltransferase. Diabetologia. 2007; 50: 643-53.

Nobecourt E, Tabet F, Lambert G, Puranik R, Boa S, Yan L, Davies MJ, Brown BE, Jenkins AJ, Dusting GJ, Bonnet DJ, Curtiss LK, Barter PJ, Rye KA. Nonenzymatic glycation impairs the anti-inflammatory properties of apolipoprotein A-I. Atheroscler Thromb Vasc Biol. 2010; 30:766-72.

Nofer JR, van der Giet M, Töller M, Kleuser B, Schäfers M, Fabker M, Zidek W, Assman G, Chun J, Kevkau B. HDL induces NO-dependent vasorelaxation via the lisophospholipid receptor S1P3. J Clin Invest. 2004; 113: $569-81$.

Ohgami N, Miyazaki A, Sakai M, Kuniyasu A, Nakayama H, Horiuchi S. Advanced glycation end products (AGE) inhibit scavenger receptor class $B$ type-1 mediated reverse cholesterol transport: a new crossroad of AGE to cholesterol metabolism. J Atheroscler Thromb. 2003; 10: 1-6.

Oram JF, Lawn RM, Garvin MR, Wade DP. ABCA1 is the cAMP-inducible apolipoprotein receptor that mediates cholesterol secretion from macrophages. J Biol Chem. 2000; 275: 34508-11.

Oram JF, Vaughan AM. ATP-binding cassette cholesterol transporters and cardiovascular disease. Circulation Res. 2006; 99: 1031-43.

Oyama T, Miyasita $\mathrm{Y}$, Watanabe $\mathrm{H}$, Shirai K. The role of polyol pathway in high-glucose induced endothelial cell damage. Diabetes Res Clin Pract. 2006; 73:227-34.

Panousis CG, Evans G, Zuckerman SH. TGF- $\beta$ increases cholesterol efflux and $\mathrm{ABC}-1$ expression in macrophage-derived foam cells: opposing the effects of INF-y. J Lipid Res. 2001; 42: 856-63. 
Park $\mathrm{KH}$, Cho $\mathrm{KH}$. High density lipoprotein (HDL) from elderly and reconstituted HDL containing glycated apolipoproteins A-I share proatherosclerotic and prosenescent properties with increased cholesterol influx. J Gerontol A Biol Sci Med Sci. 2011; 66A: 511-20

Park Y, Pham TX, Lee J. Lipopolysaccharide represses the expression of ATP-binding cassette transporter $\mathrm{G} 1$ and scavenger receptor class $\mathrm{B}$, type 1 in murine macrophages. Inflamm Res. In Press 2012.

Passarelli M, Catanozi S, Nakandakare ER, Rocha JC, Morton RE, Shimabukuro AFM, Quintão ECR. Plasma lipoproteins from patients with poorly controlled diabetes mellitus and "in vitro"glycation of lipoproteins enhance the transfer rate of cholesteryl ester from HDL to apoB - containing lipoproteins. Diabetologia. 1997; 40: 1085-93.

Passarelli M, Shimabukuro AFM, Catanozi S, Nakandakare ER, Rocha JC, Carrilho AJF, Quintão ECR. The diminished rate of mouse peritoneal macrophage cholesterol efflux is not related to the degree of HDL glycation in diabetes mellitus. Clin Chim Acta. 2000; 301: 119-34.

Passarelli M, Tang C, McDonald TO, O’Brien KD, Gerrity RG, Heinecke JW, Oram JF. Advanced glycation end products precursors impair ABCA1dependent cholesterol removal from cells. Diabetes. 2005; 54: 2198205.

Persson J, Nilsson J, Lindholm MW. Interleukin-1 beta and tumour necrosis factor-alpha impede neutral lipid turnover in macrophage-derived foam cells. BMC Immunol. 2008; 9:70-80.

Qin B, Anderson RA, Adeli K. Tumor necrosis factor- $\alpha$ directly stimulates the overproduction of hepatic apolipoprotein B100- containing VLDL via impairment ofof hepatic insulin signaling. Am J Physiol Gastroinl Liver Physiol. 2008; 294:G1120-9. 
Qin YH, Dai SM, Tang GS, Zhang J, Ren D, Wang ZW, Shen Q. HMGB1 enhances the proinflammatory activity of lipopolysaccharide by promoting the phosphorylation of MAPK p38 through receptor for advanced glycation end products. J Immunol. 2009; 183: 6244-50.

Rader DJ, Alexander ET, Weibel GL, Bilheimer J, Rothblat GH. The role of reverse cholesterol transport I animals and humans and relationship to atherosclerosis. J Lipid Res. 2009; 50: S189-94.

Rader DJ, Puré E. Lipoproteins, macrophage function, and atherosclerosis: Beyond the foam cell? Cell Metab. 2005; 1: 223-30.

Rashiduni DL, Rifici A, Schneider SH, Khachadurian AK. Glycation of high density lipoprotein does not increase its susceptibility to oxidation or diminish its cholesterol efflux capacity. Metabolism. 1999; 48:139-43.

Redgrave TG, Roberts DC, West CE. Separation of plasma lipoproteins by density-gradient ultracentrifugation. Anal Biochem. 1975; 65:42-9.

Reznikov LL, Waksman J, Azam T, Kim SH, Bufler P, Niwa T, Werman A, Zhang $X$, Pischetsrieder M, Shaldon S, Dinarello CA. Effect of advanced glycation end products on endotoxin-induced TNF-alpha, IL-1 beta and IL-8 in human peripheral blood monuclear cells. Clin Nephrol. 2004; 61: 324-36.

Roden M. Mechanism of disease: hepatic steatosis in type 2 diabetes pathogenesis and clinical relevance. Nature Clinical Practice. Endocrinol Metab. 2006; 2: 335-48.

Rolo AP, Palmeira CM. Diabetes and Mitochondrial function: role of hyperglycemia and oxidative stress. Toxicol Appl Pharmacol. 2006; 212: 167 78.

Rosenson RS, Brewer HB, Davidson WS, Fayad ZA, Fuster V, Goldstein J, Hellerstein M, Jiang XC, Phillips M, Rader DJ, Remaley AT, Rothblat GH, 
Tall AR, Yvan-Chavet L. Cholesterol efflux and atheroprotection: advancing the concept of reverse cholesterol transport. Circulation. 2012; 125: 1905-19

Ruan XZ, Moorhead JF, Fernando R, Wheeler DC, Powis SH, Varghese Z. Regulation of lipoprotein trafficking in the kidney: role of inflammatory mediators and transcription factor. Biochem Soc Trans. 2004; 32: 88 - 91.

Sakaguchi M, Murata H, Yamamoto K, Ono T, Sakaguchi Y, Motoyama A, Hibino T, Kataoka K, Huh N. TIRAP, an adaptor protein for TLR2/4, transducer a signal from RAGE phosphorylated upon ligand binding. Plos One. 2011; 6: e23132.

Shanmugam N, Kim YS, Lanting L, Natarajan R. Regulation of cyclooxygenase-2 expression in monocytes by ligation of the receptor for advanced glycation end products. J Biol Chem. 2003; 278: 34834-44.

Shanmugam N, Reddy MA, Guha M, Natarajan R. High glucose-induced expression of proinflammatory cytokine and chemokine genes in monocytic cells. Diabetes. 2003; 52: 1256-64.

Sima AV, Botez GM, Stancu CS, Manea A, Raicu M, Simionescu M. Effect of irreversibly glycated LDL in human vascular smooth muscle cells: lipid loading, oxidative and inflammatory stress. J Cell Mol Med. 2010; 14:2790802.

Soro-Paavonen A, Naukkarinen J, Lee-Rueckert M, Watanabe H, Rantala E, Soderlund S, Hiukka A, Kovanen PT, Jauhiainen M, Peltonen L, Taskinen MR. Common ABCA1 variants, HDL levels, and cellular cholesterol efflux in subjects with familial low HDL. J Lipid Res. 2007; 48: 1409 - 16.

Sun L, Ishida T, Yasuda T, Kojima Y, Honjo T, Yamamoto Y, Yamamoto $H$, Ishibashi S, Hirata K, Hayashi Y. RAGE mediates oxidized LDL-indeced proinflammatory effects and atherosclerosis in non-diabetic LDL receptordeficient mice. Cardiovasc Res. 2009; 82: 371-81. 
Tanaka N, Yonekura H, Yamagishi S, Fujimori H, Yamamoto Y, Yamamoto $\mathrm{H}$. The receptorfor advanced glycation endproducts is induced by the glycation products themselves and tumor necrosis factor- $\alpha$ through nuclear factor-kB, and by $17 \beta$-Estradiol through $\mathrm{Sp}-1$ in human vascular endothelial cells. J Biol Chem. 2000; 275: 25781-90.

Tang C, Liu Y, Kessler PS, Vaughan AM, Oram JF. The macrophage cholesterol exporter ABCA1 functions as an anti-inflammatory receptor. J Biol Chem. 2009; 284: 32336-43.

Thornalley PJ. Advanced glycation en products in renal failure. $J$ Ren Nutr. 2006; 16(3): 178-84.

Tikellis C, Thomas MC, Harcourt BE, Coughlan MT, Pete J, Bialkowski K, Tan A, Bierhaus A, Cooper ME, Forbes JM. Cardiac Inflammation associated with a western diet is mediated via activation of RAGE by AGEs. Am $J$ Physiol Endocrinol Metab. 2008; 295: E323-30.

Toma L, Stancu CS, Botez GM, Sima AV, Simionescu M. Irreversibly glycated LDL induce oxidative and inflammatory state in human endothelial cells; added effect of high glucose. Biochem Biophys Res Commun. 2009; 390:877-82.

Uribarri J, Cai W, Sandu O, Peppa M, Goldberg T, Vlassara H. Diet-derived advanced glycation end products are major contributors to the body's AGE pool and induce inflammation in health subjects. Ann N Y Acad Sci. 2005; 1043:461-6.

Valencia JV, Mone M, Koehne C, Rediske J, Hughes TE. Binding of receptor for advanced glycation end products (RAGE) ligands is not sufficient to induce inflammatory signals: lack of activity of endotoxin-free albuminderived advanced glycation end products. Diabetologia. 2004b; 47: 844-52. 
Valencia JV, Mone M, Zhang J, Weetall M, Buxton FP, Hughes TE. Divergent pathways of gene expression are activated bu the RAGE ligands S100B and AGE-BSA. Diabetes. 2004c; 53: 743-51.

Valencia JV, Weldon SC, Quinn D, Kiers GH, DeGroot J, Tekoppele JM, Hughes TE. Advanced glycation end products ligands for the receptor for advanced glycated end products: biochemical characterization and formation kinetics. Anal Biochem. 2004a; 324: 68-78.

van Beijnum JR, Buurman WA, Griffioen AW. Convergence and amplification of toll-like receptor (TLR) and receptor for advanced glycation end products (RAGE) signaling pathways via high mobility group B1 (HMGB1). Angiogenesis. 2008; 11: 91-9.

Van Der Westhuyzen D, Beer FC, Webb NR. HDL cholesterol transport during inflammation. Curr Opin Lipidol. 2007; 18:147-51.

Van Linthout S, Spillmann F, Graiani G, Miteva K, Peng J, Craeyveld EV, Meloni M, Tölle M, Escher F, Subasigüller A, Doehner W, Quaini F, De Geest B, Schultheiss HP, Tschöpe C. Down-regulation of endothelial TLR4 signalling after apoA-I gene transfer contributes to improved survival in an experimental model of lipopolysaccharide-induced inflammation. $J \mathrm{Mol}$ Med. $2011 ; 89: 151-60$.

van Zoelen MAD, Yang H, Florquin S, Meijers JCM, Akira S, Arnold B, Nawroth PP, Bierhaus A, Tracey KJ, van der Poll T. Role of toll-like receptors 2 and 4, and the receptor for advanced glycation end products (RAGE) in HMGB1 induced inflammation in vivo. Shock. 2009; 31:280-4.

Veiraiah A. Hyperglycemia, lipoprotein glycation, and vascular disease. Angiology. 2005; 56: 431-38.

Vlassara H, Cai W, Goodman S, Pyzik R, Yong A, Chen X, Zhu L, Neade T, Beeri M, Silverman JM, Ferrucci L, Tansman L, Striker GE, Uribarri J. 
Protection against loss of innate defenses in adulthood by low advanced glycation end products (AGE) intake: role of anti-inflammatory AGE receptor1. J Clin Endocrinol Metab. 2009; 94: 4483-91.

Vogl T, Tenbrock K, Ludwig S, Leukert N, Ehrhardt C, van Zoelen MA, Nacken W, Foell D, van der Poll T, Sorg C, Roth J. Mrp8 and Mrp14 are endogenous activators of Toll-like receptor 4, promoting lethal, endotoxininduced shock. Nature Med. 2007; 13:1042-9.

Wang XQ, Panousis CG, Alfaro L, Evans GF, Zuckerman SH. Interferon-үmediated downregulation of cholesterol efflux and $A B C 1$ expression is by the stat1 pathway. Arterioscler Thromb Vasc Biol. 2002; 22:e5-9.

Wang XQ, Yang K, He YS, Lu L, Shen WF. Receptor mediated elevation in FABP4 levels by advanced glycation end products induces cholesterol and triacylglycerol accumulation in THP-1 macrophages. Lipids. 2011; 46:479-86.

Wang Y, Moser AH, Shigenaga JK, Grunfeld C, Feingold KR. Downregulation of liver $\mathrm{X}$ receptor- $\alpha$ in mouse kidney and HK-2 proximal tubular cells by LPS and cytokines. J Lipid Res. 2005; 46: 2377-87.

Xie J, Reverdatto S, Frolov A, Hoffmann R,Burz DF, Shekhtman A. Structural basis for pattern recognition by the receptor for advanced glycation end products (RAGE). J Biol Chem. 2008; 283: 27255-69.

Yamamoto Y, Harashima A, Saito H, Tsuneyama K, Munesue S, Motoyoshi S, Han D, Watanabe T, Asano M, Takasawa S, Okamoto H, Shimura S, Karasawa $\mathrm{T}$, Yonekura $\mathrm{H}$, Yamamoto $\mathrm{H}$. Septic dhock is associated with receptor for advanced glycation end products ligation of LPS. J Immunol. 2011; 186: 3248-57.

Yamauchi Y, Hayashi M, Abe-Dohmae S, Yakoyama S. Apolipoprotein A-I activates protein kinase $\mathrm{C} \alpha$ signaling to phosphorilate and stabilize ATP 
binding cassette transporter $A 1$ for the high density lipoprotein assembly. $J$ Biol Chem. 2003; 278: 47890-7

Yan SF, Berile GR, D'Agati V, Du Yan S, Ramasamy R, Schmidt AM. The biology of RAGE and its ligands: uncovering mechanisms at the heart of diabetes and its complications. Curr Diabetes Rep. 2007; 2: 146-53.

Yehuda H, Szuchman-Sapir A, Khatib S, Musa R, Tamir S. Human atherosclerotic plaque lipid extract promotes expression of proinflammatory factors in human monocytes and macrophage-like cells. Atherosclerosis. 2011; 218: 339-43.

Yin K, Deng X, Mo ZC, Zhao GJ, Jlang J, Cul LB, Tan CZ, Wen GB, Fu Y, Tang CK. Tristetrapolin -dependent post transcriptional regulation of inflammatory cytokine mRNA expression by apolipoprotein A-I: role of ATPbinding membrane cassette transporter $\mathrm{A} 1$ and signal transducer and activator of transcription 3. J Biol Chem. 2011; 286: 13834-45.

Zhang Y, Silva JR, Relly M, Billheimer JT, Rothblat GH, Rader DJ. Hepatic expression of scavenger receptor class B type 1 (SR-B1) is a positive regulator of macrophage reverse cholesterol transport in vivo. J Clin Invest. 2005; 115: 2870-4.

Zhao GJ, Yin K, Fu YC, Tang CK. The interaction of apoA-I and ABCA1 triggers signal transduction pathways to mediate efflux of cellular lipids. $\mathrm{Mol}$ Med. 2012; 18: 149-58 


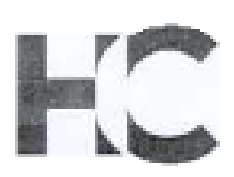

\section{APROVAÇÃO}

A Comissão de Ética para Análise de Projetos de Pesquisa CAPPesq da Diretoria Clínica do Hospital dos Clínicos e da Faculdade de Medicina da Universidade de Sőo Paulo, em sessōo de 14/05/2008. APROVOU o Protocolo de Pesquisa $n^{\circ}$ 0220/08, intifulado: "SECREÇĀO DE MEDIADORES INFLAMATÓRIOS E TRANSPORTE REVERSO DE COLESTEROL EM MACRÓFAGOS SUBMETIDOS À GUCOXIDAÇĀO" apresentado pelo Departamento de CLínICA MÉdiCA, conforme parecer anexo.

Cabe ao pesqulsador elaborar e apresentar à CAPPesq, os relatórios parciais e final sobre a pesquisa (Resoluçăo do Conselho Nacional de Saúde $n^{\circ} 196$, de 10/10/1996, inciso (X.2, letra " $c "$ ").

Pesquișador (a) Responsável: Dra Edna Regina Nakandakare/ Dra. Marisa PassarellI

Pesquisador (a) Executante: Ligia Shimabukuro Okuda

CAPPesq, 19 de Maio de 2008

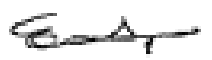

Prof. Dr. Eduardo Massad Presidente da Comissao de Ética para Análise de Projetos de Pesquisa

Comissso de Etica para Analise de Projetos de Pesquisa do HCFMUSP e da FMUSP Diretoria CIínica do Hcspital das Clinicas da Faculdade de Medicina da Universidade de Sá Paulo Rua Ovidio Pres de Campos. 255, $5^{\circ}$ andar - CEP 05403010 - Sas Paulo - SP Fone: 01130696442 Fax: 01130696492 e-mai: cappesqeihcnet usp.br/ secretariacappesq2 ghcret.usp br 